NOTE TO USERS

This reproduction is the best copy available. 



\section{VIOLENCE (DIS)LOCATED: \\ ON THE SPATIAL IMPLICATIONS OF VIOLENCE ON THE WESTERN FRONT DURING THE FIRST WORLD WAR}

by

\section{CHRISTOPHER K. SCHULTZ}

BA, Carleton University, 2008

A thesis submitted to the Faculty of Graduate and Postdoctoral Affairs in partial fulfillment of the requirements for the degree of

Master of Arts

in

History

Carleton University

Ottawa, Ontario, Canada

(C) 2010, Christopher K. Schultz 
Library and Archives

Canada

Published Heritage

Branch

395 Wellington Street

Ottawa ON K1A ON4

Canada
Bibliothèque et

Archives Canada

Direction du

Patrimoine de l'édition

395 , rue Wellington

Ottawa ON K1A ON4

Canada
Your file Votre référence

ISBN: 978-0-494-71715-8

Our file Notre référence

ISBN: 978-0-494-71715-8
NOTICE:

The author has granted a nonexclusive license allowing Library and Archives Canada to reproduce, publish, archive, preserve, conserve, communicate to the public by telecommunication or on the Internet, loan, distribute and sell theses worldwide, for commercial or noncommercial purposes, in microform, paper, electronic and/or any other formats.

The author retains copyright ownership and moral rights in this thesis. Neither the thesis nor substantial extracts from it may be printed or otherwise reproduced without the author's permission.
AVIS:

L'auteur a accordé une licence non exclusive permettant à la Bibliothèque et Archives Canada de reproduire, publier, archiver, sauvegarder, conserver, transmettre au public par télécommunication ou par l'Internet, prêter, distribuer et vendre des thèses partout dans le monde, à des fins commerciales ou autres, sur support microforme, papier, électronique et/ou autres formats.

L'auteur conserve la propriété du droit d'auteur et des droits moraux qui protège cette thèse. $\mathrm{Ni}$ la thèse ni des extraits substantiels de celle-ci ne doivent être imprimés ou autrement reproduits sans son autorisation.
In compliance with the Canadian Privacy Act some supporting forms may have been removed from this thesis.

While these forms may be included in the document page count, their removal does not represent any loss of content from the thesis.
Conformément à la loi canadienne sur la protection de la vie privée, quelques formulaires secondaires ont été enlevés de cette thèse.

Bien que ces formulaires aient inclus dans la pagination, il n'y aura aucun contenu manquant. 


\begin{abstract}
The trenches of the Western Front during the First World War were a space subordinated to the immense destructive capacities of industrial weaponry. Within the trench environment, however, competing discourses arose in relation to that space: those aimed at facilitating violence, those arising from being on the receiving end of violence, and also those which appropriated trench space in an act of dislocating violence from the self. This thesis explores these three central concerns first by examining the specific forms of violence prevalent on the Western Front, and then by exploring the soldiers' competing-and at times paradoxical-interpretations of that violence to which they were exposed. The result is the articulation of a parallax, or rather the shifting of violence in war from active subject (and thus becoming a hellish agent) to passive object (and thus rendering violence mere spectacle or ornament).
\end{abstract}




\section{Acknowledgements}

Writing this thesis has been an arduous if rewarding task, right from the first steps in choosing a topic (and changing one's mind several times!) to the final editing. It was arduous in that every step seemed to introduce new challenges, every book I read seemed to introduce new ideas, and every person I met had different ideas about what they thought should be included (or excluded, as the case often was). I can say that I am happy with how this project has turned out, that I have taken something I have found fascinating and hopefully presented it in an equally interesting way to any readers stumbling across it.

These projects do not complete themselves, of course, and the community of thinkers, critics, and friends I have encountered along the way have all bolstered whatever personal sense of determination I may have had along the way. Firstly, I owe a great debt of gratitude to my supervisors, Dr. Tim Cook at the Canadian War Museum and Prof. David Dean at Carleton University. Each of them allowed me to explore the trenches (of academia and of my topic) on my own recognizance, providing more or less firm guidance along the way as required, and always reminding me that I was "on the right track." They have entreated me to many insights and caffeine intakes, and their generosity in all regards cannot be overstated.

For the duration of my studies, I was also surrounded by a group of exceptional scholars, both in my colleagues and in the staff at the Department of History at Carleton University. There are too many professors and classmates to thank individually, though a few are certainly deserving of special mention. Prof. Dominique Marshall has provided excellent guidance for my research, while Joan White-saint and saviour to so many history graduate students! - was always there to help me navigate the bureaucratic labyrinth. The History Graduate Students Association, of which I was a part for these past two years, has provided me new perspectives on academia and also new friendships along the way. Finally, three colleagues of mine-Amanda Sauermann, Justin Rivest, and Abraham Plunkett-Latimer-deserve special mention for their many, late-night, oneoff insights during the writing process. I am glad to have met them and hope to continue learning from them.

On a personal level, I also have much to be thankful for, and most of that is directed at my family. For starters, I must acknowledge the contributions of my parents, Susan and Nick, and my brothers, Matt and Dave, to what I am today. All determined and thoughtful individuals, collectively they formed an environment where critical thinking was valued, dialogue encouraged, and humour embraced. I must also thank my wonderful wife and children: Marie-Andrée, Anne-Élise, and Théodore. I could say so much about them, but will leave it at this: there are few things that provide better motivation to succeed than warm hugs and wet kisses. Their love and patience have sustained me over many long, sometimes lonely days.

Finally, I dedicate this thesis to my grandparents and great-parents-Fred and Anne Pollak, Chris and Mary Schultz, and Ken and Kay Guthrie. Most of them are gone now, but their trials in life are never forgotten, their experiences in both World Wars as fresh as the day I first heard them. Most importantly, their collective effort to maintain their humanity through terrible violence has been a constant inspiration. They have been and continue to be at the heart of this thesis. 
Table of Contents

Abstract

ii

Acknowledgements

Table of Contents

List of Illustrations

iii

iv

V

Introduction

A Contemporary Image of War

Situating Trench Culture and Practices

The Cannon is a Good Converter, or A Phenomenology of Violent Space on the

Western Front

The Establishment of the Western Front 25

Unseen/Unseeing Armies $\quad 28$

A Change in Focus $\quad 39$

Proxy Vision and the View from Above 45

$\begin{array}{lr}\text { Violence without Warning } & 56\end{array}$

$\begin{array}{ll}\text { Conclusion } & 68\end{array}$

The Hell of War, or The Social Construction of Violated Space 70

$\begin{array}{ll}\text { The Blasphemed Landscape } & 75\end{array}$

Sisyphean Labours $\quad 93$

$\begin{array}{ll}\text { What Hope! } & 109\end{array}$

Appropriation and Differentiation, or The Self Separated from Violence 112

$\begin{array}{ll}\text { Spectatorship and its Limits } & 116\end{array}$

$\begin{array}{ll}\text { Violence By-Passed / Passed By } & 123\end{array}$

$\begin{array}{ll}\text { Material Transformation } & 134\end{array}$

$\begin{array}{lr}\text { Singing and (S)laughter } & 146\end{array}$

$\begin{array}{ll}\text { Conclusion } & 157\end{array}$

Conclusion: At the Intersection of Violence and Spatial Studies $\quad 158$

$\begin{array}{ll}\text { References } & 163\end{array}$ 


\section{List of Illustrations}

Figure 1: Paths of Glory (Christopher R.W. Nevinson)

Figure 2: "ANZAC Soldiers Walking on Duckboards through the Remains of Château Wood" (Australian official photographer)

Figure 3: "The Remains of Delville Wood Near the Somme" (Ernest Brooks)

Figure 4: For What? (Frederick H. Varley)

Figure 5: Leaving the Trenches (Paul Nash)

Figure 6: "Making the Camouflage Instead of the Trench"

(Canadian official photographer)

Figure 7: The Ypres Salient at Night (Paul Nash)

Figure 8: "French Attack on the Hart Wood on the Somme" (Hallo Charles-Jean)

Figure 9: "The Falfemont Farm on the Somme" (Jolibois Emile)

Figure 10: "Trench Map of Passchendaele Area" (unknown creator)

Figure 11: "The 16-Inch Sensation" (Bruce Bairnsfather)

Figure 12: "All that Remains of a Village Church"

(Canadian official photographer)

Figure 13: We are Making a New World (Paul Nash)

Figure 14: L'Enfer (Georges Leroux)

Figure 15: Void (Paul Nash)

Figure 16: Gas Attack, Liévin (A.Y. Jackson)

Figure 17: “Gong Shell” (unknown creator)

Figure 18: “Trench Art Ring, Inscribed 'Ypres"” (Sgt. W. Skinner)

Figure 19: “Engraved Shell Case, 18 Pounder” (unknown creator) 


\section{Introduction}

There is something otherworldly about the Western Front of the First World War that has captured the imagination of novelists, filmmakers, tourists, and historians (amateur and professional alike), among many other people. Some are drawn to the brutality of the trenches; others appreciate the quasi-religious tones of sacrifice, honour, and duty in times of war; some are attracted by its status as a watershed moment in world history, the birthplace of Total War, the subsequent death-knell for nineteenth century positivism, and the ostensible birth of modernity. Still others see the First World War as the prelude to the greater atrocities of the Second World War. Whatever their motivations, one need only say "Western Front" and most people can easily conjure up an image of muddy holes, years of futile attacks, and millions of dead or maimed. All of these tropes of the Great War are true enough, but lack nuance, rarely taking into account the many hours spent by the soldiers doing very little at all, waiting for attacks that more often than not never came, digging trenches that were never assaulted, and generally being bored. As Reginald Farrer wrote in his 1918 memoir, The Void of War, while contemplating the nearly half-million British casualties of the Somme offensive in 1916: "[war's observers] cannot be troubled to notice the ordinary and everyday; we reserve our perception for only the salient sensational points—-men dying violently, not men living ordinarily." Farrer's inference is that on the Western Front, the oft-employed metonym to symbolize the overall sense of calamity attached to the First World War, soldiers did attempt to live ordinarily, albeit under rather extraordinary—and extraordinarily violent—circumstances.

\footnotetext{
${ }^{1}$ Reginald Farrer, The Void of War: Letters from Three Fronts (New York: Houghton Mifflin, 1918): 50.
} 
While violence and war appear as obvious counterparts, the space in which violence occurs and the resulting effect that space has on the forms of violence employed have been largely ignored as a point of inquiry in First World War historiography. Contemporary historians have generally overlooked the spatial implications of specific forms of violence employed on the Western Front (in terms of grand strategy, such as the development of aerial optical surveillance, and in terms of socio-cultural responses to violence of the soldiers on the ground, such as the unique songs arising out of trenches). Yet the circumstances to which Farrer refers—both the seemingly mundane and the extraordinary—are inherently spatial concerns, occurring within the same space of the Western Front. The following chapters explore the space of the Western Front at the time of war, taking snapshots of institutional, social, and material manifestations occurring within that space, and the chapters do so under the unifying rubric of violence which, in a time of war, informed the production of every one of the aforementioned interpretations of space, both implicitly and explicitly. This thesis argues that the belligerents' grand strategy, with its reliance upon high explosives and heavy ordinance, created a unique set of material conditions on the Western Front, to which the social response of the soldiers was frequently one of being tortured, tormented, and generally subordinated to the seemingly ubiquitous violence of the Front. Yet even as "hell" became a common linguistic trope to describe the trenches as the most awful space imaginable, the soldiers also refused to abandon their humanity to the inhuman artillery, and in spite of their hellish surroundings, this thesis will argue that a broad culture of resistance to violence sprung up amongst the trench dwellers. 
In terms of methodology, I have endeavoured to draw upon a trans-national perspective, focusing primarily upon Canadian sources but complimenting these materials by British and French resources wherever available. I have also attempted to balance the use of primary documents, employing as many memoirs as I have letters and diaries from the front in the hopes of locating unified sentiments between these public and private reflections on war. Without exception, the multitude of sources used in the coming pages — photographs, paintings, trench art, or written observations-were created by eye-witnesses to the conflict. Though this in no way ensures that the creators were not being overly imaginative in their depictions or did not suffer from other, external production pressures, I can be fairly certain that (especially in the case of narrative memoirs) their ideas are based upon wartime writings and are not wholesale fictions. ${ }^{2}$ Finally, I have drawn upon a number of theoretical concepts throughout the following chapters, but have done so with the intent of constructing subtle linkages between ostensibly disparate concerns rather than any desire to ignore the nuances of any one theoretical approach. I have done my best to provide signposting to my reader so that the singular components of my theoretical dalliances recall their connection to the thesis in its entirety.

Finally, and before pressing forward, I have included in this introduction a brief discussion of contemporary historiography on the First World War, some of it addressing the dynamics of cultural memory of the war, but all generally interested in the post-war

\footnotetext{
${ }^{2}$ For a discussion of "the man who was there," see Samuel Hynes, The Soldiers' Tale: Bearing Witness to Modern War (New York: A. Lane, 1997). Hynes' text is particularly concerned with the notion of firstperson testimonials of soldiers, and the authority which they construct (or have constructed) around their narratives. See also Dan Todman's exploration of the British fascination with the Great War veteran's authority to speak of his experiences, even many decades later when fading memory has often taken its toll, in The Great War: Myth and Memory (New York: Hambledon Continuum, 2005). While there are certainly pitfalls in the use of all historical testimony, all historians must nonetheless use these sources and while they have limitations, they also provide tremendous insight.
} 
period. This discussion is included not to distract from the issues which will be argued in the forthcoming chapters, but rather to emphasize that such discussions do not occur in a vacuum. Only through acknowledging and challenging the cultural discourses surrounding an event can one hope to approach it with any semblance of phenomenological honesty. As a result, the following discussion attempts not only to situate the chapters that follow in relation to particular historiographical trends, but also to invite the reader into arguably a more nuanced reading of the events themselves.

\section{A Contemporary Image of War}

Some ten million people (mostly soldiers) were killed in Europe from 1914 to 1918 as a result of war, part of what historian John Keegan calls the "tragic and unnecessary conflict" known as the First World War. ${ }^{3}$ Keegan so characterizes the conflict for the scale of its carnage, and for what he sees as its utter preventability by the Imperial powers of the day—-those same powers whose saber-rattling and total lack of foresight destroyed those millions of civilians-turned-soldiers, and also propelled the radical reshaping of Europe, Africa, and Asia many times over in the intervening decades. ${ }^{4}$ It is fairly clear how we, in contemporary times, have responded to the Great War, with virtually every school curriculum in the English-speaking world using the now-famous war poet Wilfred Owen's words as inspiration for the detestation of war. In Owen's own words, typically appropriated as our own, we see the soldiers of the Great War as victims of violence, men dwarfed by the scale of the conflict surrounding them,

\footnotetext{
${ }^{3}$ John Keegan, The First World War (Toronto: Vintage Canada, 2000 [1998]): 3.

${ }^{4}$ For an excellent discussion of the immediate aftermath of the war and the reshaping of political entities during the interwar period, see Zara Steiner, The Lights That Failed: European International History 19191933 (New York: Oxford University Press, 2005).
} 
"bent double, like beggars under sacks, / Knock-kneed, coughing like hags," and soon to be choking to death in the unnatural environment of modern war. The oppressive burden of the conflict reduces the able-bodied to transient, sickly creatures. The conditions of war render these men barely human and certainly a far cry from Victorian or Edwardian ideals of civility, or the fraternity of the Third Republic in France. In this place, men are broken down by the very environment they occupy, compounded by the viciousness of the fighting, the weight of their equipment, and the gravitas of each serving unit suffering almost daily casualties. ${ }^{6}$

Indeed, these images are pervasive if later representations of war are any indication. A memorable scene in Stanley Kubrick's 1957 film Paths of Glory—a title taken directly from a famously ironic (and controversial) painting by British Great War artist Christopher R.W. Nevinson (Figure 1) -involves an ill-fated French scouting party out in No Man's Land. The commander of the party becomes terrified in the horrible void between the trenches, with its bloated corpses, barbed wire, machine-gun soundtrack, and popping flares. Except for their movement, the living are virtually indistinguishable from the dead, though Kubrick uses the flare lighting to give the impression that the dead are still active in this space-much as Owen blurs the line between life and death with his perpetually broken and seemingly diseased figures. In countless films and novels, we see these same matters arise: the soldiers are lost, lonely souls upon a terrible landscape. Paul Gross's 2008 film Passchendaele, one of the latest

\footnotetext{
${ }^{5}$ Wilfred Owen, "Dulce et Decorum est," The Penguin Book of First World War Poetry, George Walter, ed. (Toronto: Penguin Classics, 2006): 1-2.141.

${ }^{6}$ Several hundred soldiers were killed daily when averaged out-and that was only in the British-held trenches (to which the Canadians were frequently assigned). Paul Fussell quotes 7000 daily dead in The Great War and Modern Memory (Toronto: Oxford University Press, 2000): 41. This estimate is wildly inaccurate and is in all likelihood closer to the average for all armies on all fronts, and not merely the British.
} 


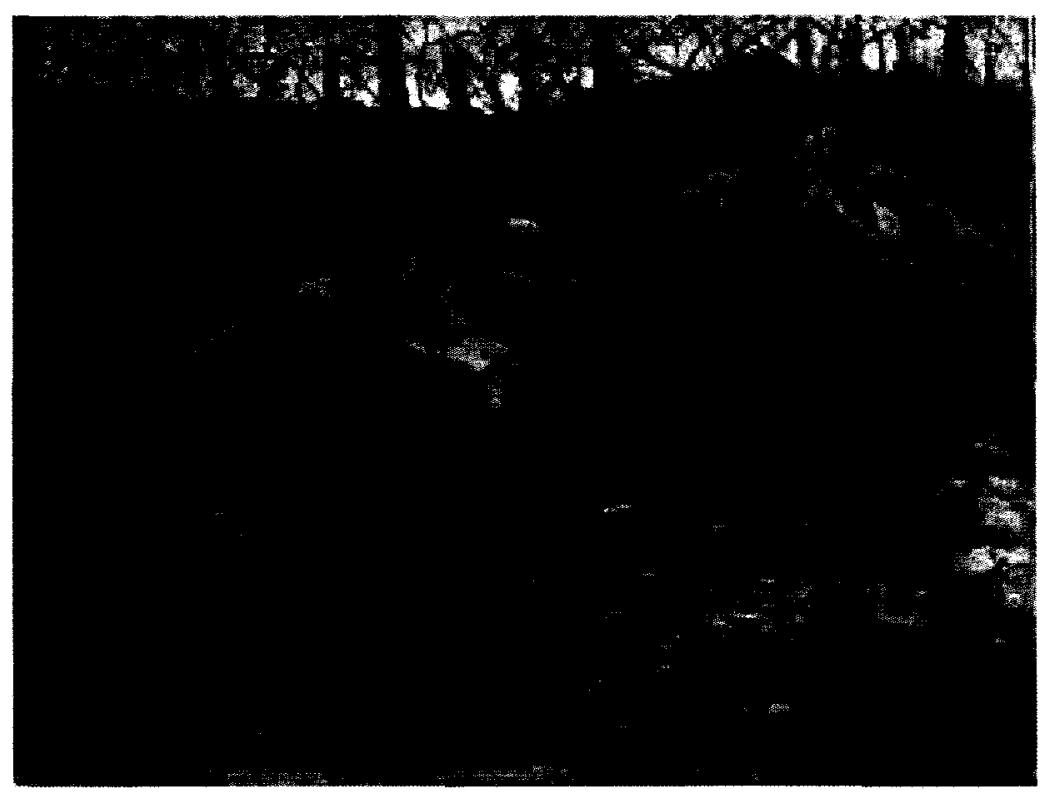

Figure 1: $\quad$ Imperial War Museum (IWM), IWM ART 518, Christopher R.W. Nevinson, Paths of Glory, 1918, Oil on canvas, 61 x $46 \mathrm{~cm}$. London, UK.

popular representations of the Great War, similarly features this idea at the end of the titular battle. As fighting ceases, the camera pulls back and soars upwards while maintaining its focus upon the muddy conditions on the ground. In so doing, Gross shifts from localized suffering to widespread, uninterrupted devastation. The soldiers are still visible in their water-filled, makeshift trenches but the lips of their cratered shelters frame them in; their individuality is now faceless, drowned in the muck.

Such are the images of the First World War we have come to expect, coming almost exclusively from the Western Front which wended its way for 600-plus kilometres through France and Belgium, from North Sea to Swiss border. And if words cannot suffice to generate the proper contemporary image of the conflict, the proliferation of First World War art and photographs on the internet, or the constant reprinting of the same images in newspapers every November $11^{\text {th }}$ (and often for a week prior) can 
certainly evoke the appropriate feelings of despair, desolation, and wastefulness. There are surely a number of iconic images of war-Australian soldiers advancing through the Château Wood near Ypres is one (Figure 2), ${ }^{7}$ which is also cleverly reproduced in

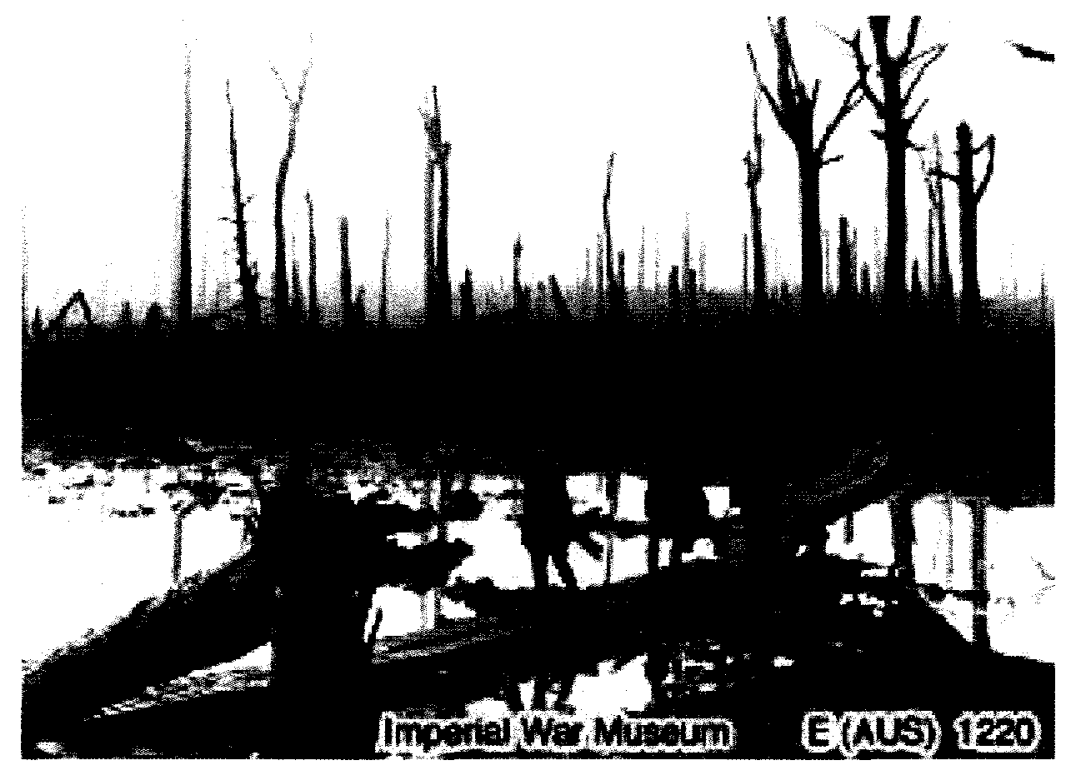

Figure 2: $\quad$ IWM, E(AUS) 1220, Australian official photographer, 29 Oct 1917, "ANZAC soldiers walking on the duckboards through the remains of the Château Wood."

Gross's film, clearly cashing in this most recognizable photo. Of course, a staggering number of photos from different places tend to show the same things without receiving the same popular exposure. A photo of the Somme's Delville Woods, seen far less frequently by a viewing public, similarly captures nearly everything we have come to understand about the First World War, including the iconographic depictions of shredded earth and matchstick trees (Figure 3). In the former photograph, the British propagandists' intent to show the plucky soldiers persevering despite their hardships has

\footnotetext{
${ }^{7}$ Historian Dan Todman identifies this particular photo as one of, if not the most reproduced photo from the Great War, and is still one of the most requested photographic documents at the Imperial War Museum by historians, journalists, and other people. See Dan Todman, The Great War: Myth and Memory (New York: Hambledon Continuum, 2005): 1.
} 
been lost, ${ }^{8}$ obscured by what historians Leonard V. Smith, Dan Todman and others from a variety of national perspectives have identified as the "metanarrative [of the Great War] as tragedy," to use Smith's words. ${ }^{9}$

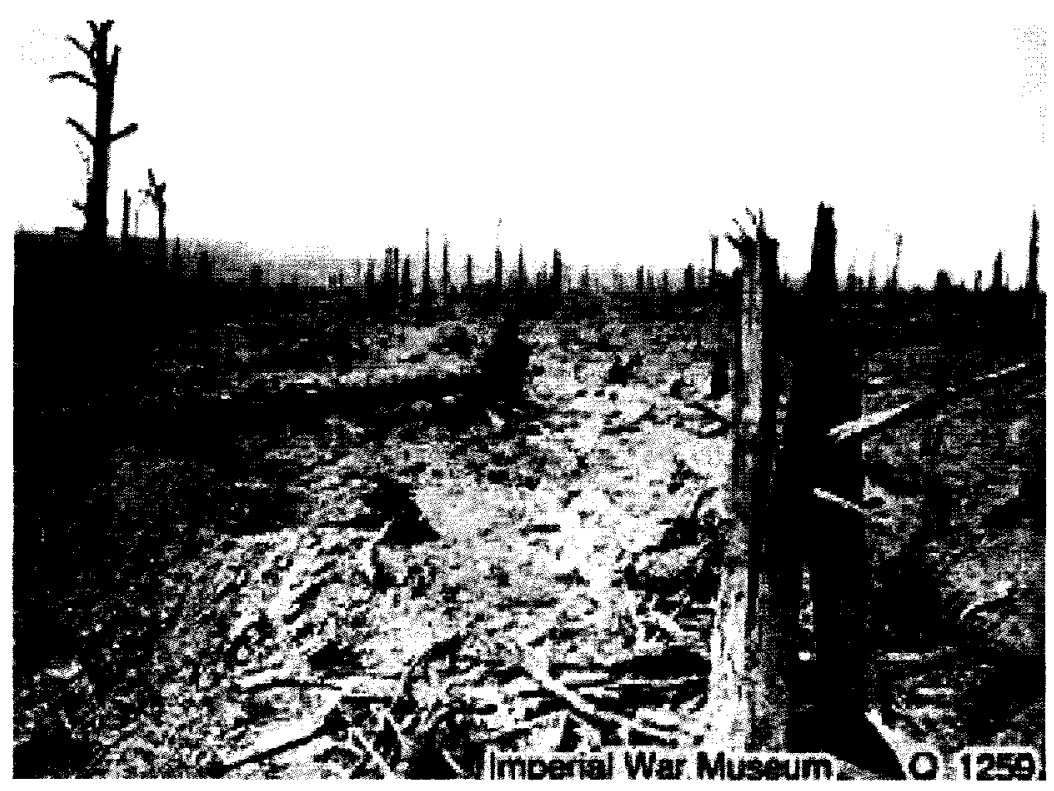

Figure 3: $\quad$ IWM, Q 1259, Ernest Brooks, Sept 1916, "The remains of Delville Wood near the Somme."

Such is the nature of hindsight, which has permitted those of us who dwell in the present day to formulate historical narratives that, as philosopher Arthur C. Danto has stated, "give descriptions of events under which the events could not have been witnessed, since they make essential reference to events later in time than the events they are about." 10 This is, in fact, the central preoccupation of Smith and Todman, whose

\footnotetext{
${ }^{8}$ Many front line photographs were intended to be printed for home front consumption. While many of the scenes are brutal, and at the risk of oversimplifying what is itself a complex topic, they nonetheless were generally intended to inspire the Home Front's continued support of the war effort and of any loved ones overseas, while also showing that the soldiers were carrying on just fine despite enormous hardships. See Peter Barton, The Battlefields of the First World War: The Unseen Panoramas of the Western Front (London, UK: Constable, 2008); and Peter Robertson, "Canadian Photojournalism during the Great War," History of Photography, 2 (1) (Jan 1978): 37-52.

${ }^{9}$ Leonard V. Smith, The Embattled Self: French Soldiers' Testimony of the Great War (Ithaca: Cornell University Press, 2007): 19

${ }^{10}$ Arthur C. Danto, Narration and Knowledge (New York: Columbia University Press): xii.
} 
respective books The Embattled Self: French Soldiers' Testimony of the Great War and The Great War: Myth and Memory, attempt to elucidate the development of the tragic meta-narrative by untangling its myriad components, many of which did not even exist during the war. As Danto further states, it is not enough for an ideal observer to understand the entirety of an event at the time of its occurrence-assuming such a thing were possible-because the consequences of an event are part of the event itself. "The whole truth concerning an event can only be known after, and sometimes only long after the event itself has taken place," writes Danto (though he makes no illusions about the impossibility of a "whole truth"- this is simply a rhetorical technique). ${ }^{11}$ Smith explores how

literary trends in France shift from 1914 to the 1930s, beginning with "consent [for the war morphing] first into rejection and then into trauma." There was a resultant belief in the inevitability of further conflict coupled with a sense of general disillusionment among French veterans, at least partly attributable to later events (such as the rise of Fascism and the Great Depression). ${ }^{12}$ Todman is more thematic in his exclusively British assessment, exploring the numerous contemporary commonplaces of First World War knowledge (such as muddy battlefields and inept generals), tracing their roots to later political movements, popular media presentations, and the socially constructed reverence of veterans' Great War testimonies. In other words, these historians both show how histories change over time.

Smith and Todman are writing in the tradition of contemporary cultural history, exploring the ways in which ostensibly authoritative histories are created, sustained, and

\footnotetext{
${ }^{11}$ Danto, Op. Cit., 151.

${ }^{12}$ Smith, Op. Cit., 19.
} 
transformed-occasionally even in contradistinction with so-called "official" histories. ${ }^{13}$

Their work is not without precedent, however, and perhaps the most influential cultural study of the First World War is Paul Fussell's seminal text The Great War and Modern Memory. In it, he articulates many of the sentiments about the First World War that we consider today: that the Great War was the great undoing of the Imperial Age of the nineteenth century, that it spurred new trends in literature through the brutal, frank styles of the Owenses and Sassoons, and that it generally signifies the start of the "Modern" age. ${ }^{14}$ Fussell's preoccupation with the language of a particular experience-that of the British upper-middle class officer on the Western Front, primarily--is not without its problems or its academic opponents, ${ }^{15}$ but Fussell's writing nonetheless emphasizes a post-Second World War vision of the "Lost Generation" of disillusioned, dejected former First World War combatants. In the case of Wilfred Owen, he symbolizes everything that was wrong with the Great War: a sensitive young man and aspiring poet recruited to fight under brutal conditions, becoming shell-shocked, being hospitalized and treated, and ultimately sent back to meet his demise exactly one week before the guns finally fell silent on November $11^{\text {th }}, 1918$. Owen, like so many of his generation, was slain for what? This was not an uncommon sentiment if the centrality of a corpse cart upon a discoloured and devastated landscape in F.H. Varley's painting For What? is any indication (Figure

\footnotetext{
13 "Official" histories typically refer to those histories written during the post-war period, often commissioned by institutional interests at various levels: regimental, governmental, and even for veterans' groups. As Tim Cook remarks in his assessment of such interests from the Canadian perspective, "official" histories are not always free to discuss problematical elements of the events they purport to depict, nor are they always so constrained as some academic historians have claimed. Still, they are almost invariably met with a degree of scepticism by a post-modern society. See Tim Cook, Clio's Warriors: Canadian Historians and the Writing of the World Wars (Vancouver: UBC Press, 2006): 3-9.

${ }^{14}$ Paul Fussell, The Great War and Modern Memory (Toronto: Oxford University Press, 2000 [1975]).

${ }^{15}$ For a fairly blunt criticism of Fussell's approach, see Brian Bond, The Unquiet Western Front: Britain's Role in Literature and History (New York: Cambridge University Press, 2002): 12, 72, 76, and 100.
} 
4), but according to Fussell it was the allegedly dominant sentiment among war's witnesses.

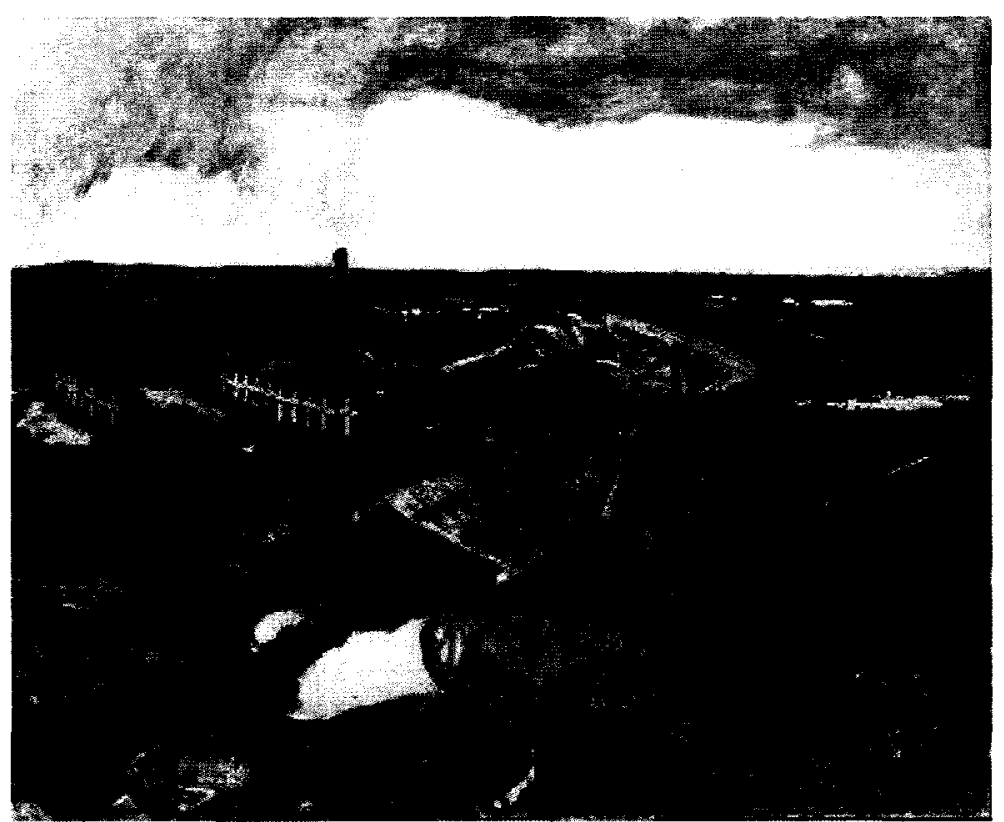

Figure 4: $\quad$ Canadian War Museum (CWM), 19710261-0770, Frederick H. Varley, For What?, Painting, Oil on canvas, 147.4 x $180.6 \mathrm{~cm}$. Ottawa.

As Todman and Smith show, the Great War was not a singularly schismatic event, neatly separating pre- and post-war Europe, and other recent scholars such as Jay Winter and Jonathan Vance have similarly argued as much. Winter's Sites of Memory, Sites of Mourning specifically takes issue with the idea of the Great War being the major step in the onward march of "Modernist" thought. Winter argues, firstly, that "Modern" movements were afoot well before the Great War (such as in various avant-garde art movements, Futurism being most prominent among them), and also that there was never a clear break with tradition. ${ }^{16}$ Instead, Winter is attempting to show how both soldiers and civilians - a distinction not easily made, I think, since the soldiers of the Great War were

\footnotetext{
${ }^{16}$ Jay Winter, Sites of Memory, Sites of Mourning: The Great War in European Cultural History (New York: Cambridge University Press, 2007 [1995]): 3-5.
} 
civilians prior to the war, and mostly became so again in its aftermath-attempted to "find ways to comprehend and then to transcend the catastrophes of war" in public and private fashion. ${ }^{17}$ The cultural production of the formerly warring peoples, found in monument construction, ceremony, and also literature (among other things) often employed very traditional expressions, found in some of the oldest religious and nationalistic discourses. The deaths of young men were sacrifices. Civilization had hung in the balance, and so theirs was a noble cause. Vance, writing strictly from the Canadian inter-war perspective, has argued in Death So Noble: Memory, Meaning, and the First World War that these discursive practices "convey the myth [of the Great War] to those people who had not experienced the events themselves and to ensure that a certain version of the war became the intellectual property of all Canadians." ${ }^{, 18}$ In yet another, still more overt response to Fussell's work, Stefan Goebel's comparative study of German and British nationalist rhetoric is entitled The Great War and Medieval Memory: War, Remembrance, and Medievalism in Britain and Germany, $1914-1940 .{ }^{19}$ In it, Goebel stresses a backward looking, ultimately romantic set of tropes about war and its meaning that was articulated in both nations right up until the Second World War.

The central preoccupation of these texts-Fussell, Vance, Winter, et al.-is that of language and representation, and the ways in which they are employed or deployed in response to war. They are, however, almost exclusively fixated upon post-war concerns, as so many of the titles clearly indicate through words such as "memory," "remembrance," and "mourning." It is impossible to consider these terms without

\footnotetext{
${ }^{17}$ Ibid. 1.

${ }^{18}$ Jonathan Vance, Death So Noble: Memory, Meaning, and the First World War (Vancouver: UBC Press, 1997): 3.

${ }^{19}$ Stefan Goebel, The Great War and Medieval Memory: War, Remembrance, and Medievalism in Britain and Germany, 1914-1940 (New York: Cambridge University Press, 2007).
} 
considering the events to which they are attached as past. The "memory boom," 20 as Winter calls it, has been and continues to be tremendously fruitful as an academic and amateur pursuit. There have been a myriad of different memorial periods (inter-war, 1960s, 1990s, and lately as we approach and inevitably surpass the one-hundred year anniversaries of the Great War's start and finish), and also the diverse practices of what one might semi-facetiously term "rememberers" (children and grand-children of veterans with their collections of medals and paraphernalia, political officials and their speeches, battlefield tourists, webmasters, and preservation or historical societies) to be explored by historians of all types. There is, it seems, a notable absence in these works that is only just now being explored, but about which very little has been written in a rigorous, analytical fashion: soldiers' culture which emerged during the war itself. ${ }^{21}$ What is most interesting of the aforementioned contemporary historical approach to the Great War is the historians' preoccupations with the prevailing sense of tragedy which has become attached to the First World War narrative. As previously mentioned, this project takes aim at the period of 1914 to 1918 , seeking its conclusions therein while considering both the semantic and interpretative elements of wartime discourses and practices.

This text focuses upon the Western Front for a variety of reasons, the most important of which are its relatively static frontage, the fairly consistent exposure to

\footnotetext{
${ }^{20}$ Jay Winter, Remembering War: The Great War Between Memory and History in the Twentieth Century (New Haven: Yale University Press, 2006): 1.

${ }^{21}$ There are a number of authors who have looked at the soldiers' culture in the trenches, but usually as part of a larger project. Nicholas J. Saunders' Killing Time: Archaeology and the First World War (Gloucerstershire: Sutton Publishing, 2007) looks at material culture in the context of broader archaeological implications. Leonard V. Smith's Between Mutiny and Obedience: The Case of the French Fifth Infantry Division during World War I (Princeton: Princeton University Press, 1994) examines power structures within the titular division, with particular attention paid to the French mutinies of 1917. Tim Cook has recently published articles on soldiers' popular culture-singing, and interpretations of cartoons, for example-while Shock Troops: Canadians Fighting the Great War 1917-1918 (Toronto: Viking Press, 2008) covers other aspects of trench culture in chapter form.
} 
violence experienced by the soldiers in their entrenched positions, and the high numbers of people populating the front- "underground trench cities," as Tim Cook calls them. ${ }^{22}$ These conditions permitted for a fairly sustained interaction with one's spatial environment and its occupants of all types, both material and personal, but nonetheless of a temporarily limited type. These were "cities" for several years only, sustained and maintained of and for the purposes of violence. That highly temporary structure suggests, as I will argue in the chapters to come, that the spaces created and occupied by and for the soldiers must be temporally situated accordingly. Few historians dispute that war was an awful experience for virtually all participants, or that the Western Front was viewed as an awful space. What is less clear, however, is the myriad of responses the soldiers had to this space in which their subordination to violence was typically ever-present and also typically always resisted. In so resisting, the soldiers took the chaotic, even hellish environment of modern war and created life-affirming pockets of creative, tactical appropriation in opposition to destructive strategies; stability and continuity were similarly engaged as forces of will against forces of sudden, violent discontinuity. In essence, the soldier-as-victim is only part of the Western Front's story. The soldier was also, among other things, a subversive whose energies quite frequently went into practices of personal survival. For every one of Owen's coughing hags, for every screaming shell or anguished cry, one must also recall that there was a chuckling Tommy or un Poilu chantant. ${ }^{23}$ It is with all of these notions that I preoccupy myself for the next few chapters.

\footnotetext{
${ }^{22}$ Cook, At the Sharp End, 223.

${ }^{23}$ Translation: "a singing Poilu." Tommy and Poilu were the respective nicknames for British and French soldiers. The former comes from "Tommy Atkins," an old, ostensibly generic name in British military culture; the latter refers specifically to the hairy-faced French soldiers who were allowed to grow their
} 


\section{$\underline{\text { Situating Trench Culture and Practices }}$}

The aforementioned Memory Boomers are expressly concerned with the construction of narratives over time, using temporal markers (now, then, before that, afterwards, and so on) to illustrate a story arc. Meaning is derived through these temporal markers by elaborating connections between past episodes and what philosopher Paul Ricoeur calls "an absolute 'now'," referring to the spatial-temporal point from which one looks backwards. ${ }^{24}$ This is ongoing and fruitful work, given the vast array of temporal and spatial locales which one might choose as a point to call "now" and up to which one might draw their causal line: Todman's "now," meaning the point at which he begins (or rather, ends, if one prefers a linear, forward-moving temporal flow) his inquiry is the late 1990s in England. Smith's is the late 1930s in France. These retrospectives are fascinating and are possessed of the benefit of potentially being ever-current histories, but the strategic, arcing sketch excised from the fait accompli of the past has its limitations. Even as cultures actively construct meaning through time, so too did the soldiers of the First World War construct a meaningful environment for themselves at the time. In other words, there is always an immediate response to one's present situation; the soldiers of the Western Front were no different, and their material legacy of letters, trench art, and other historical objects reveals many of those responses and much about the men and their perceived situation.

beards in the trenches (Poilu translates roughly to "furry," though it is a culturally specific term and works poorly as a translated term).

${ }^{24}$ Paul Ricoeur, Memory, History, Forgetting, Kathleen Blamey and David Pellauer, trans. (Chicago: University of Chicago Press): 155. The "now" to which Ricoeur refers is the time of remembering, and I propose that the aforementioned historians appropriate a historical point in time, and designate it the "now" to which all earlier matters will be referred. It does not have to correspond to any present sense of "now" because the careful historian can simply cease his or her investigation at the designated calendar time (a term Ricoeur uses to distinguish between experienced time and empirical time). 
Henri Lefebvre's The Production of Space speaks of space as a seemingly unlimited container, once understood in purely empirical terms but now taken to mean virtually any number of mental, social, and institutional constructs (to name but a few). ${ }^{25}$ His lament over the imprecision of these terms is well made, and his principle complaint is that few if any of the noted philosophers he discusses (Sartre, Foucault, Derrida, and others) seem interested in elaborating upon how the liberally employed, aforementioned spaces are produced and to what end, and also how those spaces relate to other conceived spaces (mental to social, for instance) ${ }^{26}$ This thesis attempts to address at least one of Lefebvre's complaints by showcasing the connections between an institutional space (the battlefield as constructed through the lens of an evolving grand strategy), the social response to that space and that space's relocation (or reorientation) into a set of discursive tropes, and finally how physical space might yet be appropriated, dislocated, and transformed through cultural practices that appear antithetical to institutional design.

The first chapter establishes the extreme destructive forces on the Western Front as the principle, formative element of soldiers' space in that warfare always entails a specific attempt to inflict subjective violence (the killing or injuring of living beings), in addition to other forms of more objective violence (economic blockades, for example). ${ }^{27}$ Indeed, Stéphane Audoin-Rouzeau and Annette Becker, in 14-18: Understanding the

\footnotetext{
${ }^{25}$ Henri Lefebvre, The Production of Space, Donald Nicholson-Smith, trans. (Malden, MA: Blackwell Publishing, 1991 [1974]): 2-4.

${ }^{26}$ Ibid. 5-6.

${ }^{27}$ Admittedly, objective versus subjective violence is something of a false dichotomy, in that it would be rare indeed to experience no sense of violence directed at the self if one's food supplies were slowly being choked off. Similarly, regime change and its accompanying ideological shifts often result in one or more social groups being subjectively targeted for sanctions. Still, I employ the distinction because warfare, as stated, involves an active and persistent attempt to harm another group's members using physical violence, directed by people at people (hence giving us yet another interpretation of Carl von Clausewitz's "war is a continuation of politics by another means"). The differentiation appears to be one of process rather than product, indirect violence versus direct.
} 
Great War, state that corporeal violence is a part of every war: "bodies strike each other, suffer and inflict suffering., ${ }^{28}$ The first chapter draws some inspiration from their approach to violence, and argues that the destructive forces operating on the Western Front are the foundation for virtually all things that follow. Without the destructive force of artillery and the rapid-firing rifle, for instance, there are no pseudo-siege conditions, no dugouts in which to hide and also in which to form microcosms of creative activity, and so on. In order to effectively instigate a shift from the empirical space of the past to the experienced space of the past, I will show how the material conditions of this violence were experienced by the soldiers in their trenches. In short, the speed with which violence was inflicted upon the soldiers was extraordinary in the trench setting, resulting in a perception of haphazard and instantaneous transformation. As a result, there developed very quickly an overwhelming need for stability within this otherwise chaotic, seemingly accidental environment.

The second chapter focuses upon the soldiers' discursive response to the practically capricious environment of the Western Front's trench lines, which was in a constant state of becoming disordered. The way soldiers responded to the space with which they were confronted was often quite negative, and the dominant trope of these wartime narratives is of a hellish environment. As a site of constant violence, endless tedium, and unpredictable transformation it is easy to see why "hell" as a spatial descriptor comes up so frequently in soldiers' letters and diaries. Most soldiers were of the Abrahamic faiths, with the overwhelming majority being Christians. ${ }^{29}$ This fact also

\footnotetext{
${ }^{28}$ Stéphane Audoin-Rouzeau and Annette Becker, 14-18: Understanding the Great War, Catherine Temerson, trans. (New York: Hill and Wang, 2002): 15.

${ }^{29}$ This statement is not intended to diminish the many worthy contributions of soldiers of other ethnicities or religions, such as the many Hindu and Sikh soldiers recruited from India, the largely Buddhist Chinese
} 
helps us understand the use of hell as a spatial trope, given its cultural prevalence: hell could effectively serve as a ready-made term that would lend the soldiers' narratives some coherency, albeit of a paradoxical kind. While it appears true that in all linguistic representation there is some slippage in meaning-as Hayden White suggests, "the data always [resists] the coherency of the image which we are trying to fashion" 30 - hell is deliberately employed by the soldiers to represent the worst of all imaginable spaces. It is, by its very nature, an incoherent space, even as it remains open to interpretation through the imagination. Regardless, many soldiers describe in great detail why their surroundings appear hellish; these descriptions are also coupled with the same sense of tedious, torturous labours associated with a hellish environment, and the chapter argues that spatial description and spatial activity are part of the same description.

The final chapter addresses a last set of spatial concepts that bring our attention away from the awfulness of modern war and instead focuses upon the soldiers' practices of making war space comfortable, endurable, and even aesthetically appealing. This chapter is intended as a response to both previous chapters, in that it represents an antithetical view to the hell in which the soldiers are ostensibly mired, while also being part of a practice of appropriation of spaces intended for one use, and subsequently transforming those spaces for other use. In this final chapter, I attempt to elaborate some important connections between the act of distancing oneself from violence and coming to view war as a spectacle, the material transformation of objects formerly intended for

labourers, and so on. Indeed, it would be a fascinating comparison for an expert in such subjects to conduct a similar analysis of their views in the interests of determining if there were any cultural specificity to these spatial concerns, and whether or not there are counter-narratives at work in different ethnic or religious groups on the Western Front. Sadly, it was beyond to my expertise to consider such a discussion beyond this proposal stage.

${ }^{30}$ Hayden White, "Introduction: Tropology, Discourse, and the Modes of Human Consciousness," Tropics of Discourse: Essays in Cultural Criticism (Baltimore: Johns Hopkins University Press, 1985 [1978]): 1. 
killing but now used as aesthetic pieces, and the appropriation of the soundscape of war from killing and disharmonious barrage to the unified voices of the soldiers raised in song and laughter. Each of these acts, from the private practices of soldiers carving shell casings by candle light to the commonly known songs sung on the march, are subversive. Each act or practice points towards the violence to which they stand opposed, condemning that violence in some cases, but always invoking the persistence of human life in a space so readily associable to death.

In addition to the theoretical concerns previously mentioned, I must also draw attention to two other cultural theorists whose work has proven both important in discussing some key issues, while also proving inspirational in their style and structure. The first, whose appearance in this work is primarily located in the fourth chapter, is the late French historian and historical theorist Michel de Certeau. In volume one of The Practice of Everyday Life, his signature piece of critical theory, he elucidates a theory of spatial appropriation by ordinary people operating in regulated, institutionalized spaces. In Certeau's own words, he is interested in how "users-commonly assumed to be passive and guided by established rules-operate" within a collective setting. ${ }^{31}$ The claim in Certeau's work is that the authoritative structures which attempt to lord over their space are rarely so fixed and stable as they purport to be. ${ }^{32}$ In other words, the occupant of any given space, even one constructed with a particular intent, is nonetheless free to occupy it and employ it in whatever way he or she sees fit. Certeau distinguishes between two concepts in his book: strategies and tactics. The former is where the notion of "proper" place is established, and from whence exterior relations are defined; tactics, on

\footnotetext{
${ }^{31}$ Michel de Certeau, The Practice of Everyday Life, Steven Rendall, trans. (Berkeley: University of California Press, 1988 [1984]): xi.

${ }^{32}$ Certeau, Op. Cit. xix.
} 
the other hand, are the constant manipulation of events "in order to turn them into "opportunities" that change the values of what is deigned "proper." 33 The use of such ideas should be fairly obvious in the fourth chapter, with soldiers taking what was given to them and through their creative practices, ascribing new values to those spaces.

Certeau also makes some interesting claims in the realm of spectatorship, though that concept will receive a more detailed treatment in Chapter Four.

The other thinker who has inspired this project is a prolific if iconoclastic cultural theorist, Paul Virilio. Virilio earned his reputation as the foremost theorist of speed and perception-“Dromology" as he calls it—but has also written extensively on art, architecture, the unforeseen accidents of human ingenuity, and what he sees as attempts by military interests to appropriate the globe through a perceptual apparatus of sight machines. In various ways his ideas have influenced my thinking during the planning of this project, even if some of his concepts are not explicitly cited. Regardless, his work on speed and its role in shaping both time and space finds its way into my second chapter, ${ }^{34}$ as does his thinking on the nature of the modern accident in that the trenches were an unforeseen consequence of new technology $\mathrm{y}^{35}$ - a matter I argue in some detail in the next chapter. His views on the military appropriation of all three dimensions of geometrical space (length, width, and height/depth) have also inspired my thinking on the subordination of the soldiers to the trench system in which they were seemingly, even hopelessly mired. ${ }^{36}$ Finally, like Certeau, Virilio's profound ambivalence toward the

\footnotetext{
${ }^{33}$ Ibid.

${ }^{34}$ Virilio's seminal texts on speed and perception are War and Cinema: The Logistics of Perception, Patrick Camiller, trans. (New York: Verso, 2000 [1988]); Speed and Politics: An Essay on Dromology, Mark Polizzotti, trans. (Los Angeles: Semiotext(e), 2006 [1977]); and The Aesthetics of Disappearance, Philip Beitchman, trans. (Los Angeles: Semiotext(e), 2009 [1980]).

${ }^{35}$ See Paul Virilio, The Original Accident, Julie Rose, trans. (Malden, MA: Polity Press, 2007 [2005]).

${ }^{36}$ See Virilio, War and Cinema.
} 
means and methods of institutional control, part of an explicit humanistic agenda, has inspired the central organizational concerns of this thesis, as the chapters transition from the collective voice of the guns, to the isolated voice of the soldier, and ending with the collective voices of the men on the ground. 


\section{Chapter Two:}

The Cannon is a Good Converter, or A Phenomenology of Violent Space

on the Western Front

It is a phenomenological certainty that without acts of violence, there is no waging of war. People are hurt and killed; places are destroyed. The matter is implicit in the first few lines of Sun Tzu's The Art of War: "[War] is a place / Of life and death," becoming more explicit throughout the text. It is similarly the fundamental starting point in Carl von Clausewitz's definition of war: "War ... is an act of violence intended to compel our opponent to fulfil our will." ${ }^{, 37}$ One need not go much further than this in order to construct a basic definition of war: it is the enacting of violence, with life and death hanging in the balance. Yet it is rare in much contemporary First World War historiography that violence becomes the focal point around which other concerns revolve. In one particularly egregious case of overlooking violence's centrality in wartime, Hunt Tooley, in a very recent survey of the Western Front, suggests that violence was viewed as "incidental" to the experience of warfare, despite spending the next ten-odd pages of his book discussing the soldiers' various responses to and engagement with violence and its effects. ${ }^{38}$ One should not characterize Tooley's eagerness to omit the soldiers' experiences of violence as the norm, yet it is indicative of

\footnotetext{
${ }^{37}$ Respectively: Sun Tzu, The Art of War, John Minford, trans. (Toronto: Penguin Books, 2005): 1; and Carl von Clausewitz, On War, J.J. Graham, trans., Anatol Rapoport, ed. (Toronto: Penguin Books, 1982 [1832]): 101. Emphasis in the latter quote are the original author's.

${ }^{38}$ Hunt Tooley, The Western Front: Battle Ground and Home Front in the First World War (New York: Palgrave Macmillan, 2003): 218-228. In the text, the pages immediately following Tooley's assertion about "incidental" violence are replete with discussions of burying the dead, repairing trenches, bombardments, and seemingly interminable marches to and from the front. These matters, as I will demonstrate, are fundamentally oriented around violence and the testimonies of the soldiers reveal there is no sense that these are "incidental" circumstances.
} 
a need to more thoroughly inquire into the means, methods, and effects of violence in wartime, rather than subordinating violence to other concerns. It appears quite obvious, too, that at least some better acknowledgement of how violence shapes the space of war, and indeed its reciprocation, is needed.

The problem, as it appears to be, is that the point about violence is perhaps too obvious to belabour or highlight. And yet this is precisely why one must engage with violence and its myriad effects if one is to consider the impact of war upon the many constructions of the space of war-strategic, social, cultural, or otherwise. As French historians Stéphane Audoin-Rouzeau and Annette Becker state, violence in war "renders visible things that are ordinarily hidden from view" such as the power relations that provoke human beings to kill one another. ${ }^{39}$ Audoin-Rouzeau has elsewhere written that "to refuse to look at ... the violence of combat" is in fact "a refusal to grasp the central phenomenon of war." ${ }^{40}$ Yet Audoin-Rouzeau and Becker consider violence in war as a "staging of the political," in what appears to be a more micro-focused, Michel Foucaultinspired twist on Clausewitz's view of war as "politics by another means." ${ }^{\text {, } 1}$ In other words, they are interested specifically in how violence is employed to shape social interactions, how narratives of victimhood are used in political power structures, and so on. Yet violence-active and ongoing, rather than in its aftermath phase as AudoinRouzeau and Becker consider it-has a profound effect upon the spaces in which it is

\footnotetext{
${ }^{39}$ Audoin-Rouzeau and Becker, Op. Cit., 17.

${ }^{40}$ Stéphane Audoin-Rouzeau, "Extreme Violence in Combat and Wilful Blindness," International Social Science Journal v. 54, i.4 (2002): 497.

${ }^{41}$ Respectively: Audoin-Rouzeau and Becker, Op. Cit., 17 and Clausewitz, Op. Cit., 109-10. Clausewitz was interested in both the means of war and its object, the latter of which he viewed as political on a macro scale (i.e. relating the national or state interests). The manner in which Audoin-Rouzeau and Becker employ the term "political" is at a micro level, and specifically as an exploration of cultural tendencies to endorse war, to remember military violence in particular ways, and to commemorate war.
} 
deployed, from the geo-physical space of the trenches, to the strategies of geo-physical spatial representation, and also to the experiential space of the soldiers in the trenches. This chapter explores the formative and experiential aspects of violence in the trenches of the Western Front. I focus upon the ways in which violence and human perception interact, and how the confluence of these two seemingly disparate issues results in a particular perception of violence that is a direct product of the material conditions of the First World War. The necessary, living interment of combatant armies all along the Western Front was a response to the new killing technologies introduced on the modern battlefield and this forced burial gave the impression of an empty battlefield to its participants. The resulting void of perceptible activities resulted in military strategists on both sides adopting new techniques designed to overcome the deficiencies of trying to fight an invisible enemy from one's own obscured position. These novel strategies resulted in an ever increasing reliance on indirect, area effect weapons, typically deployed from unseen positions. This process of blind firing and dependence upon proximity over precision all but removed the issue of human perception from the process of inflicting violence: gunners 'saw' their targets by proxy, on maps or through the eyes of another in a forward observational position, while the victims of indirect forms of violence rarely perceived their assailants in most circumstances. Thus, the perception of violent forces was such that individuals in the front lines would experience moments of instantaneous, terrible transformation, with the objects of bloodshed appearing to have no origins. This form of violence would not only shape military strategy but, as will be demonstrated in the next chapter, it would also become a central component of the soldiers' social construction of their surroundings. 


\section{The Establishment of the Western Front}

The establishment of the trench lines on the Western Front has been welldocumented, and a brief summary of the changing context of warfare is presented only insofar as it provides a base from which to elaborate further ideas about notions of front line space. To begin with, military technology had undergone major changes in the years leading up to 1914. All soldiers in the European armies were equipped with magazinefed, bolt-action rifles; artillery, like small-arms weapons, was now rifled and using chemical propellants. ${ }^{42}$ Historian Stephen Bull has noted, "according to British definitions, 'close range' [for a rifleman] was anything up to 600 yards" and those rifles could be fired 15 times or more per minute by a trained infantryman. As Martin van Creveld states, that is a rate of fire three or four times faster than the rifles of the nineteenth century. ${ }^{43}$ Armies were not oblivious to these issues of increased effective range and the capacity of combatants to hurl rounds down range at an incredible rate: senior commanders knew that any battle between major powers would be incredibly costly. Even so, it was a chance chiefs of staff were willing to take as the major belligerent powers all continued to espouse a doctrine of attack, albeit with the tacit acceptance that casualties would be high. ${ }^{44}$

Timothy Travers has identified British attack doctrine as being based on three key factors: fire-power, a pessimism directed toward modern values and corresponding lack

\footnotetext{
${ }^{42}$ Dennis E. Showalter, "Mass Warfare and the Impact of Technology," Great War, Total War: Combat and Mobilization on the Western Front, 1914-1918, Roger Chickering and Stig Förster, eds. (New York: Cambridge University Press and the German Historical Institute): 75.

${ }^{43}$ Respectively: Stephen Bull, World War I Trench Warfare 1914-1916, Vol. 1 (New York: Osprey Publishing, 2002): 9 and Martin van Creveld, "World War I and the Revolution in Logistics," Great War, Total War, 65.

${ }^{44}$ Dominick Graham, "Sans Doctrine: British Army Tactics in the First World War," Men at War: Politics, Technology and Innovation in the Twentieth Century, Timothy Travers and Christon Archer, eds. (Chicago: Precedent, 1982): 73.
} 
of trust in working-class recruits, and finally a belief that warfare is "structured, ordered, and therefore potentially decisive." ${ }^{, 45}$ It is hard to fathom how the abstract, rhetorical values of "structure" and "order" would stand up to the undeniably real impact of a $15 \mathrm{~cm}$ schwere Feld-Haubitz (a medium calibre field gun): as we now know, it would take far more than simple determination to make any progress in this techno-centric war environment. French historian and Great War veteran Marc Bloch remarks upon this matter in describing his German opponents, whose determination is unable to penetrate Bloch and his companions' wall of fire. "They left their trenches," Bloch writes in his memoir, and "our bullets stopped them each time." 46 Closing with and destroying the enemy typically required crossing several hundred yards of terrain with only light supporting fire, and this was recognized as a strategic problem before the war. ${ }^{47}$ Despite a continued pre-war belief by most generals that tenacity could carry the day, ${ }^{48}$ those precious yards proved mostly insurmountable in 1914, resulting in a deadlock of inconceivable proportions. It would require much more firepower to break the increasingly strong defensive positions of the combatants. As a result, artillery became the primary weapon of the modern army, exponentially increasing in use throughout the war, and ultimately accounting for over half of all casualties by some estimates. ${ }^{49}$ The

\footnotetext{
${ }^{45}$ Timothy Travers, The Killing Ground: The British Army, the Western Front, and the Emergence of Modern Warfare (London, UK: Allen \& Unwin, 1987): 37.

${ }^{46}$ Marc Bloch, Memoirs of War, 1914-15, Carole Fink, trans. (New York: Cambridge University Press, 1988 [1969]): 133.

${ }^{47}$ Graham, Op. Cit., 73.

${ }^{48}$ Joseph Joffre, top general in the French army, employed the terms "offensive capacity" as a euphemism for fighting spirit, feeling that its absence had caused the failure of the 1914 French attack upon the AlsaceLorraine regions. See Marc Ferro, The Great War 1914-1918, Nicole Stone, trans. (Boston: Routledge \& Kegan Paul, 1980 [1969]): 50.

${ }^{49}$ For the increase in artillery use, see Alan Kramer, Dynamic of Destruction: Culture and Mass Killing in the First World War (New York: Oxford University Press, 2007): 226. For rough estimates of numbers of soldiers killed by artillery, see Tim Cook, At the Sharp End, 257. Cook also gives a more detailed analysis of Canadian casualty numbers in Shock Troops: Canadians Fighting the Great War 1917-1918 (Toronto: Viking, 2008): 611-20. Cook disputes the long-accepted statistic that artillery accounts for nearly sixty
} 
First World War very rapidly became the first war in history whose matériel requirements exceeded the soldiers and suppliers' food and fodder needs. ${ }^{50}$ It is also worth recalling that, prior to the mid-nineteenth century, the greatest killer of soldiers during war was disease. ${ }^{51}$ Soldiers on the Western Front were dying or being wounded as a direct result of violent forces far more often than not, with a substantial minority of wounds and fatalities being inflicted by small arms fire and close combat, but more often than not by explosives and other area effect weapons like poison gas.

As alluded to above, these developments were spurred by a shift in armies' reliance upon new technologies, and those technologies in turn shaped the space of conflict. In Bunker Archaeology, cultural theorist Paul Virilio touches upon the significance of the rifled cannonade, observing: "It was no longer in distance but rather in burial that the man of war found the parry to the onslaught of his adversary; retreat was now into the very thickness of the planet and no longer along its surface."52 Technology did not permit otherwise. Virilio is suggesting that simple, geographical separation from one's enemy was no longer a guarantor of safety; weaponry, and especially of the heavy supporting variety, could fire further and faster than that separation could be attained. Rifles were effective at one thousand yards and very accurate at six-hundred, meaning a rifle round could pierce practically as far as the naked eye could see. Even the lightest field guns could be fired many times that distance, while a pair of machine-guns could

percent of casualties on the Western Front, noting that gas casualties are not acknowledged at all in the British source from whence those claims first came, yet Canadian records indicate nearly twelve percent of their casualties were gas-related. Clearly, more scrutiny of the numbers is needed, even if one can generally accept that artillery was extraordinarily damaging.

${ }_{50}^{50}$ Martin van Creveld, "World War I and the Revolution in Logistics," Great War, Total War: Combat and Mobilization on the Western Front, 1914-1918, Roger Chickering and Stig Förster, eds. (New York: Cambridge University Press with the German Historical Institute, 2000): 65-6.

${ }^{51}$ Audoin-Rouzeau and Becker, Op. Cit., 23.

${ }^{52}$ Paul Virilio, Bunker Archaeology, George Collins, trans. (New York: Princeton Architectural Press, 2008 [1975]): 38-9. 
unload a rifle battalion's worth of firepower per minute. Seeing became killing and perception became projection (and consequently penetration). The prospective human killer, chemically assisted, could hurl forth his "will" in the form of a machine-cast ball from an engineered barrel, collapsing the intervening space between target and shooter in an instant. As long as the enemy remained visible, both retreat and pursuit would prove terribly costly, as the British and German armies learned in 1914 during the retreat from Mons. The trenches from late 1914 onwards, as Marc Ferro puts it poetically, thus became a case of "the grave [preserving] life."53

\section{$\underline{\text { Unseen/Unseeing Armies }}$}

Horizontal distance in space was all too easily conquered with such long-range technologies at the disposal of every soldier-though of course, the soldier himself could not hope to attain the same distance-covering velocity of his weaponry. Vertical descent, then, became his salvation. Once the principle German attacks in the west were turned back by the French, Belgian and British forces in 1914, the armies on all sides quickly realized they would need more permanent fortifications. The shell scrapes, earthen mounds, and ditches previously used as hastily conceived shelters were quickly connected together, deepened, and typically reinforced. ${ }^{54}$ The front lines of opposing trenches were almost invariably within shooting distance, and occasionally even within throwing distance for makeshift bombs and later grenades. As a result, keeping one's

\footnotetext{
${ }^{53}$ Ferro, Op. Cit., 86.

${ }^{54}$ There was some difference of opinion between strategists in each army as to the most effective trench construction: the British tended to model themselves upon the Germans' strategies, while the French seemed to believe they would drive the Germans from their lands sooner rather than later, thus resulting in less craftsmanship. The Germans, for their part, were mostly an occupying force and so their fortification efforts were also partly intended to hold the ground they had seized. Still, the general consensus was that trenches were essential to survival.
} 
head down and generally remaining imperceptible became an important fact of life in the trenches, and also one that impacted upon the way in which the space of war was experienced, especially at a perceptual level. This portion of the chapter is concerned with the perceptual effects of interment upon the individual soldier, while later sections will address how grand strategy sought to overcome these perceptual limitations, and what the implications were for the inflicting of violence and experiencing of violent acts against the individual soldier on the Western Front. The first matter to consider is how the burial of large armies in the landscape produced the conditions under which they could not be seen, also creating the conditions under which they, themselves could not see (and also under which they could not see themselves). In short order, every army on the Western Front had become part of the landscape while this integration resulted in a mostly impassable landscape bristling with explosive kinetic potential.

"The Way of War is / A Way of Deception," wrote Sun-Tzu, ${ }^{55}$ and so the concealment of one's army—or at least one's army's activities and strength-has for centuries been an important aspect of warfare. Concealment implicitly contains a certain measure of security, and so it was for the fighting men of this war. Trenches were eventually systematized, appearing as a zipper pattern of short fire bays, interrupted by traverses, and enjoined to supporting trenches (some medical, some sleeping quarters or latrines, some home to reserve soldiers, and the like) by means zigzagging communication trenches running perpendicular to the front. Short of getting a rare good look over land, this design caused severe limitations to soldiers' visual vistas. Rarely did soldiers venture above the parapets at the front edges of the trenches unless they had to, and even then they did so mostly under the cover of darkness. Snipers were practically

${ }^{55}$ Sun Tzu, Op. Cit., 4. 
omnipresent and at least as concealed as anybody else at the front; any carelessness in such an environment most often proved fatal. With the equivalent of small cities of men dwelling across from each other, almost always below ground and thus invisible, the front lines accordingly had all the appearance of an empty battlefield. British Second Lieutenant E.J. Russell remarked at Loos: "I shall never forget the disappointment of my first view of the "front' ... not a soul to be seen." ${ }^{, 56}$ John Singer Sargent, British official war artist during the war, also wrote about this effect of being forced below ground: "The further forward one goes the more scattered and meagre everything is. The nearer to danger, the fewer and more hidden the men-the more dramatic the situation the more it becomes an empty landscape." Implicit in Sargent's description is that the men became less visible, not that they became less present, a point corroborated by Canadian Private Alf Johnson. In a letter dated October $5^{\text {th }}, 1915$, he writes: "what a queer war, yourself and the enemy both hidden away along miles of sand bags, barbed wire and dugouts. [...] [The] only thing is you keep ducking your head when the bullet whistles over."58 Johnson's letter illustrates perfectly the dilemma of seeing and being seen: in order to do the former, one had to risk the latter. And being seen, as one might imagine, most often proved fatal.

Soldiers became very adept at absenting themselves from vision, yet every combatant knew the enemy was out there somewhere. In their memoirs, diaries and letters, most soldiers recount the presence of the enemy, such as Canadian scouting

\footnotetext{
${ }^{56}$ Quoted in Malcolm Brown, "No-Man's-Land," Military History Quarterly v. 8, i. 4 (1996): 30.

${ }^{57}$ Charles Merrill Mount, John Singer Sargent: An Autobiography (Crescent Press, 1957): 297. Quoted in Paul Gough, "The Empty Battlefield," Imperial War Museum Review 8 (1993): 41.

${ }^{58}$ Canadian Letters and Images Project (CLIP), Alf Johnson, letter to George Wyatt, 5 Oct 1915. Online: http://www.canadianletters.ca/letters.php?letterid $=2300 \&$ warid $=3 \&$ docid $=1 \&$ collectionid $=142$. Last accessed: 26 May 2010.
} 
officer George J. Spencer, who writes in his diary of early 1918 a rather banal yet common entry: "a few blows of hammering were heard from [the German] lines." ${ }^{, 59}$ Paul Nash, arguably the most celebrated of Britain's official war artists and himself a junior infantry officer prior to his recruitment as a war artist in November, 1917, presents the concept in typically lucid fashion with his early-1917 painting entitled Leaving the Trenches (Figure 5). Not only does the painting expose the means of concealment, such as the large camouflage screens erected around the communications trench snaking its way through the centre of the image, but it also shows the degree to which the phenomena of war could vanish into the landscape. The marching soldiers become increasingly invisible as they recede into the background; the tops of their rifles merge with the vertical lines of the camouflage fence posts and tree limbs. A Canadian photo

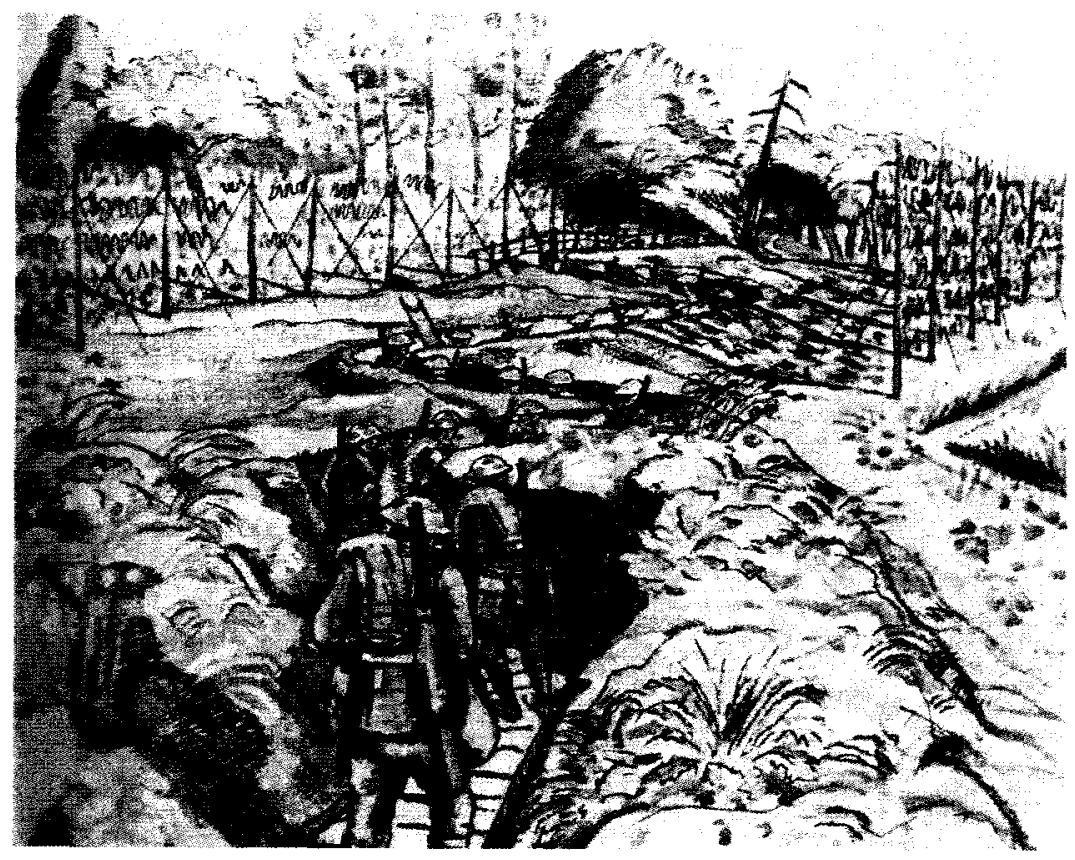

Figure 5: $\quad$ Paul Nash, Leaving the Trenches (1917). Watercolour, pen and chalk. Dimensions and location unknown. In Margot Eates, Paul Nash: The Master of the Image 1889-1946 (London: John Murray): Plate 13B.

\footnotetext{
${ }^{59}$ Canadian War Museum (CWM), Military History Research Centre (MHRC), 58A 1 43.1, George Johnson Spencer, Diary entry, 16-17 Feb 1918.
} 
of a camouflage fence being inspected shows similarities to Nash's depiction (Figure 6), albeit without the artistic license that Nash employs to demonstrate the fence's effect in distorting one's sense of distance, dimension, and space generally. There is a sense of clarity in the foreground of the painting — full figures, identifiable equipment, and even distinguishable plants in Nash's work-yet this becomes increasingly fractured as the shadows from the camouflage netting fall across the ground. Familiarity and intelligibility of one's surroundings are immediate, yet as distances are increased this familiarity decreases incrementally until finally it vanishes.

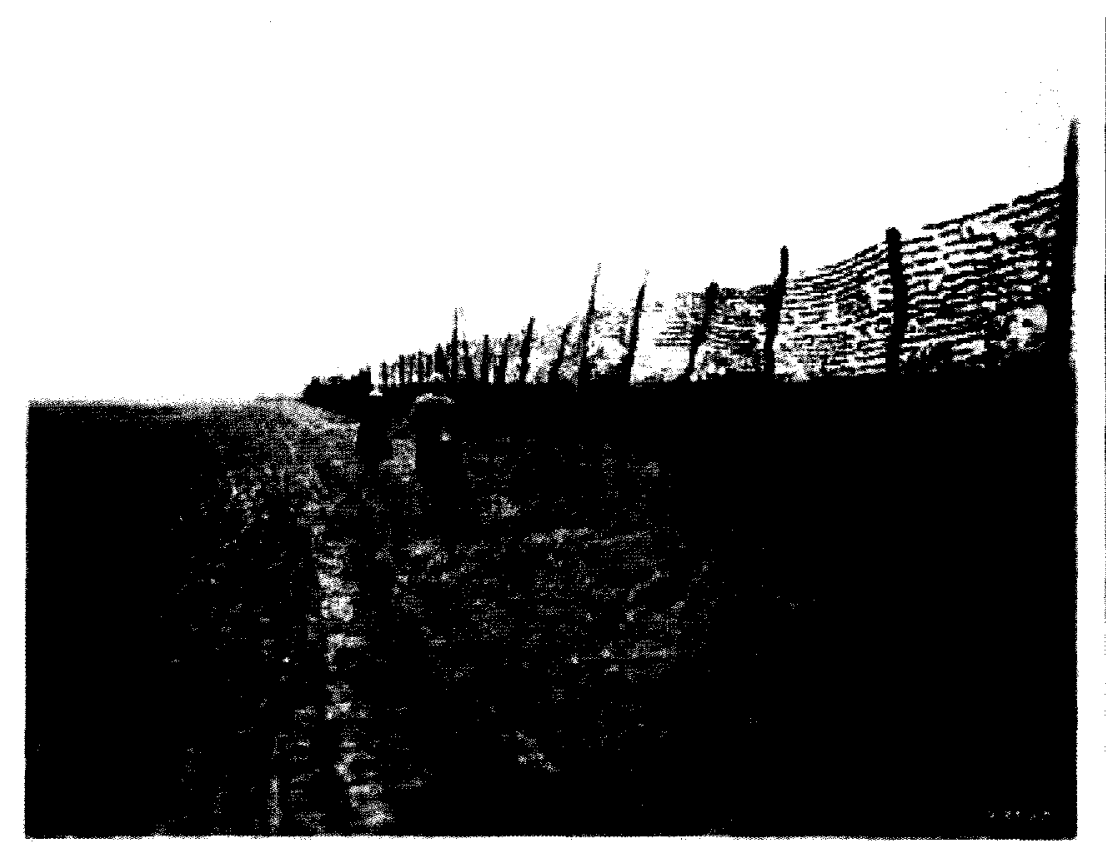

Figure 6: CWM, MHRC, O.2417, Unknown Photographer, Jan 1918, Official photograph, "Making the Camouflage Instead of the Trench."

In essence, the soldiers in the trenches were perched on the edge of a void-that most feared of spaces beyond the realm of human knowledge. In ages past, the void was the vast expanse of the ocean where lurked creatures from the deep that could swallow a ship whole. Voids were, in the words of James Romm, "the terrifying aperion of primal 
chaos ... banished to the outmost edge of the globe. ${ }^{60}$ By 1915 , the void at the edge of one's own space, in addition to being a social construct (which forms the subject of the next chapter), was also materially man-made: it was prone to constant shifting, and was extraordinarily, genuinely dangerous to the point that this "frieze of dead ground," as historian Malcolm Brown calls it, was termed No Man's Land. ${ }^{61}$ Above ground, fields of barbed wire were planted and maintained, while new saps and trenches were dug almost daily by both sides. These activities required almost constant scrutiny so that soldiers were not caught unaware by a surprise raid or assault from a well-hidden, unidentified jumping-off point. Rudimentary patrolling began in the winter of 1914; trench raiding followed soon after. ${ }^{62}$ These developments were all part of increasingly sophisticated strategies of supervision-in the air, on the ground, and even in the depths of the earth where undermining activities were a regular feature of the Great War-all in a vain attempt, as Tim Cook notes, "to exert control over the uncontrollable."63 While many of the aforementioned activities were conducted as aggressive actions in order to inflict casualties, many times they were simply employed as a means of extracting information from a space constructed to resist scrutiny.

Control is not merely a matter of occupying space, but of making it one's own. This is a matter of knowledge and intelligibility; there must be a sense of stability or some supervisory capacity that contributes to a sense of permanent perceptibility. While the principal trenches could indeed be fairly stable, and some lengths of trenchesespecially in the south of France-were considered inactive for the majority of the war,

\footnotetext{
${ }^{60}$ James S. Romm, The Edges of the Earth in Ancient Thought: Geography, Exploration, and Fiction (Princeton: Princeton University Press, 1992): 32.

${ }^{61}$ Malcolm Brown, "No-Man's-Land," Military History Quarterly, V. 8, I. 4 (1996): 30.

${ }^{62}$ G.W.L. Nicholson, Canadian Expeditionary Force 1914-1919 (Ottawa: Queen's Printer, 1962): 122.

${ }^{63}$ Cook, At the Sharp End, 272.
} 
there was no denying their labyrinthine qualities at virtually any spot along the Western Front. As the war went on, trenches became deeper, more solid, and more inclined toward the deception of one's enemies (so-called "dummy trenches" were common enough, but so too could abandoned trenches be used in this way). These patchworks of zigzagging communication trenches, crossed by the surgical, stitched pattern of firing and support trenches, ${ }^{64}$ were coupled with dead-ends, destroyed sections, new trench sections, and so on. It was difficult to determine the enemy's location in their trenches, but these features could also obscure one's view of one's own allies. G.W.L. Nicholson, writing about the Canadians at the battle of Second Ypres in 1915, mentions that combat under these conditions made "the enemy's dispositions (or indeed those of our own troops)" inordinately difficult to locate. ${ }^{65}$ In other words, the trenches had the accidental property of obscuring one's own position from oneself. Nicholson makes his observation from the brigade level: one can only imagine the perceptual deficiencies of the individual soldier. In his firing bay, the trench-dweller would have been perceptually isolated from many of his companions in the line except his immediate partners, who would have been helping him maintain vigilance over their section. Even then, as Canadian Henry Crozier Smith writes, one could "[sit] alone most of the morning, the other men resting in a little dugout." His only sense of his surroundings came in the form of a "little periscope," through which he could gaze over the sandbags. ${ }^{66}$ The best these soldiers could expect in

\footnotetext{
${ }^{64}$ John Ellis, Eye-Deep in Hell (London: Fontana/Collins): 14.

${ }^{65}$ Nicholson, Op. Cit., 91.

${ }^{66}$ CLIP, Henry Crozier Smith, Letter to his Wife, 20 Aug 1916. Online: http://www.canadianletters.ca/ letters.php?letterid=7666\&warid=3\&docid=1 \&collectionid=316. Last accessed: 27 May 2010.
} 
their isolation was to receive what Alf Johnson calls "scraps of news about what is going on in the line" by telegraph, field telephone, or a runner (messenger) passing through. ${ }^{67}$ Intelligence officer Eric Fisher Wood writes in his memoir of looking out across No Man's Land: "The bodies of two Germans, scarcely distinguishable from the gray earth in which they lie, are pointed out to us. [...] Shell-holes and wire entanglements are the only definite features of the empty landscape. Everything else is vague." ${ }^{, 68}$ This sense of vagueness applied not only to the details of the landscape in No Man's Land, but also to any sense of direction, only compounding the experience of sensory disruption built into the trench system. After all, one's own holes in the ground looked much like the enemy's. The British soldiers had a favourite story of a subaltern recently arrived on the Western Front, who drags an experienced sapper officer from the sapper's mine in a panic. Making their way through the trenches to the subaltern's observation post, the subaltern indicates to the sapper a German mine being dug as they speak. It turns out the subaltern "had forgotten the windings of the trench" and was "looking down on [the sapper's] own mine." ${ }^{\circ 9}$ This tale, true or not, expresses some obvious concerns held by the common soldier regarding the intelligibility of the space in which they found themselves. Stripping away the overt comical tone results in an implicit sense of anxiety in the ostensibly educated officer being unable to discern his own army's activities from the enemy's. Also, the sapper officer corrects the subaltern, rendering moot any reading of this joke as a soldier's expression of superiority over his officers. Regardless, there is not merely the matter of "the windings of the trench," as the story states, but also the fact

${ }^{67}$ CLIP, Alf Johnson, Op. Cit.

${ }^{68}$ Eric Fisher Wood, The Note-Book of an Intelligence Officer (New York: The Century co., 1917): 183.

${ }^{69}$ G. Valentine Williams, "With Our Army in Flanders," True Stories of the Great War Vol. VI, Francis Trevelyan Miller, ed. (New York: Review of Reviews Company, 1917): 172. 
that the officer could not determine whose digging was whose without speaking to an actual participant.

As the story above indicates it was not uncommon for soldiers to get lost in the trenches. An anonymous French soldier writes in a trench newspaper: "Fighting in a modern war $[\ldots]$ means going round and round the same point for hours without ever finding it." ${ }^{, 70}$ Eric Fisher Wood notes the "maze of trenches" in which they must pose "continual inquiries [to] keep to [their] appointed ways." ${ }^{71}$ Siegfried Sassoon, the officer and poet, notes in his memoir that once during an attack, another officer failed to lead his company forward because "they didn't know which way to go to find the Germans." 72 In far greater detail and engaging in a discussion of the labyrinthine qualities of the trenches, war correspondent Reginald Farrer echoes the confusion of others:

[The trenches'] blind labyrinths are so baffling that one gets dazed and stunned and stupid. One just goes on, in an accelerando of helplessness, like a squirrel on its treadmill. You cannot see out or over, of course: you lose all sense of direction - especially as no trench ever goes straight for more than a few yards. [...] All intelligence and observation go to pieces in their viewless mazes: and all emotion goes too. You become merely a mechanism. And there is never any Ariadne with a ball of wool. How even

\footnotetext{
${ }^{70}$ Le Filon, 1918. Quoted in Stéphane Audoin-Rouzeau, National Sentiment and Trench Journalism in France during the First World War, Helen McPhail, trans. (Washington: Berg, 1992): 45. It should be noted that the soldiers in the French army involved in trench publications were often anonymous out of necessity. As Audoin-Rouzeau notes in the text, their publications were tolerated to a point, but were often quite critical of the war efforts and of the General Staff. As such, anonymity was essential in ensuring the continued publication of these documents, and so when these newspapers-made by soldiers, for soldiersare referenced, the writers of the articles will almost invariably be anonymously given. Where names are known, they will be provided, but as Audoin-Rouzeau himself notes, it is most often impossible to determine who was involved in such publications.

${ }^{71}$ Wood, Op. Cit., 181.

${ }^{72}$ Siegfried Sassoon, Memoirs of an Infantry Officer (London: Faber, 1947 [1930]): 62.
} 
the most practiced manage to keep their way I cannot conceive: in fact, I have noticed that they very often don't—in spite of the little wooden signposts at the various divergencies, indicating 'Annie's Walk,' or 'Evelyn's Way,' of 'Kate's Cut. ${ }^{73}$

Farrer's claims are somewhat sensational, almost certainly intended for an educated, domestic readership. Some Canadian accounts of getting lost in the trenches are not reported with anywhere near the distress implicit in Farrer's account. Alfred Andrews's banal observation mentions a ration party getting lost en route to his location, but it "eventually turned up;"74 John Newton, in a similar tone, writes of a night-time ammunition supply party which, while headed to the dump site, "got lost both going and coming., ${ }^{, 75}$ In another instance, and adding two more dimensions of perceptual encumbrance through the presence of enemy gas and the subsequent need to don a gas mask, Bertram Cox writes in a rather exuberant tone that "the old saying was true, I could not see my hand in front of my face, consequently, we all got lost. She was some trip!,776 Regardless of sentiments attached to the seeming inevitability of getting lost, the trenches were a space of human presence, and also a space of unusual perceptual absences: absence of direction, absence of enemy, absence of visibility (of both self and others), and absence of perspective.

\footnotetext{
${ }^{73}$ Farrer, Op. Cit., 122.

${ }^{74}$ CLIP, Alfred Herbert John Andrews, Diary, 9 Apr 1916. Online: http://www.canadianletters.ca/ letters.php?letterid $=8088 \&$ warid $=3 \&$ docid $=2 \&$ collectionid=328. Last accessed: 27 May 2010.

${ }^{75}$ CLIP, John Newton, Diary, 22 Apr 1917. Online: http://www.canadianletters.ca/letters.php?letterid $=8350 \&$ warid $=3 \&$ docid $=2 \&$ collectionid $=310$. Last accessed: 27 May 2010 .

${ }^{76}$ CLIP, Bertram Howard Cox, Letter to Carl, 17 June 1918. Online: http://www.canadianletters.ca/ letters.php?letterid=1009\&warid=3\&docid=1\&collectionid=115. Last accessed: 27 May 2010.
} 
Cox's claim is temporally bound to his immediate situation, however, and it should be said that it was rare not to see one's immediate, intimate surroundings at least with some measure of clarity. It was also quite possible to see one's broader surroundings, though such acts had to be conducted under the strictest of conditions: hooded loopholes in the daytime (giving a tight, singular framing within a deliberately structured firing arc), or else periscopes, which were shot out by the snipers with modest frequency. At night, men frequently peered out into the darkness because they could do so reasonably safely—but to what end? Under bright or full moon conditions, any activity that involved exposure was akin to suicide. ${ }^{77}$ On dark nights, enemy and ally alike shot flares out over the battlefield. Tom Kettle, a British officer and war correspondent during the first two years of war (he was later killed at Ginchy in 1916), describes the night-time as "stabbed with malign illumination as the Véry lights shoot up, broaden to a blaze, and go out. ${ }^{, 78}$ The unnatural suns of the night flares only further the fragmentation of the senses by floating down to the ground, casting all in ghostly light and throwing harsh shadows. Even still objects, bathed in such light, possessed the appearance of movement as Canadian chaplain William Beattie reports: "When a flare light would go up, Of [sic] course every tree and stump resolved itself into as enemy moving with stealthy tread towards me. ${ }^{, 79}$ Returning again to Paul Nash's paintings, one can see the perceptually distorting effects of the Verey lights in The Ypres Salient at Night (Figure 7). ${ }^{80}$ Not only does he capture the limited vistas of trench life, but he also identifies a certainty of trench

\footnotetext{
${ }^{77}$ Cook, At the Sharp End, 273.

${ }^{78}$ Tom Kettle, The Ways of War (New York: Charles Scribner's Sons, 1917): 178.

${ }^{79}$ CLIP, William Beattie, Letter to Mr. Horne, 19 Mar 1915. Online: http://www.canadianletters.ca/letters. php? letterid=2822\&warid=1\&docid=1 \&collectionid=205. Last accessed: 27 May 2010.

80 There are a variety of spellings of "Verey," including Very and Véry. I will always use an author's own spelling in quotes, but will use the more widely accepted (and correct) spelling of Verey in my writing.
} 


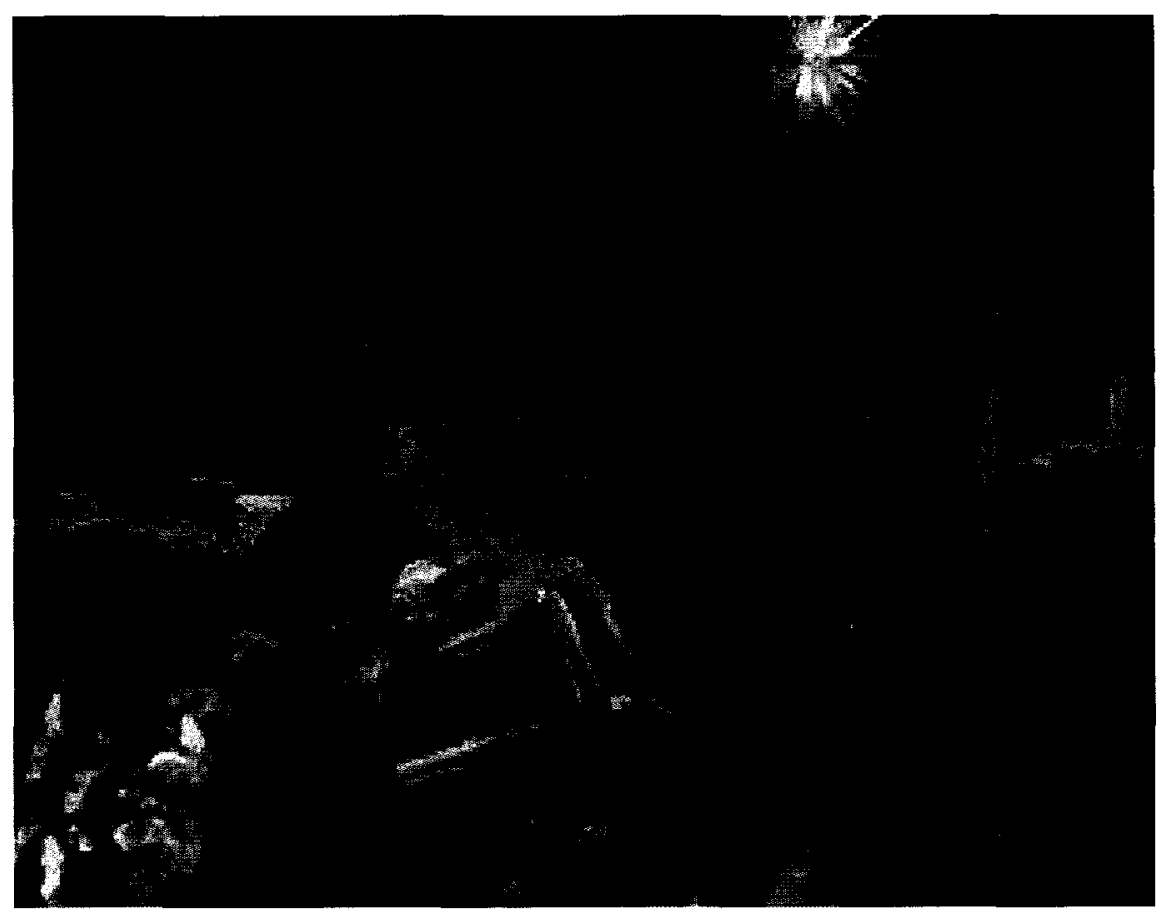

Figure 7: $\quad$ IWM, IWM ART 1145, Paul Nash, Painting, 1918, The Ypres Salient at Night, Oil on canvas, dimensions not listed. London, UK.

life: observation brings destruction. The light knifes out from its elevated sources, illuminating its enemies while blinding its targets and heightening the darkness from whence it originated. Any larger sense of space is captured in fleeting fragments of time before the flickering lights fade. In the absence of a sustained, stable light source from a single location, each flare gave the landscape a different appearance, to say nothing of the way in which artillery could alter the space from day to day.

\section{$\underline{\text { A Change in Focus }}$}

G.W.L. Nicholson's remarks about the experiences at Ypres in 1915, and generally about intelligence deficiencies before 1916 , identify a real problem for command: the challenges of waging war blindly. The defensive potential of rifles and 
machine-guns fired from concealed positions required a new strategy, and in virtually every army_French, British, and German alike—the attack doctrine shifted to one of attrition. For the French, the proposed grand strategy of a percée (piercing, or breakout attack) in 1914 became grignotage (nibbling) by the end of $1915 .{ }^{81}$ When the German High Command focused its attention on Verdun in 1916, the objective was to "bleed" the French into submission, ${ }^{82}$ having formally failed two years earlier in their plan to knock France out of the war in one fell swoop with the inadequate and hopelessly antiquated Schlieffen Plan. France adjusted its strategy to simply "hold on" until the Germans exhausted themselves, even as the British General Douglas Haig adopted a policy that shifted from breaking the German line to "biting" into it—akin to Falkenhayn's plans at Verdun, but with a stronger focus on capturing ground than did his German counterpart. ${ }^{83}$ In other words, as the war dragged on and decisive battles became unlikely, the generals invariably turned to attrition as the principle through which the combatants could dislodge the enemy from his strongholds or otherwise force him to capitulate. Pitched battles against soldiers hardly visible was not a viable means of waging war; the individual soldier's relatively minuscule firepower-even when massed together—could not provide the amount of firepower needed to break the trench fortifications.

Additionally, in a space notable for its submerged targets, weapons that could cover large areas and could be used effectively from and against a concealed position became vital. Artillery and gas seemed to accomplish these needs (though so too could machine guns

\footnotetext{
${ }^{81}$ Leonard V. Smith, Stéphane Audoin-Rouzeau, and Annette Becker, France and the Great War 19141918, Helen McPhail, trans. (New York: Cambridge University Press, 2003): 79.

${ }^{82}$ Holger Afflerbach, "Planning Total War? Falkenhayn and the Battle of Verdun, 1916," Great War, Total War: Combat and Mobilization on the Western Front, 1914-1918, Roger Chickering and Stig Förster, eds. (New York: Cambridge University Press with the German Historical Institute, 2000): 114.

${ }^{83}$ Respectively in Smith, Audoin-Rouzeau and Becker, Op. Cit., 79; and Keegan, Op. Cit., 290.
} 
and mortars, and later, tanks). These weapons could be employed at any time or even at all times without exposing one's soldiers unnecessarily to the enemy's defences and also without affording the enemy too much opportunity to hide.

In essence, the terrestrial limitations imposed upon the battlefield by weapons technology had to be overcome by new technologies which were not restricted to the planes of natural human movement. This shift in plans, from infantry attack to industrialized attrition, is a marked change from the "human battlefield" which all armies had previously endorsed and had entailed human agents performing the bulk of all military aggression. ${ }^{84}$ This is not to say that the infantry were not still expected to take ground, however they were asked to do so under conditions that required extraordinary amounts of industrialized, massed firepower that they were incapable of delivering themselves. Against a hiding target, a rifleman had very limited effectiveness unless he caught an unfortunate soldier who exposed himself. Though there are many exceptional stories of riflemen inflicting more than their share of casualties, such as the case of Canadian Will R. Bird being able to snipe four Germans in a matter of seconds while his partner 'pips' another three, ${ }^{85}$ these types of opportunities were uncommon even when one was facing an inexperienced battalion in the lines, as in Bird's anecdote. Instead, the human hidden in the battlefield became a secondary concern to the targeting of entire regions. Attrition still related to inflicting human casualties, but did so by means of spatial destruction.

Grand strategy had called for the infantry to be the primary strike force in 1914 , and the principle of fixed bayonets and "cold steel" routing the enemy seems to have

\footnotetext{
${ }^{84}$ For a detailed discussion of this concept, see Tim Travers, The Killing Ground.

${ }^{85}$ Will R. Bird, Ghosts Have Warm Hands: A Memoir of the Great War 1916-1919 (Ottawa: CEF Books, 2002 [1930]): 21-2.
} 
persisted far longer than it rightfully should. ${ }^{86}$ While the First World War was rhetorically touted as a war of the sword by drawing upon romantic medievalisms, ${ }^{87}$ this tendency to emphasize close-quarters attacks well into 1916 seems to suggest an element of actuality that exceeds mere rhetorical flourish. The infantry was still a central component of the bite-and-hold strategies of the Somme in 1916, but its movement would heretofore be facilitated by the increasingly use of artillery. ${ }^{88}$ The Somme campaign finally ground to a halt at the onset of winter without decisively breaking the back of the German army as planned. Even so, new strategies had been tested, such as the use of air superiority, attacking with the support of massed artillery, the deployment of the first tanks, and the allied forces' continued development of gas warfare. While geography remained of primary import for the armies standing against Germany, it became so under new, industrialized circumstances that took the responsibility for killing mostly out of the hands of the infantry. The rifle shot sighted by human eyes, previously the most important tool of the army, was effectively replaced by a system of optical displacement located in blind artillery firing and other strategies of generalized destruction such as grenades, generalized suppressive fire by machine guns, and other area-effect weapons rather than the individualized killing associated with a single bullet.

Eric Fisher Wood observes that "the tendency [in the Modern War] has constantly been towards the use of munitions which wound many men rather than kill a few." ${ }^{\prime 89}$ In other words, Wood is describing a type of violence that is not confined to an immediately

\footnotetext{
${ }^{86}$ Travers, The Killing Ground, 67. Travers's point is that "cold steel" (bayonets and other close-combat weapons) as an extensive of the infantry's willpower would not be the sole demoralizing force deployed on the battlefield.

${ }^{87}$ Goebel, Op. Cit., 81.

${ }^{88}$ Andrew Robertshaw, Somme 1 July 1916: Tragedy and Triumph (New York: Osprey Publishing, 2006): 35-6.

${ }^{89}$ Eric Fisher Wood, Op. Cit., 232.
} 
localized space, such as a single soldier's body. Rather, the violence inflicted by these munitions is intended to spread out from a single point, covering a much larger space instead of single, arcing trajectory. The artillery, the gas, the machine-gun, and even the tank are weapons capable of appropriating space in a far more destructive capacity than even an infantry volley. These munitions occupy an area, even if only for the briefest of moments, and in so doing they subordinate all but the luckiest souls within their area to their effects, forcing soldiers to dive on the ground or duck, choking them or forcing them to wear masks, wounding them, and often enough killing them outright. While the rifle must have certainly kept many heads below ground level, it is undoubtedly the other weapons which exercised the most control over trench space and its occupants.

The industrial weapons of the First World War elicit a constant reminder of their spatial presence, too, even when the soldiers at the front are not being targeted. During the Vimy Ridge campaign in 1917, Canadian engineer Duncan Campbell Macgowan recounts a stretcher bearer telling him how they feel "boxed in. Your artillery pounding him, his pounding your lines and supports the noise so terrific yet seeming to come from a long distance. Shells bursting on all sides and overhead." ${ }^{90}$ Only days after lambasting a soldier for having written a "bloodcurdling yarn" about the brutal effects of shellfire, Canadian John Patrick Teahan's naïveté about the nature of this war is stripped away when he is taken aback by the "shells constantly pouring across the sky over our heads.. ${ }^{91}$ Teahan was later reported missing at Thiepval in October, 1916, undoubtedly interred or obliterated by those same shells he so underestimated at war's start. Even at times of rest, soldiers frequently remark upon the persistent rumble of the guns, such as

\footnotetext{
${ }^{90}$ CWM, MHRC, 58A 1 154.1, 19990026-006, Keith Campbell Macgowan, diary entry: 6 Apr 1917. ${ }^{91}$ CWM, MHRC, 58A 1 113.2, 19950023-002, John Patrick Teahen, diary entries: undated May 1915 and 25 May 1915, respectively.
} 
the case of Private John Oswald Doyle, whose birthday was celebrated some twenty-two miles from the front, but was nonetheless accompanied by the sound of the "Big Guns.",92 American William James Leach, writing in a letter to his wife dated April $20^{\text {th }}, 1918$, states: "We are never without the rumbling of guns, day or night, and much of the time it is much more than rumbling." 93 There is a sense in all of the above testimonies that the artillery exercises near absolute control over the space of war. Even when liberated from the front lines, Leach indicates that he is not free from the guns' control and remains penned in—at least in a metaphysical sense.

The remarks of the above soldiers emphasize the destructive nature of artillery, but one must recall that, in one of the paradoxes of military logic, the destruction (of people, of places, of economies, etc.) is constructed. Considerable creative energies must be put forth in order to unleash the potential of disintegrating forces, and the First World War was, as previously mentioned, significant for its unprecedented use of these forces. The guns could not be fired completely blindly, even if the gunners themselves were not seeing directly. In a space like the Western Front, with its absences and invisibilities, effective spotting and communications had to be created and maintained, but this was nearly impossible in an environment in which official strategies were dedicated to active destruction. New controlling measures, through the transformation of traditional terrestrial mapping into combined aerial and terrestrial interpretation were enacted and subordinated to the artillery on the Western Front.

${ }^{92}$ CWM, MHRC, 58A 1 188.26, 20030163-012, John Oswald Doyle, diary entry: 20 Sept 1915.

${ }^{93}$ William James Leach, Poems and War Letters (Peoria: Manual Arts Press, 1922): 111-2. 


\section{Proxy Vision and the View from Above}

When the war began in 1914 , armies accustomed to wars of movement used enormous mapping scales $(1: 80,000)$ to depict troop movements, locate suitable battlegrounds, identify marching routes, and the like. Once the Western Front became mired in a stalemate, however, more details were required than could be provided on such a massive scale; new maps of $1: 40,000$ and $1: 20,000$ were thus commissioned. ${ }^{94}$ In other words, the lack of mobility was effected by new killing technologies, and these new technologies were in turn exercising their authority over earlier, imprecise strategic representations of the battlefield. The persistent problem of a concealed enemy meant that aerial reconnaissance-creating a vantage from which trenches and other concealed positions could easily be observed, as is clear in many aerial photos of the front (Figures 8 and 9) - became the most important development in battlefield intelligence during the First World War. According to retired American colonel and historian Terrence J. Finnegan, aerial reconnaissance "reinvented the way that modern battle was envisioned, planned, and executed" by facilitating the use of artillery, the planning of assaults, and providing a vital observational position which could be combined with nineteenth century practices of sonic interpretation and terrestrial spotting. ${ }^{95}$

\footnotetext{
${ }^{94}$ Peter Chasseaud, "British Artillery and Trench Maps on the Western Front 1914-1918," Map Collector 51 (1990): 24-5.

${ }^{95}$ Terrence J. Finnegan, Shooting the Front: Allied Aerial Reconnaissance and Photographic Interpretation on the Western Front-World War I (Washington: National Defense Intelligence College Press, 2006): 3. The practices of listening for the sound signature of artillery and watching for muzzle flashes were commonplaces in $19^{\text {th }}$ century military strategy to determine the location of a battery. As one can well imagine, it was an inexact science.
} 


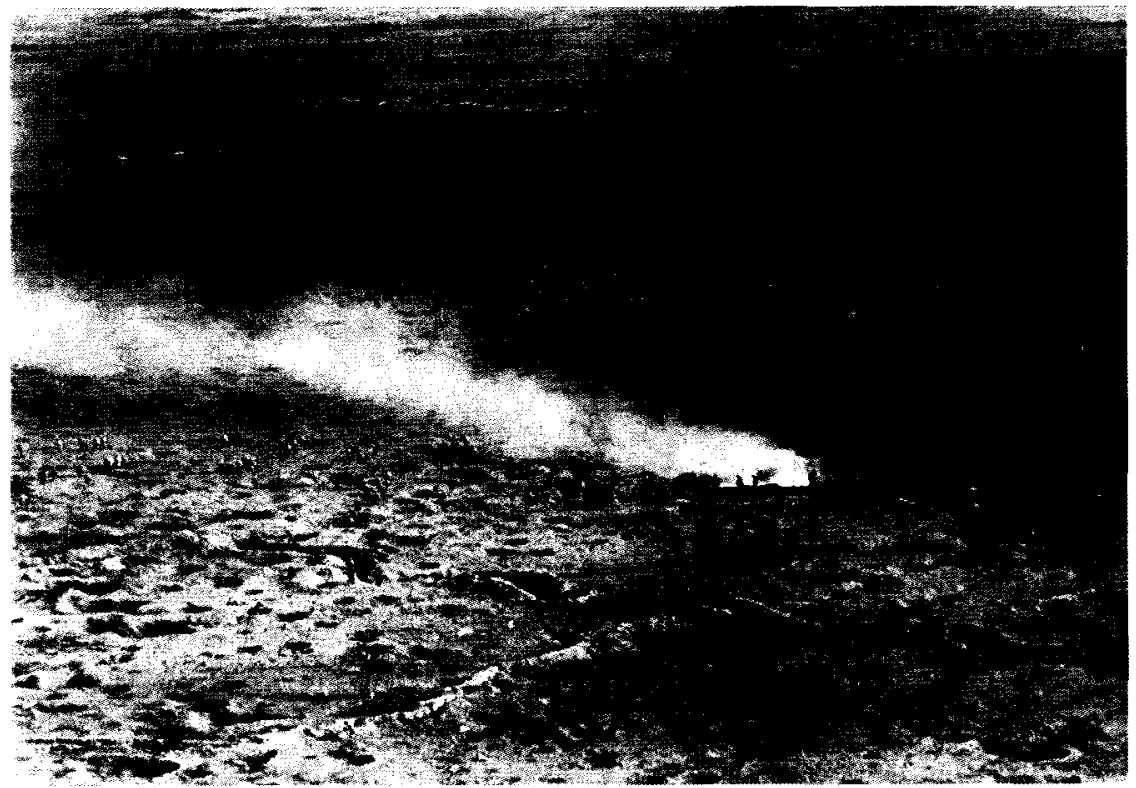

Figure 8: $\quad$ Musée de l'Armée, Paris, France (MA), 05-533965, 09656.24, Hallo Charles-Jean, 10 Oct 1916, Official photograph, "French Attack on the Hart Wood on the Somme."

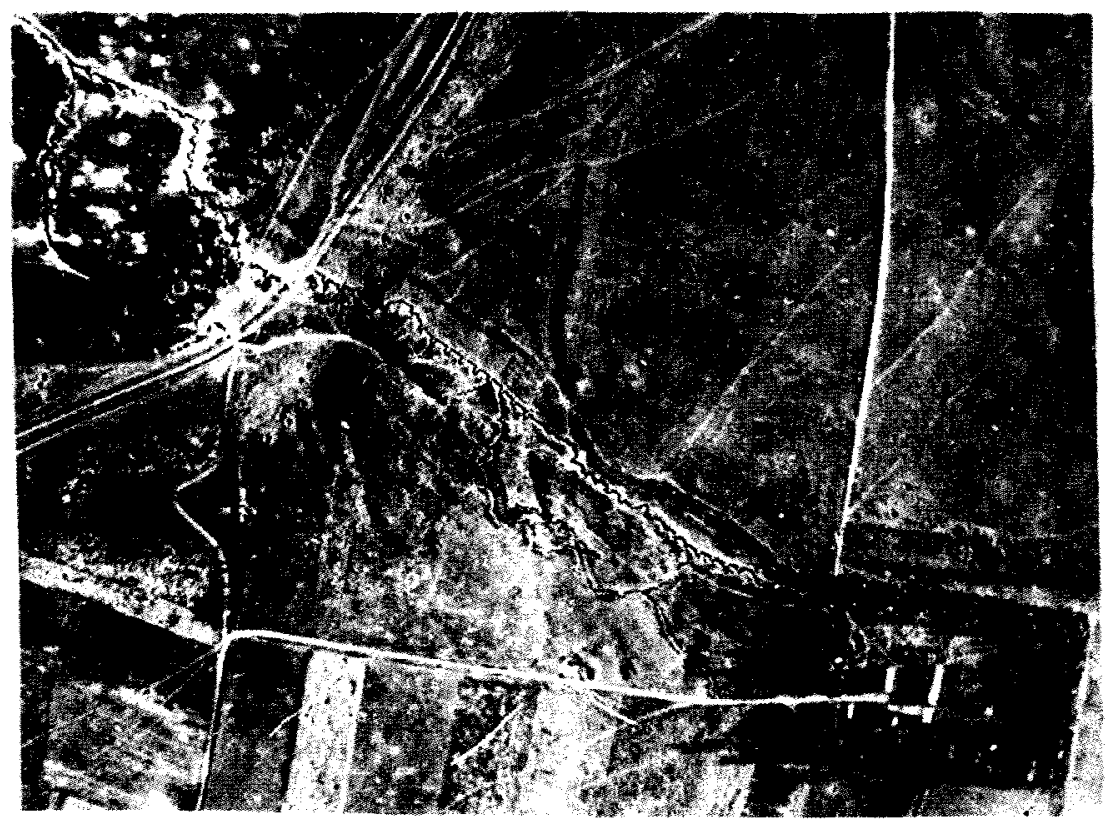

Figure 9: $\quad$ MA, 08-518959, Inv 28854 fb1170, Jolibois Emile, 1916, Official photograph, "The Falfemont Farm on the Somme." 
An example of early artillery spotting by air occurred at the Battle of the Aisne on September $13^{\text {th }}, 1914$. The entrenched Germans, hidden beyond a ridge near the Aisne river, could only be spotted from above using the then-limited resources of the Royal Flying Corps (RFC); the effectiveness of these early efforts to integrate artillery and aerial observation was negligible, however. Regardless, the acknowledgement of the need and recognition of a means to spot the hidden enemy was a valuable lesson learned and prompted the development of combined cartographic and photographic strategy in identifying artillery targets. ${ }^{96}$ Gunners and pilots operated in conjunction with each other for the remainder of the war, first communicating through dropped messages and later by wireless transmissions. ${ }^{97}$ Enemy positions, like in all past wars, had to be observed, plotted, and engaged with military force. These issues required an immense survey of the Western Front to be undertaken, and aerial reconnaissance played a central role in creating the new maps. Those maps were then utilized by the artillery bombardiers as part of their firing plans, gradually incorporating more details such as trenches, barbed wire entanglements, and machine gun emplacements as the war continued. ${ }^{98}$ Though maps were used by all branches of the military for intelligence and strategic purposes, the maps' format was created with the artillery in mind.

One need not belabour the intricacies of this development. Suffice it to say that through a variety of technological and perceptual processes, bombardments were conducted using maps, employing a trigonometric "theatre grid" system, ${ }^{99}$ while

\footnotetext{
${ }^{96}$ Finnegan, Op. Cit., 30-1.

${ }^{97}$ Chasseaud, Op. Cit., 24.

${ }^{98}$ Chasseaud, Op. Cit., 25-6.

${ }^{99}$ A theatre grid employs a common point of origin, from which all other squares are numbered off in "eastings" and "northings." This practice meant that disparate maps could nonetheless be used to calculate ranges and positions accurately and easily: all that has to be known is the battery and target positions using the common theatre grid.
} 
commanders relied upon the optics in airplanes to correct and interpret their maps on a daily basis. Historian Jeffrey S. Murray laments that other historians fail to consider these matters when employing maps as simple illustrations to accompany the documentary record-mere lines, boxes, and arrows alongside quotations. ${ }^{100}$ What similarly get ignored are the spatial implications of those lines and boxes, and while Murray's plea for the use of maps as documents in and of themselves is well-made, he is no exception in failing to recognize those implications. Allyson Booth writes that "[depth collapses] when a mud trench is reduced to an inked line," thus exposing "the dangerous gap between representation and experience." ${ }^{101}$ What matters here is the conversion of destruction to a scientific expression: its human component in terms of both killer and tobe-killed takes a back seat to the discourse of the authoritative, carefully plotted logic of elevations, calculations, articulations (the firing of the gun itself), and finally impact. As Canadian captain and gunner R.S. Robinson writes in a letter home, "the gunners never, or rarely ever, see the object fired at, but the range is shown on their maps very accurately."102 This is what Paul Virilio calls the "derealization of military engagement" through proxies and peep-holes. ${ }^{103}$ The map and a ruler say nothing of the impact of shellfire, even if their employment may well lead to some imaginative understanding of the effects of a bombardment. The viewer is certainly implicated in the object, but it is to

\footnotetext{
${ }^{100}$ Jeffrey S. Murray, "British-Canadian Military Cartography on the Western Front, 1914-1918," Archivaria 26 (Summer 1988): 52.

${ }^{101}$ Allyson Booth, Postcards from the Trenches: Negotiating Space between Modernism and the First World War (Toronto: Oxford University Press, 1996): 88-9 and 100, respectively. Quoted in Fran Brearton, "Mapping the Trenches: Gyres, Switchbacks and Zig-zag Circles in W.B. Yeats and Ciaran Carson," Irish Studies Review v.9, no.3 (2001): 376.

${ }^{102}$ CLIP, R.S. Robinson, Letter to Mrs. Robinson, 29 Apr 1915. Online: http://www.canadianletters.ca/ letters.php?letterid $=2265 \&$ warid $=3 \&$ docid $=1 \&$ collectionid=142. Last accessed: 28 May 2010. Emphasis added.

${ }^{103}$ Virilio, War and Cinema, 1.
} 
the guns-the geometrically objective photo-cartographic representation being an extension of now-ancient sight lines-that all are subordinated.

Philosopher Ludwig Wittgenstein, himself a veteran of the First World War, posits this dilemma as a problem of authoritative linguistic representation versus the manner in which the purportedly depicted object is actually experienced. He writes: "I tell someone that I walked a certain route, going by a map which I had prepared beforehand. Thereupon I shew [show] him the map, and it consists of lines on a piece of paper; but I cannot explain how these lines are the map of my movements." ${ }^{104}$ The problem articulated by Wittgenstein is the disconnection between the creation of authoritative structures and the experiences of individuals within them and informing them. The lines on Wittgenstein's map do not mark any journey, but instead mark the path of a private journey. In essence, the map effaces the actual journey, showing the whole of the experience of walking as a compacted artifact, lacking in nuance. In the case of the First World War, plotted destruction is subsumed with vectors on a piece of paper or an artillery board, and those vectors emphasize rational linearity over the irrational, unpredictable, and transformative dynamics of concussive force. At the far end of the shell trajectory's looping arc, depicted mathematically by the two-dimensional line traced between two points, is another line: the target trench. There is no trace of the impact of shellfire on a map, except in the form of corrective calculations relayed through the disembodied voice of the spotter. The soldier-occupant is subordinated to the form of the battlefield; the battlefield is subordinated to its representation.

\footnotetext{
${ }^{104}$ Ludwig Wittgenstein, Philosophical Investigations, G.E.M. Anscombe, trans. (Malden: Blackwell Publishing, 2008 [1953]): 141e.653.
} 
Even in the map indicating machine gun firing arcs, there is something notably absent in the intermediate space between its two outer edges. War has always been a function of vectors, with boxed insignias and arrows connoting troop movements, or lines drawn in the sand to represent supply routes. The difference in the First World War is the role of the weaponry in developing the total "vectorization" (for lack of an existing term) of the modern battlefield. A set of machine guns in action, if translated to a 1:10,000 infantry map, would be nothing but a series of overlapping threads spraying out towards the enemy lines from the entrenched guns. Similarly, the artillery could easily adjust their firing lines to provide enfilade support virtually anywhere along the lines, provided the target is within the six or seven kilometre range of the batteries. The key to the exploitation of vectors is not merely that they can be created and acted upon: it is the speed at which they can be exploited. What is sketched here is a logistics of destruction, wherein the transference of potential destructiveness is maximized through the technological sublimation of lived space into a represented space over which a scientific control is exerted. It was not until the last two years of the war that the artillery, assisted by the topographical vision of aero-photography, in simultaneous conjunction with the vectored movement of tank-supported infantry, reached its full assertive potential as a suppressive device.

Paul Virilio's insights on the development of the tank are especially interesting for his view of how tanks came to exert control over space in a unique fashion. The terrestrial difficulties facing the advancing infantry were no obstacle for a tank. As Virilio states, the tank, "able to go over every kind of terrain, erases the obstacles ... it climbs embankments, runs over trees, paddles through the mud, rips out shrubs and piece of wall 
on its way, breaks down doors." Most importantly, a tank "escapes the old linear trajectory of the road or the railway," thereby asserting a greater control over the space of war by creating its own vectors of advancement. A tank also serves as a mobile gunnery platform, increasing the control of space by spewing gunfire at the enemy from enfilading positions previously difficult to attain. ${ }^{105}$ In essence, the technological conditions of the war permitted the exertion of control by military strategists over a formerly uncontrollable space, facilitated by vectors of engagement not previously available even in 1915, and not strategically viable until 1917 - much less at any other time before the First World War.

These ideas of Virilio's—vectors and representational technologies—are aimed at elaborating a theory of a "speed economy," or how a technologically developed nation is able to transform potential military force into kinetic military force by means of rapid arms deployment subordinated to a sophisticated perceptual apparatus. The matter of spatial domination is implicit in Virilio's work, despite space being subordinated to his theories of speed. Still, Virilio omits one very important aspect of First World War military technology, and which only reinforces his thesis: the all-enveloping clouds of poison gas. Like tanks which create their own paths, and the simple trigonometry which could bring a calculated rain of death by the guns upon any indirectly sighted trench, poison gas in favourable wind conditions could simply overwhelm the enemy's entrenched positions. The soldiers on the Western Front were forced underground by the weaponry deployed against them in 1914, thereby creating an entrenched environment that limited the effectiveness of assault-oriented, infantry-driven strategy. The artillery, which had also helped to create the environment by exposing fragile bodies to its

${ }^{105}$ Virilio, Speed and Politics, 76-9. 
unprecedented concussive force, then became the primary weapon against the enemy. Whatever the artillery could not reach, however, the gas theoretically could, and could do so precisely because of the big guns' atomizing capacities against those fleeing from the toxic depths of the trenches.

Edmund Blunden, the British war veteran and poet, writes of the signs of chemical warfare during the preparation for Third Ypres in 1917: "Gases of several kinds oozed from the crumbled banks and shapeless ditches, souring the air. One needed no occult gift to notice the shadow of death on the bread and the cheese in one's hand, the discoloured tepid water in one's bottle." 106 Such was the tendrils' reach. Poison gas easily could penetrate the space of war in ways a shrapnel shell or high explosives could not, requiring no kinetic energy for its danger to persist. Gas did not throw out a thousand splinters, but rather was formed of tiny particles by the millions. Gas thickened the air with its suffocating or burning fumes, and worst of all to a soldier buried below ground it seeped under dugout doors while drifting around trees and through barbed wire; it could slip between parapets and parados before plunging into dugouts and funk holes. Gas was the ethereal ancestor of the tank, ponderously crossing No Man's Land undeterred, and lacking only the deadly punch of chemically accelerated steel.

Gas presented more of a perceptual crisis to the individual soldier than a deadly force, its effectiveness more psychological than physiological. Tim Cook remarks that in the early days of chemical warfare, confusion reigned due to contradictory orders and primitive deterrents (often noxious, themselves), as well as the general unfamiliarity with

\footnotetext{
${ }^{106}$ Edmund Blunden, Undertones of War (Toronto: Penguin Classics, 2000 [1928]): 151.
} 
this type of fighting. ${ }^{107}$ Even when effective respirators were introduced, the fear of chemical death was never fully quashed. Moreover, gas had access to another vector beyond the geo-physical space dominated by other weapons of war: it also resided in time. Gas continued to affect soldiers on the Western Front not only during their military service, but long after the war in various ways-burns that never heal, respiratory problems, and so on. ${ }^{108}$ Even so, Canadian soldier Keith Campbell Macgowan wrote in his diary that, all other considerations aside, the artillery was the one thing one never gets used to, stating: "You simply can't argue with artillery or trench mortars." ${ }^{\text {109 }}$ Presumably, Macgowan felt his gas mask and training were deterrent enough against gas. Though gas was nonetheless terrifying for most, it was at least modestly predictable due to sentries on the alert for changing wind conditions, the slow movement of the clouds, the training regimen that was eventually implemented, and the fact that gas rarely proved fatal. Macgowan's observation is telling in this regard: arguments are rational, planned, and coherent. An artillery shell, more than any other weapon, produced the opposite of an argument. It was sheer force, and no amount of fieldcraft or battlecraft could shake a direct hit from a "coal box" or a "Jack Johnson." Cook observes that "gas was viewed [by soldiers] as the more villainous weapon system" because they could not effectively escape it. ${ }^{110}$ And of course they could not escape the gas because the artillery and machine guns would annihilate them if they fled. The effectiveness of gas was also subordinated to the rapid-firing, deep-penetrating technology of the rifled, breach-loading guns.

\footnotetext{
${ }^{107}$ Tim Cook, Nowhere to Run: The Canadian Corps and Gas Warfare in the First World War (Vancouver: UBC Press, 1999): 39 and 6, respectively.

${ }^{108}$ Ibid. $163-4$ and 218-20.

${ }^{109}$ CWM, MHRC, 58A 1 154.1, 19990026-006, Keith Campbell Macgowan, diary entry: 8 March 1917.

${ }^{110}$ Cook, Nowhere to Run, 4 .
} 
The general matter to consider here is the type of violence being inflicted during the First World War. There is no question that men fought other men in close quarters often enough, yet this type of fighting was far rarer than the technological weapons employed in a "fire-and-forget" style. By this term, I mean that the effects of the weapons were seldom seen by those who were charged with their unleashing. Gunners, especially, "witnessed" their handiwork indirectly, often receiving targeting information through a field telephone, a dropped message from an airplane, and later through wireless communications. The spotter does not fire the gun; the gunner is blind to the results. The hidden enemy is not revealed so much as he is hypothesized and then calculated. The shots are "registered" and "corrected," utilizing a bureaucratic language of killing which sees the state of the battlefield in terms of model forms, paper trails and grid references. The Western Front was constructed as a site of disappearances, and the individual's cognitive structures were adjusted accordingly. This adjustment occurred as part of a process of what Virilio calls the "geometrification of looking" that began with the ideal line through the rifle's sights, now taken to extremes by firing without ever seeing one's target. $^{111}$

Given the absences of the front, almost all soldiers had their vision transferred on to a theatre grid and its mathematical illusions of stability, even if that ostensible stability was intended as a means to inflict destabilizing violence. The alpha-numeric indicators of a map contain a certain sense of permanence and security in its perfect forms, but the viewer of such representations often ignore how the synecdoche is distanced from the topographical reality to which it refers, and more importantly to the experience of that reality. It is altogether too easy to look upon a trench map (Figure 10), with its two

${ }^{111}$ Virilio, War and Cinema, 2-3. 
dimensions, and forget that the white spaces between red, blue, and black lines are not actually blank at all. There was no small degree of violence inflicted upon a significant number of those ostensibly blank zones, and soldiers had to cross them regularly. The scientifically calculated decimation of lived space is rarely noted on the official, empirical trench maps, and yet the logic of shelling affected the lived space of the soldiers in a profound way. The combined effect of shellfire and limited perceptual capacities of the individual soldier led to the conquest of lived space by the official strategies of destruction, located in explosive technology and officially out of the hands of the individual. What remains unexplored, however, is the effect that this type of violence had upon the individual, or rather the way in which this "derealized" violence was experienced in the blind alleys of the trenches.

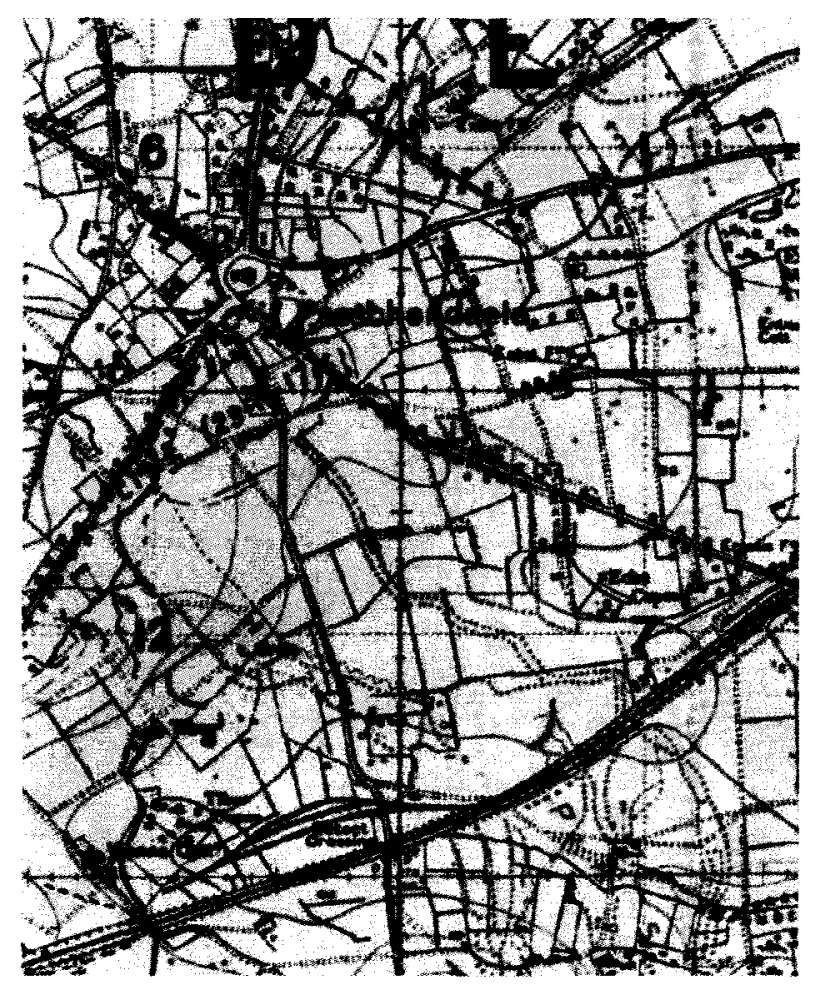

Figure 10: $\quad$ Private Collection, Crooenart Research Services, Dec 1917, "Trench Map of Passchendaele Area." Online: http://www.pathsofglory.co.uk/ Trenchmap\%20extracts.htm. Last accessed 29 Jul 2009. 


\section{Violence without Warning}

This chapter has progressed from the role of violence in shaping trench space, to the resulting effects the trenches had upon soldiers' perception, and has most recently been concerned with the geometrically structured means by which violence was facilitated on the Western Front. As a result of these developments, the trenches' occupants, within a space of significant perceptual limitations, were simultaneously intimately engaged with the effects of violence while being disengaged from the violent forces' origins. As previously mentioned, a trench map could no more express the impact of a shell than it could show the water levels in the trench after a hard rain. Explosions had a very real effect on an individual soldier's experience of his environment, and no amount of mapping could make that particular element of trench life intelligible. Yet the soldier himself could see such things in his immediate space, demarcating the contradictory gazes of the battlefield: the one supremely intimate, while the other remained in the realm of pure topography. Each perceptual mode is, however, subordinated to a similar concept of instantaneously occurring violence, even while there was a sense of disconnection between the experience of space in the trenches and the image of space as it was topographically represented. This disconnection only made the sense of instantaneously occurring violence, as it was experienced by the men below ground, more acute: violence had the appearance of possessing dominion over the soldiers' whole time and space through its capacity to occur seemingly at any point in the line, and at any time. 
Soldiers were not oblivious to their subordination to spatial structure organized around the destructive forces. Siegfried Sassoon, reflecting upon a private's letter which he was charged with censoring, states:

I have been looking at the map. The distance, by a straight line, was fifty miles. Sixty-five, perhaps, by road; an easy three hours' drive for the Divisional General in his car. Not so easy for the rank and file, whose experiences of migration were summarized well and truly by a private soldier, in a simple sentence which once met my eye while I was censoring the correspondence of my platoon. [...] 'Everywhere we go seems such a long way. ${ }^{112}$

From Sassoon's remarks, one can clearly see that he is separating his experience of the landscape from the order imposed upon it by official strategy. The command experience space in a different way entirely than the infantry, while the strategies they impose rely on an even greater, technological conquest of spatial dimensions. The strategic modes of mapping and tracing lines are not consistent with the temporal existence of the soldiers. Not only is the soldier in Sassoon's anecdote remarking upon the disconnection between topography and actual geography, but he is identifying a temporal schism that inevitably is linked to that geography. "A long way" is not merely a remark upon the distance one must travel, but is also explicitly related to the time taken to travel in a space made unintelligible in Euclidean terms of straight lines and simple geometrics. It is not that places are far apart, as Sassoon notes, but rather that the time taken to travel between them is much longer than it rightfully should be, and this is a direct result of the

\footnotetext{
${ }^{112}$ Sassoon, Op. Cit., 264-5. Emphasis in original.
} 
conditions of the war. Compared to the velocity of the shells and how they have affected the space of war, the soldiers' movements were all but static.

The English-speaking soldiers had a nickname for one of the more common shells fired at them during the First World War: the "whizz-bang." It is not difficult to see that the front line soldier had already identified both a temporal and a physical dimension to these objects. They were so-called because they arrived in an instant and affected an area: the "whizz" and the "bang" respectively. In the time it takes to say the object's name, it is too late to do anything about it, as Will Bird notes in his memoir. In early 1917, Bird was travelling down a communication trench when he "heard the familiar phew-phew-phew in the air and yelled ... but my world crashed in a bang. [...] Eventually I got up, to stare at a smoking crater not ten feet from where I had fallen." 113 The lesson learned is that this space is not his space, but rather the artillery's. What was once a submerged walking path was now reclaimed by the violent forces that prompted its construction. Not only is the problem expressed in Bird's narrative one of space, but the fact that he could not escape the potentially deadly blast shows an attempt to control space through the speed of destructive execution. In short, the brief time it takes to destroy undermines the tenability of the space which the soldiers occupy. A human being inhabiting physical space is possessed of finite and very modest velocity-at least in this pre-personal-vehicular society - and the shell asserts its spatial control precisely because it moves so quickly.

Perhaps the best indicator of the disparity between human and technological spatial control is the effect of shellfire upon the towns and cities near the Western Front. Frederick Palmer, an American war correspondent following the French army, notes that the town of Guillemont had been reduced to rubble by "blasts of shell fire which crushed

${ }^{113}$ Bird, Op. Cit., 13. 
solids into dust and splintered splinters." ${ }^{114}$ Palmer expresses this transformative force as a function of the calculable becoming the incalculable. Describing Arras, British correspondent V.C. Scott O'Connor states in similar terms of what was once identifiable becoming so much wreckage:

[In this town] there is complete annihilation. All semblance of human settlements has vanished. There are no more any streets, or walls, or houses; nought but the earth, riddled and scarred and torn as if by some horrible disease. [The remains of the towns are] a heap of soiled mud and stone, or a hole in the earth littered with dead things, or something so nondescript as to be indescribable. ${ }^{115}$

O'Connor, like Palmer, is describing former habitations, the wreckage of structures erected to claim a permanent place by past persons. What took years to accomplish could be destroyed in mere moments by a bombardment. Reginald Farrer, also describing Arras, notes that the "foundations of one's life" are found in the perceived permanence of a dwelling place and the "indispensable realities" of floors and walls. ${ }^{116}$ There is stability in these tiny containers, through which the transience of life passes on a daily basis. And yet, when they are exposed to atomizing forces, they are reduced to unidentifiable things; the puzzle-pieces that were stones and wooden beams are reduced to unidentifiable particles. The illusion of spatial control is bared in a flash and a bang, just as it was in Bird's trench.

\footnotetext{
${ }^{114}$ Frederick Palmer, "An American at the Battle of the Somme with the French Army," True Stories of the Great War Vol. V, Francis Trevelyan Miller, ed. (New York: Review of Reviews Company, 1917): 41. Online: http://openlibrary.org/details/truestoriesofgre05mill.

${ }^{115}$ V.C. Scott O'Connor, The Scene of War (London: William Blackwood and Sons, 1917): 192. Online: http://openlibrary.org/details/sceneofwar00oconrich.

${ }^{116}$ Farrer, Op. Cit., $21-2$.
} 
What each of the above remarks seems to indicate is a degree of futility in the painstaking labours of preservation. Describing the burial service of a close friend, Sassoon states: "Once the chaplain's words were obliterated by a prolonged burst of machine-gun fire; when he had finished a trench-mortar 'cannister' fell a few hundred yards away, spouting the earth up with a crash.... A sack was lowered into a hole in the ground. The sack was [his friend] Dick."117 The passage might be read for its sense of loss, or as justification for the murderous feeling of vengeance which overtake Sassoon shortly thereafter. Another interpretation of this passage is the treatment of the solemn service by the mortar shell, which acts as a reminder that no ground is sacred in this war. The spout of earth thrown up by the blast indicates that all objects in the ground are subject to its rule- the dead and living alike. Even spoken language is obliterated, adding yet another dimensional loss, eloquently stated by British Major James Caldwell to his friend, Reverend Andrew Clark: "The noise is so constant and the racket so appalling that the ears cease to take it in. In the firing-line you almost think you are in a perfect silence until you try to speak to the man next [to] you and cannot make your voice heard." 118 The distance between speaker and listener, that dialogical space of intelligibility between interlocutors, is conquered by violence. In yet another example of firmer ground corrupted, Farrer describes the former farmlands of the trench lines as being "ploughed and ploughed and ploughed with mines and shells till the whole of its face has been so churned as to be made new. And from such a ploughing has sprung this strange harvest of evil weeds, thistle and couch and Persicaria in an unbroken sheet of dull green mildew

\footnotetext{
${ }^{117}$ Sassoon, Op. Cit., 288.

${ }^{118}$ Quoted in James Munson, ed., Echoes of the Great War: The Diary of the Reverend Andrew Clark 1914-1919 (New York: Oxford University Press, 1985): 215.
} 
over the whole scene. ${ }^{119}$ Nourishment, continuity, and control are lost to the crashing shells.

Humankind's structures and their inherent fragility are revealed in explosive fashion: instead of the gradual erosion of objects in time, in modern war this fact is posited as the dynamic annihilation of time itself. No longer being gradual, transformation under these technological conditions becomes instantaneous. It is critical to make clear one simple principle related to this notion of speed: speed is always relative to space. Without any perceptible space, there is no need to quantify or qualify speed. As spatial distances are decreased and speed of an object is increased, the closer to instantaneity one gets from a perceptual point of view. When spatial distances are as intimate and immediate as they were in the trenches of the Western Front, and the speed of shell movement vastly exceeded the perceptual capacities of the human participants, the appearance of instantaneity was easily achieved. Instantaneity is directly related to non-movement, itself a kissing cousin of inertia. The coupling of limited perceptible space and the high velocity of the explosive intruders into that space made the entire environment seem prone to violent upheaval, generally without warning, and without any predictable model against which the effects could be anticipated. The brutal dynamics of explosives only helped to reaffirm the relative stasis of the bodies in the trenches as they were subjected to the onslaught.

This is not to say that all soldiers were constantly under fire-in fact, the opposite was true except in the direst of situations, such as the prolonged engagements on the Somme, at Verdun, or during Third Ypres. The barrage more often missed than it hit, as most soldiers grimly observed: "if every shell fired had killed one soldier there would not

\footnotetext{
${ }^{119}$ Farrer, Op. Cit., 56.
} 
be an able-bodied man in uniform left alive on the continent of Europe."120 It was easy enough to know when the big guns had missed one's own position, though not so easy to tell what had been hit or the effects thereof. Edmund Blunden, describing the fighting at Givenchy, states that the guns were active but that his own trench was quiet. "A few rounds might occasionally go whizzing over our heads," he writes, "and I was alarmed by the report that one had burst almost exactly over the doorway of battalion headquarters, a thousand yards behind! Was there no safety anywhere?"121 His question is significant, for it shows how one could approximate the trajectory of the shells without actually recognizing their real impact, or out and out forgetting the existence of a world beyond his own limited space. Blunden is oblivious to the impact of the shell until it is brought to his attention; up to that point, it had simply missed him and had vanished from his experiential space.

While Blunden's empathetic response is central to his observation, Sassoon writes of a similar occurrence in a detached, yet poignant manner. Sassoon describes a shell exploding down the line, its black cloud draping itself across the landscape, remarking as an afterthought: "Perhaps the shell has killed someone."122 There is no question that soldiers learned to listen for the distinct register of the different guns, adopting certain ritual responses to the sounds: falling flat for high explosives, pressing oneself against the trench wall for shrapnel, and so on. ${ }^{123}$ These techniques might even prove effective from time to time, but soldiers hit by shrapnel or explosives were rarely afforded the opportunity to complain that their evasive tactics had failed them. Unless they were deaf

\footnotetext{
${ }^{120}$ Frederick Palmer, My Year of the Great War (New York: Dodd, Mead \& Company, 1916): 49.

${ }^{121}$ Blunden, Op. Cit., 16-7.

${ }^{122}$ Sassoon, Op. Cit., 291.

${ }^{123}$ Palmer, My Year of the Great War, 48-9.
} 
or already dead, it would be a mistake to assume the men killed were oblivious to the sounds of the shells. Rather, the wounded or killed had finally got theirs; after all, most soldiers believed there was a bullet out there with their name on it. ${ }^{124}$ Tom Kettle, with typical lucidity, writes: "In the trenches death is random, illogical, devoid of principle. One is shot not on sight, but on blindness, out of sight. [...] Here one is in a place where a very trivial piece of geographical bad luck may be fatal."

There are two issues at work in the above passages, both related to the experience of time and space. For the latter, there is the clear sense that the soldier's individual space was infringed upon by the violent forces unleashed during the war. The sanctity of a burial ground and its holy discourse is moot as Sassoon observes; the structure of command is subordinated to transformative violence in Blunden's remark; the ritualized precautions against death tautologically prove their effectiveness to the living, while the dead offer little but silence. Kettle's remarks illustrate the matter of time quite clearly, in that his lines depict a sense of pure, pervasive happenstance. These geographical ruptures caused by explosions simply occur, randomly in time and in place: the fated death of a companion is beyond the ken of the observer. At any point on both the temporal and the spatial axes of experience death awaits, unanticipated.

Soldiers frequently write about their companions suddenly succumbing to a fatal injury, emphasizing the seeming randomness of violence and the suddenness with which it arrives. Bird writes of waking up only to find he has been buried by a cave-in of the trench walls and his own groundsheet threatens to smother him, ${ }^{126}$ illustrating the fragility of the trench environment and its occupants. In a more brutal description,

\footnotetext{
${ }^{124}$ Cook, At the Sharp End, 265-6.

${ }^{125}$ Kettle, Op. Cit., 177.

${ }^{126}$ Bird, Op. Cit., 33
} 
Canadian Captain H.C. Duncan, in a letter to his father in May 1915, states the inverse tale of Bird's burial situation. "Men blown out of a trench was a common occurrence," he writes, "leaving nothing but possibly a boot or a Glengarry." 127 In each of these cases, one is reminded of the biting truth of Bruce Bairnsfather's cartoons, and especially "That 16-Inch Sensation" (Figure 11), depicting a colossal shell falling upon a man whose attempt to escape the impending impact is thwarted by the shackles upon his legs. There is a strong sense of relative inertia against which the soldiers struggle but ultimately cannot circumvent in any traditional way. The bodily response, in the form of flight from

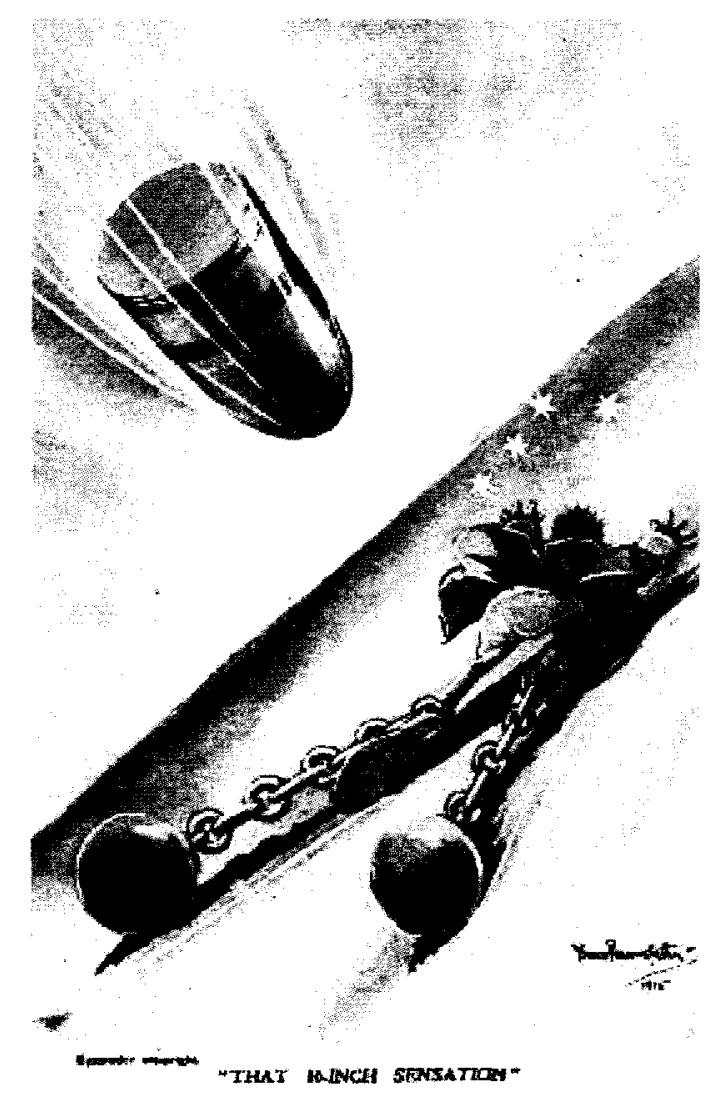

Figure 11: Bruce Bairnsfather, "That 16-Inch Sensation." Online: http://www.firstworld-war.co.uk/images/cp7.jpg.

${ }^{127}$ Letter dated 13 May 1915, published in Canadian Bank of Commerce, Letters from the Front; Being a Record of the Part Played by Officers of the Bank in the Great War, 1914-1919 (Toronto: Southam, 1920): 15. 
the violent prosthetics of the enemy, is wholly inadequate. Again, the trench space is not theirs. Their bodies are tossed about, damaged, buried involuntarily by the shellfire, covered in filth, and generally intruded upon through these violent acts of wartime. Even the occupants' conceptions of time-as mentioned in the introduction, the refuge of the tactician through which he can mount his resistance in a space he cannot control—seems to slip away.

The randomness of the acts of violence, coupled with the lack of perceptual acuity, results in an environmental level of violence that appears as a part of nature. In other words, it is persistent, unending, and seemingly beyond the control of the individuals. This is made especially clear by the pervasiveness of its transformative effects, and not merely in the physical appearance of the battlegrounds, but also through the senses. In particular, the smells of effluence and death-two intimately linked concepts, and the two most obvious markers of transformation for a mortal being ${ }^{128}$ were ever-present on the Western Front, denoting the effects of shellfire in horrific fashion. Like the constant rumble of the guns, the smell of death was all but inescapable. Yet unlike sound, coming and going in an instant, the smells of the front never leave. Emanating from the surroundings, the often overwhelming presence of industrial

\footnotetext{
${ }^{128}$ Post-Freudian psychoanalysts have given us much to think about along these lines, such as Julia Kristeva's work on the abject functions of the body, or Klaus Theweleit's psychoanalytic reading of a particular body of interwar German literature, whose members were closely linked to the rise of Nazism. Kristeva's simplified thesis is that we fear that which demonstrates our impermanence: excrement, bodily penetration, and so on. Theweleit, speaking more directly to matters of the First World War, shows these same fears at work in the writings of those former German soldiers, now turned inspirational writers (Ernst Jünger, et al.). See Julia Kristeva, Powers of Horror: An Essay on Abjection, Leon S. Roudiez, trans. (New York: Columbia University Press, 1982) and Klaus Theweleit, Male Fantasies Vol. 1 \& 2, Stephen Conway, trans. (Minneapolis: University of Minnesota Press, 1987 and 1989).
} 
carnage—-Wastage," as the British called the ostensibly incidental dead ${ }^{129}$ — sought residency in the olfactory space of the common soldier.

Again, the matter of intimacy and immediacy is encountered in the trenches, with the environmental hazards impressing upon the individual. The violence, perceived as a natural component of trench space, is made abundantly clear in Edmund Blunden's poem, “Come On, My Lucky Lads":

$$
\text { ...Icy-clear }
$$

The air of a mortal day shocks sense,

My shaking men pant after me here.

The acid vapours hovering dense, $[\ldots]$

These bombs in boxes, the craunch of shells, The second-hand flitting round; ahead!

It's plain we were born for this, naught else. ${ }^{130}$

What are most striking in Blunden's writing are not the simple observations of duty and the presence of tools with which to carry it out, but rather the preceding lines. The implements of violence are of the hand; the violence itself is of the air. When Blunden writes of the "acid vapours" of the "icy-clear" air, one encounters a sentiment echoed widely by those in the front lines. Alan Seeger, an American in the French Foreign Legion and frequent contributor to the New York Sun, writes in December 1914: "The smell of the wicker screens and the branches in the dirt on top of the trench reminds me of Christmas odors in American houses decorated with green things for the holidays.

${ }^{129}$ Fussell, Op. Cit., 41.

${ }^{130}$ Blunden, "Come On, My Lucky Lads" in Undertones of War, 200. 
Then the smell of powder from the shrapnel kills the holiday reminder." remarks about the smells of the implements of war would remain relevant observations for the duration of the war on the Western Front. As Tim Cook observes, "all year long the reek of the wet earth burned and tainted by explosives and cordite was unmistakable." ${ }^{132}$ Seeger's letter, however, was written before the corpse-riddled landscape was excavated and re-excavated during the following four years.

It did not take long for the rot of decomposing bodies to overwhelm most other scents on the Western Front. "The stench turns one's stomach," observes Marc Bloch, stating that "the ground was strewn with all sorts of debris, weapons, equipment, and human fragments." ${ }^{133}$ Henry Sheahan, a war correspondent following the poilus, also notes that "the war has a smell that clings to everything military, fills the troop-trains, hospitals, and cantonments, and saturates one's own clothing, a smell compounded of horse, chemicals, sweat, mud, dirt, and human beings." ${ }^{134}$ His observation of the smell of "human beings" is perhaps intended as a polite way to indicate the corpses which were constantly being discovered - after all, he has already indicated the more natural smell of sweat. After an attack at Neuve-Église, John Patrick Teahan hypothesizes that, in time, the entire front will simply be "one huge uncovered grave" because the corpses cannot be retrieved between the lines. ${ }^{135}$ Only a month earlier, Teahan found that he and his companions had been camped on a shallow, massed grave. They discovered it not by digging in the trench walls as so many other soldiers did, but rather through the

\footnotetext{
${ }^{131}$ Alan Seeger, Letters and Diary of Alan Seeger (New York: Charles Scribner's Sons, 1917): 48. Online: http://openlibrary.org/details/lettersanddiary01 seeggoog.

${ }^{132}$ Cook, At the Sharp End, 226.

${ }^{133}$ Bloch, Op. Cit., 96.

${ }^{134}$ Henry Sheahan, A Volunteer Poilu (New York: Houghton Mifflin Company, 1916): 60. Online: http://openlibrary.org/details/avolunteerpoilu00bestgoog.

${ }^{135}$ CWM, MHRC, Teahan, Op. Cit. Vol. 2, pp. 117-8.
} 
seemingly innocuous rising of the sun: the "very marked odor" appeared due to the "action of the sun on the ground." 136

The localized smell of the dead was one thing, the extended stench another entirely. Still a long way from the trenches around Ypres in October of 1917, Will Bird states that "the whole Salient had an odour beyond description." ${ }^{, 137}$ His immersion in this space of violent death was complete, the stench of unburied bodies, as he notes at Hill 70 in August of the same year, was simply to be endured. These types of sensory observations were so mundane after his many months of trench warfare that Bird simply found them unremarkable. ${ }^{138}$ The soldiers could do little about such matters. The seemingly ordinary state of decomposition effected by the constant presence of violence had taken hold of the lived space of the men in the trenches. The guns had effectively gained control over the space of war, and they had also left in their wake the persistent effects of their aftermath, thereby establishing a temporal authority over the Western Front as well. The soldiers found themselves bound to an environment from which they could not flee, its oppressiveness impacting upon the individual's limited sense of space in a myriad of ways.

\section{Conclusion}

It seems altogether too obvious that violence and war are coterminous, yet I have attempted here to illustrate that the technological conditions of the First World War established a new type of violent environment. Gone were the discrete battle sites of Napoleonic times, from which armies could retreat and thereby extricate themselves from

\footnotetext{
${ }^{136}$ Ibid. 2.55-6.

${ }^{137}$ Bird, Op. Cit. 49.

${ }^{138}$ Ibid. 42.
} 
the sites of slaughter. With the advent of industrialized warfare, complete with rapid firing and long range weaponry, improved explosives, gas, tanks, and a number of other innovations, the battlefield became a space of macroscopic inertia. Burial became the best chance for survival in the industrialized killing fields, even as technological means sought to expose the living bodies, now interred and hidden beyond the cognitive space of their equally blind adversaries. Blindness was overcome through strategic innovation, all but entirely dedicated to the facilitation of firing the biggest guns from the safety of cover. The product of photographic optics was translated into a scientific language of mathematical vectors and arcs of fire; targets became quadrants on a map, rather than individual bodies. The authorial voice of the cannon was reasserted over the troglodyte world of the soldiers, its incessant assaults infringing via representation of space upon the lived space of the men charged with inhabiting an environment over which they had little control. Even their bodily space met the wreckage of war, the catastrophic effects of violence on the Western Front inhabiting the very air the men were forced to breathe. Not only had the guns conquered the earth, so too had they mounted a coup upon time itself through the persistent, pervasive signposts of death and destruction. The opera of violence was a clanging paradox of continuity and decomposition. A satire of life, replete with ever-crumbling structures and constant decay, was writ large upon the landscape of the Western Front. Facing this brutal onslaught, it should come as no surprise that the soldiers turned to an old standby to denote the worst of all places: hell. 


\section{Chapter Three:}

The Hell of War, or The Social Construction of Violated Space

The phrase "War is Hell" is attributed to American General William Tecumseh Sherman, spoken on the $11^{\text {th }}$ of August, 1880, to an audience of young men in Columbus, Ohio. The attribution is problematic, however, in that he never said those exact words. Rather, he stated: “There is many a boy here to-day who looks on war as all glory, but, boys, it is all hell." ${ }^{\prime 39}$ The longer quote, while perhaps lacking the broad serviceability of the shorter, contains a more precise expression of what war is in opposition to what it is imagined to be. The quote also emphasizes that the actuality and the anticipation are both social constructions, and in the context of a modern war-arguably the proto-modern war, as historians tend to understand the American Civil War-the glory of war and the hell of war are antithetical constructs. What is striking in Sherman's quote is his claim that war is all hell. As I shall demonstrate, this matter of "all" has implicit spatial dimensions in addition to experiential. Indeed, I will argue that the experience of war and the space in which that experience occurs are inextricably linked. This idea that war "is all hell" is here applied to the Western Front, forming the basis of this chapter's inquiry.

There are ample descriptions by soldiers of the "hell" of the Western Front in a variety of forms: letters, diaries, trench newspapers, memoirs, and the like. It would be simple enough to cite these, yet doing so would leave unexplored the nuances of hell as a conceptual space and its many manifestations in First World War soldiers' writings, both

\footnotetext{
139 "William Tecumseh Sherman" Oxford Dictionary of Quotations. By Elizabeth Knowles. Oxford University Press Inc. Oxford Reference Online. Oxford University Press. Carleton University. 15 December 2009. http://www.oxfordreference.com/views/ENTRY.html?subview=Main\&entry=t1 15.e2981. Sherman is hardly the first person to suggest a parallel between hell and war, though according to the Oxford Reference collections, he is the first to make the relationship explicit.
} 
implicit and explicit, and how hellishness relates to their sense of space in the trenches. The previous chapter's exploration, from a macroscopic perspective of the changing space of war and its technological and strategic impositions, now seeks to restore the soldiers to the space of war and explore a particular social response to their surroundings. Whereas Chapter Two focused primarily upon the institutional strategies that aimed to effect maximum destruction upon the whole of the Western Front while reducing the relevance of the individual soldier, effacing them or else aiming at their erasure, this chapter shows one side of their reaction to such surroundings of constant, violent transformation. The other side, which is positioned as the antithesis of hellish conceptualization, will be explored in Chapter Four.

This chapter, like the last, is a series of sketches which contribute to a broad theme of hellishness on the Western Front. Sentiments of disharmony, disunity, and destruction were commonplace among the soldiers, resulting in themes of paradoxical collectivism in the form of group suffering and futile labours. As argued in the previous chapter, efforts to maintain any sense of wider goings on along the front were difficult at the best of times; additionally, and to be explored in this chapter, is how the conditions under which soldiers worked (both material and social) often resulted in a sense that one's individual efforts accomplished little if any lasting effect. The persistence of laborious actions amidst the violence of the front-a space beyond the control of the war's front-line participants—contributes to the notion of a "hell," as well as its various metonymies ("inferno" and the like) and adjectives ("infernal" to describe the sound of the guns, for instance). All of these descriptions occur in what is vividly described or depicted as a profaned space, and therein lies the complexity of the matter of hand. Hell, 
as a place of violent punishment in the predominantly Christian imagination of the front line soldiers, could be relied upon to communicate the brutality of trench space, ${ }^{140}$ from its horrific materiality to its terrific experiential dimension. Hell is slightly less than a synecdoche for trench space, but slightly more than mere metaphor: many hellish conditions were encountered in the trenches as this chapter will demonstrate, but it must be recalled that it is also a convenient term for the worst of all places imaginable. As a result, the use of "hell" as a spatial descriptor is partly convenience, partly actualized, yet entirely employed in the broadest sense as a place of extraordinary violence, frequent hopelessness (as the gates of legend are purported to demand of its occupants), and generally a fallen space of nightmarish proportions.

Before pressing forward into the implicit concerns of the war anticipated by enlistees and promoted by the public, a caveat or two about the chapter as a whole must be forwarded. Firstly, the ideas contained herein should neither be a read as a definitive claim about the spatial character of the whole of the Western Front, nor should they be considered an expression isolated to a single locale along the front. These spaces changed regularly both in activity and appearance, and soldiers' expressions changed to match their situations, both experiential and environmental. In fact, many a soldier has written about what Paul Nash dubbed the "ridiculous incongruity" of the blooming flowers along

\footnotetext{
${ }^{140}$ See Alice K. Turner, The History of Hell (New York: Harcourt Brace, 1993) for a brief exploration of hell, from pre-Christian society through the changing face of hell over the last two-thousand years of Christianity. While it is not an exhaustively researched text, it nonetheless provides a modest overview. I realize, too, that in positing this as a matter of Christian imagination, some readers might take exception to the exclusion of Indian, African, and Middle-Eastern participants of different religious backgrounds. My intent is to showcase the majority's social constructs; it would indeed by intriguing to consider a predominantly Hindu regiment's social construction of their environment, for instance, but I must leave such explorations to others.
} 
a trench parapet in the springtime. ${ }^{141}$ Those facts do not diminish the genuinely anguished expressions of the soldiers at any given point, and they need not contradict more upbeat or oppositional testimony-often coming from those same soldier-writers. An important matter to be recalled is that war, as historian Samuel Hynes has observed, "[does] not seem to be narrative at all, [does] not seem, that is, to be a continuous and coherent action that [moves] through related events to a conclusion." 142 Hynes's comments about war as a set of experiences, full of contradictions and conflicting sensory and psychological data-illustrated nicely by Nash's words above-show that narrating such events is truly challenging. The experiences of trench life, both positive and negative, might well be called what philosopher Slavoj Žižek calls a "parallax view," or a shifting observational perspective on the same issue, between which "no synthesis or mediation is possible." 143 Žižek employs this concept primarily for a discussion of political ideologies, but its psychoanalytic foundations apply as much to individual, subjective perceptions of an event, which will become evident in the following chapter's preoccupation with the relocation (and even dislocation) of violence by the soldiers, thereby shifting from passive recipient of violence to active transformer of violence-the true parallax act. As with all ordinary people, the soldiers' conclusions on any single day were rarely an absolute reflection of their long-term attitudes, and it is important to acknowledge that perceived contradictions need be neither wrong nor misguided, but rather are part of the same event set, but at opposing ends of the experiential spectrum. The frequent

\footnotetext{
${ }^{141}$ The quote is from Paul Nash, Outline: An Autobiography and Other Writings (London, UK: Faber, 1949): n.p. Quoted in Margot Eates, Paul Nash: The Master of the Image 1889-1946 (London, UK: John Murray Ltd., 1973): 22.

${ }^{142}$ Samuel Hynes, A War Imagined: The First World War and English Culture (New York: Collier, 1990): 203.

${ }^{143}$ Slavoj Žižek, The Parallax View (Cambridge, MA: The MIT Press, 2009): 4.
} 
occurrence of hellish iconography in soldiers' testimony comes up enough to warrant this discussion, even if many soldiers would have distanced themselves from such concepts during the post-war years. ${ }^{144}$

This chapter leaps straight into the trenches, where we left off at the end of the last chapter, and consists of two principal sections. The first considers the more empirical descriptions of the Western Front as a blasphemed landscape--described by some soldiers as "hell" (or other related terminology). Recalling the previous chapter's focus upon the dislocation of the individual in the landscape, this section evokes a powerful social response to that sense of war space. The second section nuances the first by addressing action-defined spaces. In essence, the section examines the near-constant toiling of the soldiers and its effects (or rather, a frequently perceived lack of discernible effect) and looks at the descriptive language they employed. Instead of hell being a simple geo-physical trope, the Western-Front-as-hell's physical appearance is coupled with hellish activities which are inseparable from the space in which they occur, providing a further definition of hellishness on the Western Front.

\section{The Blasphemed Landscape}

One of the simplest and most common articulations of the terrible, profaned nature of the Western Front is found in the plentiful descriptions of the landscape found

\footnotetext{
${ }^{144}$ See Jonathan Vance, Death So Noble for a detailed examination of post-war discourse in Canada from the 1920 s to the 1930s. Vance works to dispel the "modern" narrative constructed by Hynes, Fussell, and Eksteins (among others) by showing the generally positive view of war experiences by veterans in the First World War's aftermath. Regardless, even amongst the soldiers cited by Vance, many continued to employ the language of awfulness which I am analyzing in this chapter, even if their general sentiments lean towards favourable views of wartime experience.
} 
in letters, diaries, memoirs, and visual representations. ${ }^{145}$ For instance, on July $19^{\text {th }}, 1917$

Canadian Harold Henry Simpson wrote from France to his mother of "the most beautiful

[sunset] ... since coming to France," yet concluding with the bitterest irony. The

"magnificent grandeur" of "the sinking sun" spreads out like a "soft afterglow over the

countryside"-yet the countryside he goes on to describe is wholly imagined. The

dreamscape is subsequently "broken by the blasphemy of many guns. [...] The sun's last

rays are fading away and as I look over the scene again I see only [a] chaotic picture of

devastated homes and blasted fields." ${ }^{146}$ Simpson's language illustrates both the

anticipation and the inevitable outcome of facing the guns of war. The mythological (that

is, essentialized or simplified) coherency he ascribes to his life outside of war, and which

he seemingly carries with him to France, is first dimmed and then ushered into ruin by

the blaspheming guns.

Simpson's idealistic vision is undermined by the grim reality of shell holes and

devastation inflicted upon the landscape. He deviates from a narrative reverie to describe what Samuel Hynes has observed in so many soldiers' writings:

The accounts are composed mainly of things ... all rather small-scale, all randomly disposed, and all rendered without judgement or expressed emotion, as though boot, helmet and human face, heaped earth and bodies,

\footnotetext{
${ }^{145}$ The last refers primarily to paintings made by soldier-artists, owing to the fact that other forms of visual representation like photographs and film were much more strictly controlled mediums and were mostly constructed to maximize their propagandist intent. Painting, on the other hand, and especially in Great Britain's official artist program, while ostensibly propagandist as well, tended to employ very avant-garde figures like former Futurist Christopher Nevinson and Vorticist painter Wyndham Lewis, whose portrayals of war are often jarring and explicitly critical. There are other surviving elements of visual culture, such as sketches and other ephemera, but these are comparatively unknown and more difficult to locate than, for instance, the many galleries of war paintings.

${ }^{146}$ CLIP, Harold Henry Simpson, Letter to Mother, 19 Jul 1917. Online:

http://canadianletters.ca/letters.php?

letterid $=8276 \&$ warid $=3 \&$ docid $=1 \&$ collectionid $=331$. Last accessed 18 Jan 2010.
} 
telephones and decapitated heads and tinned horsemeat were all morally equal parts of one chaos. ${ }^{147}$

While Hynes appears to be correct about the chaos expressed by the soldiers regarding their surroundings, it is difficult to embrace his notion that there is no judgement. Simpson's use of the word "blasphemy" is a judgement of divine proportions and is explicitly attached to the implements of violence. While many soldiers imagined the war as a "natural disaster, a flood or a great gale," to cite Hynes again, ${ }^{148}$ one must consider also that these forces of nature, in a long tradition of Abrahamic religious thought, have often been wrought by the gods. This nuancing of Hynes's analysis results in a space of divine wrath unleashed. At the very least, there is a near-constant affirmation of violence falling from the heavens that exceeds the merely pragmatic description of the obvious trajectory of shellfire. Herbert Durand describes life as "hell” precisely because "a big rain storm" of bullets, ${ }^{149}$ while Fred Adams describes "a nightmare, a hell" of "shrapnel raining down on [him]" during a retreat. ${ }^{150}$ Hell became a common trope to describe this space of violence from above, in addition to its more obvious use as a descriptor for the worst of all imaginable places.

American veteran Ernie Hill, reflecting upon his experiences, states: "There were many times [in the trenches] that I would close my eyes and wonder just what it would be

\footnotetext{
${ }^{147}$ Hynes, Op. Cit., 115.

${ }^{148}$ Ibid. 158.

${ }^{149}$ CLIP, Herbert Durand, Letter to Mother, 30 May 1915. Online: http://www.canadianletters.ca/letters.php? letterid=2271\&warid=3\&docid=1 \&collectionid=142. Last accessed: 10 Jun 2010.

${ }^{150}$ CLIP, Fred Adams, Letter to Mrs. Buckler, 28 May 1915. Online: http://www.canadianletters.ca/letters.php? letterid=2813\&warid=1\&docid=1\&collectionid=205. Last accessed: 10 Jun 2010 .
} 
like to be either in heaven or in Hell. Hell could not be any worse than what we got."151 Hill's statement expresses the convergence of imagination and reality, in evident contradistinction to the imagined space of war previously discussed by Simpson. This "Hell" to which Hill refers was reflected in many place names on the Western Front, being inscribed with the ruination described by Simpson above. A Canadian soldier, James Ross, shares some of them in a letter sent home from Ypres: "Death Valley," "Murder Hill," and "Dead Man's Corner."152 Tom Kettle describes such sites in more explicit terms, when he states that one "can turn the bend of a country road" and pass from "something that looks very much like Kent to something that looks very much like Hell." 153

In each of the above statements there is a sense of loss, and not merely of an existential type. The absence of an identifiable moral centre, or else of any semblance of proper order is seemingly most troubling. As one French observer, Paul Cazin, put it in describing a ruined church now used to clear the dead, "the house of God is nothing more than a muckheap." 154 Simpson's description of blasphemous guns converges with the idea of shattered holy icons, and indeed these images of the once-holy, now-profaned formed a central preoccupation of many soldiers on the front, as evidenced by their frequency as the subject of military photography (Figure 12). In this Canadian photograph, the image of holiness and pastoralism bound up in the country church

\footnotetext{
${ }^{151}$ In Richard Schweitzer, The Cross and the Trenches: Religious Faith and Doubt among British and American Great War Soldiers (Westport, CT: Praeger, 2003): 30. Original source not provided.

${ }^{152}$ CLIP, James Ross, Letter, 17 May 1915, Online: http://canadianletters.ca/letters.php?letterid=3252 \& warid $=3 \&$ docid $=1 \&$ collectionid=202. Last accessed: 20 Jan 2010.

${ }^{153}$ Kettle, Op. Cit., 116.

${ }^{154}$ Paul Cazin, L'Humaniste à la guerre (Paris: Plon, 1920) : 197. Quoted in Annette Becker, War and Faith: The Religious Imagination in France, 1914-1930, Helen McPhail, trans. (New York: Berg, 1998 [1994]): 41.
} 


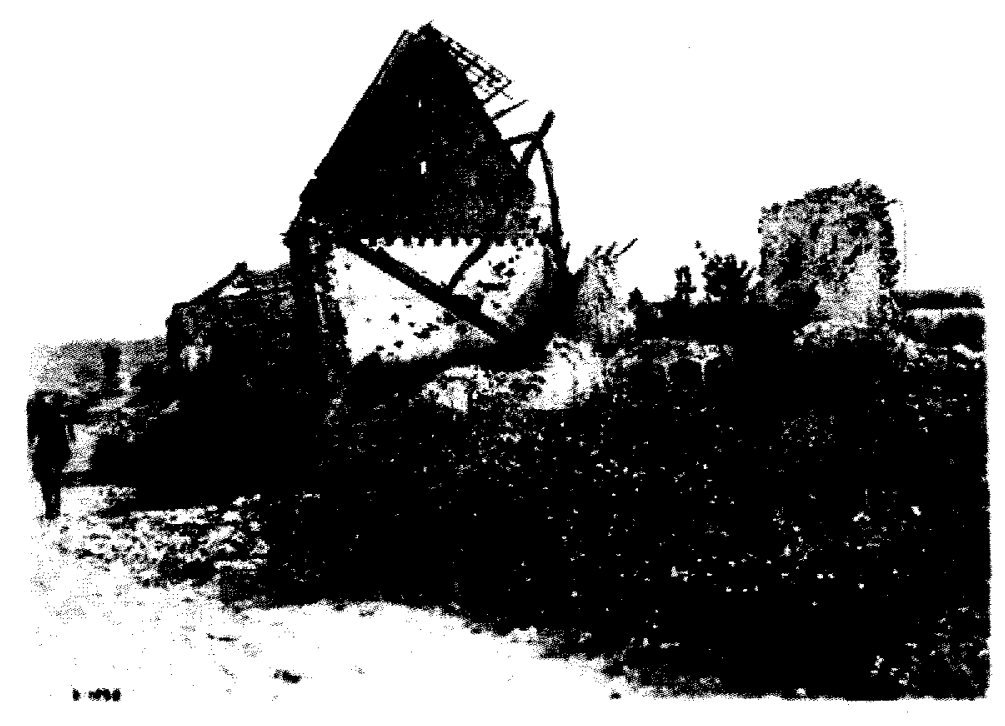

Figure 12: CWM, MHRC, O.1696, Unknown photographer, July 1917, "All that Remains of a Village Church."

is so much wreckage and untamed scrub; the soldier at the left of the frame appears positively diminutive in relation to the enormity of the calamity. As British official war artist and former infantry officer Paul Nash put it in a letter to his wife in 1917, "sunset and sunrise are blasphemous"; the entire landscape around Ypres had become "one huge grave" tended to by the incessant blasting of artillery. ${ }^{155}$ Nash's account is not merely one of dead bodies, as one might commonly understand the term "grave," but rather should be understood through its visual manifestation in his art, such as his iconic We are Making a New World (Figure 13). Firstly, the graveyard is all encompassing, from the sky to the land, from dead bodies to the shattered trees. It also depicts a graveyard for any sense of idealism, as the painting possesses the same characteristic disillusionment as Harold

\footnotetext{
${ }^{155}$ Paul Nash, Outline: An Autobiography and Other Writings (London, UK: no pub., 1949): 211. Quoted in Eates 21, and Richard Cork, A Bitter Truth: Avant-Garde Art and the Great War (New Haven: Yale University Press, 1994): 8.
} 
Simpson's aforementioned descriptions. Beyond the irony of the title is a landscape of paradox, where dried blood-coloured clouds and blue sky mingle, and where shattered figures of trees emerge from the soft yet traumatized undulations of the earth. The sun is ambiguously depicted —neither rising nor setting —which is where Nash and Simpson have seized upon the awfulness of the scene with such precision.

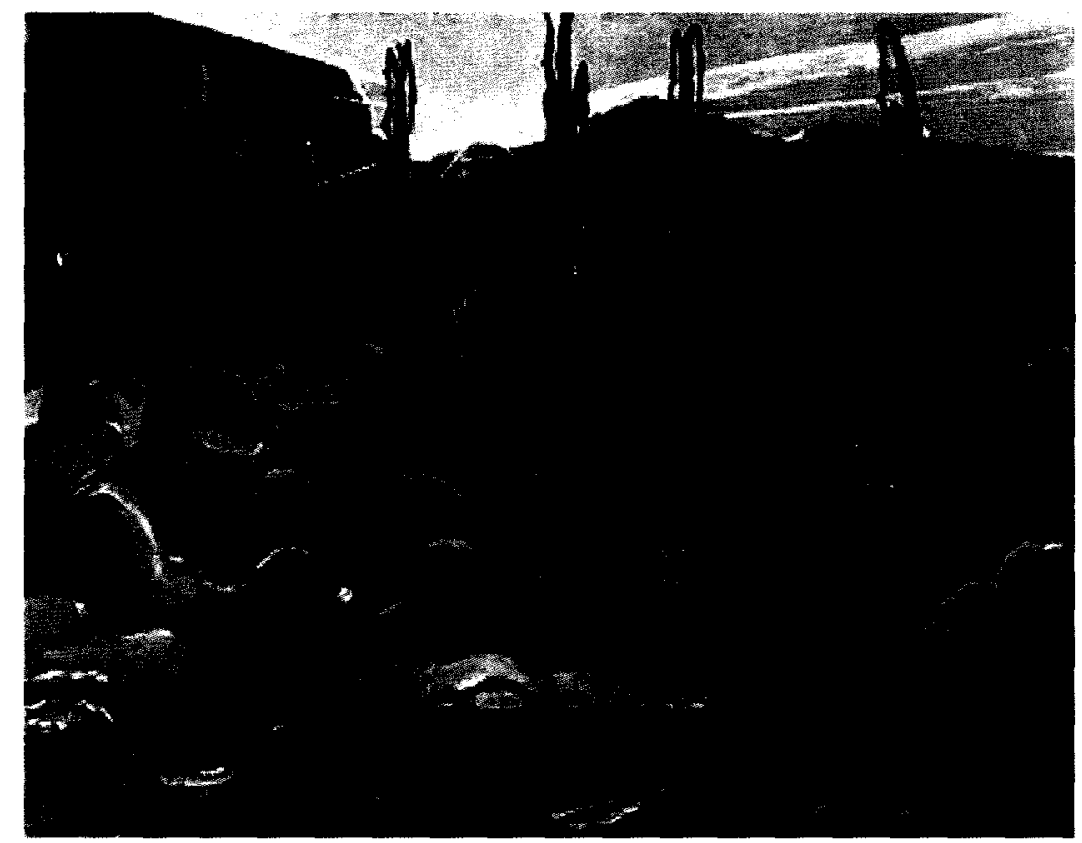

Figure 13: $\quad$ IWM, IWM ART 1146, Paul Nash, We are Making a New World, 1918, Oil on canvas, $71.2 \times 91.4 \mathrm{~cm}$.

These depictions are those of a fallen world, standing in opposition to a world of hope and promise, inspiring the use of a myriad of imagery associated with the worst of all possible spaces. As the above descriptions seem to indicate, a variety of apocalyptic visions of war, images more evocative of Golgotha than hell (as with Nash's painting), and the merely profaned tend to coalesce in a form readily identifiable with certain images of death, destruction, and uncanny familiarity (as with the ruined churches, still identifiable yet connoting a distinctly ungodly message). Many depictions above also 
employ elements of juxtaposition to emphasize the evocation of disharmony and discord.

On rare occasions, as will be shown later, the soldiers even adopt the canonical iconography of literary hells found in Dante and the like. Such accounts of the space of war as those mentioned above are commonplace in the writings of the soldiers, and the connection between them and other older notions of hellishness is the general idea of goodliness gone horribly awry.

This goodliness, an outcropping of positivism and the belief in the perfectibility of the human condition, was part of a combined moral and social sensibility. When John Keegan writes that the First World War "destroyed the benevolent and optimistic culture of the European continent, ${ }^{, 156}$ he is referring to a promising sense of political and economic connectivity between neighbour states-a system of international relations that Zara Steiner describes as "well-established" but to which "there was no possible return" after the conflict. ${ }^{157}$ There was also a very real spatial dimension to such connections, as the increasing proximity of nations was aided not only by a burgeoning free market, but also by the promise of novel technologies such as the telegraph and the cinema, as well as the train, the ocean liner, and the airplane. Such matters, it was believed, should have made war obsolete or at least unnecessary among the so-called great nations of Europe. Instead, the whole landscape of the war reflects, in the testimony of the soldiers, a profound miscalculation. The essence of a promised good becomes an unanticipated evil, perpetrated by the appositional but non-synthesized ends of the selfsame social and technological structures. If hell represents the antithesis of heaven, it also represents the

\footnotetext{
156 Keegan, The First World War, 3.

${ }^{157}$ Steiner, The Lights That Failed, 11. Steiner, it should be noted, is a staunch critic of conclusions such as Keegan's, which she says ignore the continued sense of optimism that inspired projects like the League of Nations. I believe she is correct in this matter, but Keegan is specifically referring to the war itself, while Steiner is addressing the continuity of positivistic sentiment from pre- to post-war period.
} 
tyranny of the Creator and the "accident" occurring in response to absolutist but ostensibly well-meaning authority. ${ }^{158}$

It is this unanticipated space into which the soldiers are seemingly cast on the Western Front, poignantly observed by Frenchman Henry Malherbe, who writes: Qui, enfin, retracera le désordre vibrant et chaotique d'un combat, et tout autour de nous cette fin de monde, - ou ce commencement, - ces horreurs originelles, parmi le hurlement des grosses pièces, qui rappellent les monstres antédiluviens, les mammouths et les plésiosaures? Qui osera redire, d'une voix juste, quelque épisode de ce trouble cosmique? $?^{159}$ The promise of non-war was followed by a war that promised a quick and coherent resolution. That anticipated war never arrived. Instead, it became a seemingly interminable descent into chaos. The continental accident of the longue durée of the First World War relates quite well to the cosmological accident of the invention of Hell: both are the products of the abuse of a system intended for good. In the case of the First World War, what lurks beneath the idea of "Progress" is equally the total devolution of that same concept. That the soldiers turn to an apocalyptic trope like hell under such circumstances is hardly surprising.

\footnotetext{
${ }^{158}$ Paul Virilio describes the "accident" as that which is unanticipated, but which invariably occurs as the result of all new developments, with both the intended and unintended consequences coming to define the object in question (commercial flight must include the airliner crash, for instance). While he situates his discussion within the realm of technological invention, one could easily apply his logic to social trends as well. Interestingly for a Christian, Satan's revolt in Heaven is truly the "Original Accident," with Satan's embracing of revolution against God's absolute rule resulting in the creation of Hell and setting the benchmark for all earthly apocalypses. This latter interpretation is my own, stemming from Virilio's The Original Accident.

${ }^{159}$ Translation: "Who, after all, would retrace this vibrant and chaotic disorder of combat, and all around us the end of the world, - or the beginning, - these original horrors, amid the screaming of the big guns, which recall antediluvian monsters, the mammoths and plesiosaurs? Who would dare recount, in untroubled tone, the episodes of this cosmic trouble?" Henry Malherbe, La flamme au poing (Paris: Albin Michel, 1917): 131-2.
} 
On the Menin Road near Ypres, the soldiers had named an intersection "Hell-Fire Corner" owing to the near-constant rain of ordinance upon the location. The image of hell as a pit of misery works in this regard as death appeared to fall from the sky or else materialize seemingly from nowhere and nothing, as demonstrated in the previous chapter. A 1918 edition of the French trench newspaper Le Filon expresses this sentiment with absolute clarity, stating that "fighting in a modern war means ... being hit by shells come from Heaven knows where." 160 This trait of the violence experienced by the soldiers contributes greatly to the nightmarishness of their surroundings, occasionally even explicitly conceived as hellish. As Canadian Amos William Mayse states, "The day is gone by when you can scare a man with talk about Hell-fire etc-etc. Why every day \& night here, the boys are in it." ${ }^{161}$ Another Canadian, George Hedley Kempling, describes listening to a bombardment while attempting to nap in a field behind the lines, and stating: "well we knew that before many hours we expected to be in some corner of this terrible hell., ${ }^{, 62}$ Not only have the soldiers descended into a physical space below the surface of the earth, but they also describe it in cosmological terms that situate their surroundings in a discretely conceived, albeit imaginatively constructed hellish space.

One must be cautious not to push this consideration too far into the realm of literary theory, but the parallels between the descriptions of the soldiers and other iconic images of hell are nonetheless striking. In Dante's Inferno and Milton's Paradise Lost, each author describes hell as a place where the damned are buried. In Milton's work,

\footnotetext{
${ }^{160}$ Audoin-Rouzeau, National Sentiment and Trench Journalism, 45.

${ }^{161}$ CLIP, Amos William Mayse, Letter to Betty \& Kiddies, 5 June 1917. Online: http://www.canadianletters.ca/letters.php?letterid=9595\&warid=3\&docid=1\&collectionid=369. Last accessed: 1 June 2010.

${ }^{162}$ CLIP, George Hedley Kempling, Diary entry, 7 Sep 1916. Online: http://www.canadianletters.ca/ letters.php?letterid=1523\&warid=3\&docid=2\&collectionid=129. Last accessed: 1 June 2010.
} 
"whole armies have sunk"; similarly, Dante describes his protagonist trampling the heads of the damned, who have become "shades, ashen with cold, trapped in ice up to the place the hue of shame appears." 163 Soldiers almost invariably recount similar conditions in and around the trenches, and while one might make a distinction between the living hells of Milton and Dante and the dead (as opposed to the damned) on the Western Front, one can also see that soldiers viewed the dead in a very active way. While the deceased might not have been alive in any strict sense, they were most certainly rarely departed.

Canadian soldier Will Bird, for instance, writes in his memoir that the "only thing solid underneath [his feet] was a huddled dead man, and we stumbled over five or six during the morning" while moving up to the front line at Passchendaele. ${ }^{164}$ Though Bird is not making a direct reference to hell, there are several implications to address which are evocative of hellishness. Firstly, he situates his narrative in a fluid morass of shifting surfaces, the whole of which envelops his every action. Secondly, and more importantly, there is no distinction made between himself and the dead: from a phenomenological perspective, they are equal participants-equally solid things and equally interactivewithin the space. In other words, the dead's significance is on a par with Bird's own. The dead's continued presence leaves a very real mark upon the space, as in Charles Douglas Richardson's letter home, in which he states a commonplace of the front lines, in more or less widespread fashion: "As I walked along both front and support lines I came across ... arms or legs lying around ... and the blood was in pools and spattered over trenches,

\footnotetext{
${ }^{163}$ Respectively in John Milton, Paradise Lost (Toronto: Oxford University Press, 2005 [1667]): 61-2, II.587-599; and Dante Alighieri, "Canto XXXII," Inferno, Commedia, Robert Hollander and Jean Hollander, trans., The Princeton Dante Project, Online: http://etcweb.princeton.edu/dante/pdp/, last accessed 4 Apr 2009: lines 34-5, and 77-8.

${ }^{164}$ Bird, Op. Cit., 49.
} 
[illegible] and in fact everything." 165 The entirety of the trench space holds both living and dead, and at times in Bird's narrative as in other soldiers', he occupies exactly the same space as the dead, all participants being caught in a seemingly eternal cycle of burial and un-burial. ${ }^{166}$

Other soldiers also imagine themselves as interchangeable with the dead.

Siegfried Sassoon, obviously among the more eloquent writer-combatants of the First World War, is damned not for his imagined death in a poem entitled "Memorial Tablet (Great War)," but rather for the conditions under which it occurs:

$$
\text { ...I died in hell - }
$$

(They called it Passchendaele). My wound was slight,

And I was hobbling back; and then a shell

Burst slick upon the duck-boards: so I fell

Into the bottomless mud, and lost the light. ${ }^{167}$

In Sassoon's writing, it is as though the whole of the environment is inclined to swallow him up in its murk and misery. Even in imagining his own death, Sassoon cannot envision his demise as a release in any sense-after all, one cannot die in hell, and his death is more metaphorical in that he falls into "bottomless mud" and not into any state of repose. Most importantly, then, there does not appear to be any escape from the ubiquitous conditions: here, the dead are the landscape, as they are in Milton and Dante.

\footnotetext{
${ }^{165}$ CLIP, Charles Douglas Richardson, Letter to Edna, 15 Jun 1916. Online: http://www.canadianletters.ca/ letters.php?letterid=3964\&warid=3\&docid=1\&collectionid=225. Last accessed: 1 June 2010.

${ }^{166}$ On one occasion, Bird describes the automatic actions of him and his exhausted comrades, only to juxtapose a scene of dead bodies gathered in a trench with the same expressionless faces but appearing to be in wait of some great action. In another chapter, he describes having fallen asleep in a sap only to have the walls collapse on him, mirroring the depiction to come later of the bodies underfoot. In Bird, Op. Cit.: 20 and 26 , and 33 , respectively.

${ }^{167}$ Siegfried Sassoon, "Memorial Tablet (Great War)," The Penguin Book of First World War Poetry, George Walter, ed. (Toronto: Penguin Classics, 2006): 244.
} 
Private George Hatch, writing from the Somme in 1916, states: "While in Canada I was a little shaky when I saw a dead body. Here it is like walking over rye straw." "168 Again, we see an uncanny representation of the familiar through mundane parallelism, Hatch identifying the dead strewn about as a natural commonplace. In another case, Canadian Colonel George Bradbrooke writes from the Somme to a friend that "the country here is just a cemetary [sic]."169 In an earlier letter from March 1916, Bradbrooke also fails to distinguish between his own occupation of a space and the dead's, stating that they are both occupants of the same water-filled hole. He concludes by saying: "Well Sam this is one Hell of a place ... I could not describe it," ${ }^{170}$ allowing the letter's recipient, Sam, to construct his own imaginative vision in the space of war. In another letter, W.G. Singer writes: "You have no idea what it is like. Even when the papers say 'the usual artillery activity.' It is nerve wraking [sic], but when reports acknowledge a 'bombardment', it is a simple $\mathrm{h}^{* * *} ., 171$ Even as Singer constructs an exclusive experiential space for himself, he nonetheless gives the anonymous recipient of his letter a fair opportunity to visualize the space for him- or herself, employing a most distinctive and sufficiently broad spatial trope in "hell."

That said, Bradbrooke does of course describe his surroundings, even if he has had to resort to the broadest metaphor of terror and torment he could think of in "Hell." It is also particularly appropriate that Bradbrooke and others do not distinguish between the living and the dead in the trenches while evoking ideas of hell because the very principle

\footnotetext{
${ }^{168}$ CLIP, George P. Hatch, Letter to Miss Padgington, 20 Sep 1916, Online: http://canadianletters.ca/letters. php?letterid=2939\&warid=1\&docid=1 \&collectionid=205, Last accessed 19 Jan 2010.

${ }^{169}$ CWM, MHRC, 58A 142.14, George Howard Bradbrooke, Letter to Sam, 24 Jul 1916, 20020027.002 \#3.

${ }_{170}$ Ibid., Letter to Sam, 21 Mar 1916, 20020027.002 \#2.

${ }^{171}$ CLIP, W.G. Singer. Letter, 28 Jul 1916. Online: http://www.canadianletters.ca/letters.php?letterid $=5972 \&$ warid $=1 \&$ docid $=1 \&$ collectionid $=205$. Last accessed 1 Jun 2010.
} 
of hell in the Western imagination evokes concepts of perpetual resurrection for the purposes of torment. There is no peace for either living or dead in the trenches. The two continue to interact regularly, either due to the fact that both dead and living are interred together, thus constantly affirming contact between, and thus the inseparability of these ostensibly binary positions of being. A compelling instance of these concerns comes from the memoir of Charles Henry Savage, who writes: "In most of the places where we worked there were still many unburied bodies, and in repairing old trenches we were continually digging out those who had been killed and buried by shell fire." ${ }^{\text {172 }}$ In these instances, the living are never finished with the dead and vice versa, the poles associated with such positions in normal life having become conflated into a liminal position of notquite-dead yet not-quite-alive, either. When Savage later writes that shelling was "the usual hell that preceded and accompanied an attack, ${ }^{173}$ he forges a direct relationship between the liminal conditions of trench existence, its foundational conditions (the shelling), and the convergence of these matters that form the "hell" of the Western Front. Similarly, an anonymous French memoirist writes:

La canonnade fait ses ravages sans arrêt, sans répit. La terre est labourée par les obus percutants, de tous côtés, à droite, à gauche, en avant, en arrière de nous. [...] Je regarde mes hommes courbés vers la terre, groupés comme un troupeau sous l'orage. Et qu'attendons-nous dans cet enfer? ... Que la nuit arrive. Mais il est 9 heures du matin! ${ }^{174}$

\footnotetext{
${ }^{172}$ CLIP, Charles Henry Savage, Memoir, Online: http://canadianletters.ca/letters.php?letterid=8000\& warid $=3 \&$ docid $=5 \&$ collectionid $=315$, Last accessed: 19 Jan 2010 .

${ }^{173}$ Ibid.

${ }^{174}$ Translation: "The cannonade ravages unceasingly, unrepentantly. The earth is ploughed through by the exploding shells, on all sides, to the right, to the left, to the fore, and to our rear. [...] I watch my men bent to the ground, grouped together like a herd beneath a storm. And what are we waiting for in this hell? ...
} 
In this passage, one encounters not only the convergences articulated by Savage, but also the previously mentioned concepts of seemingly interminable divine wrath so closely associated with both the Western Front and hell.

Returning to Savage, one must acknowledge that the interpretation of Savage's memoir requires some narrative gap-filling by the historiographer, owing to a likely unconscious connection created between seemingly disparate elements by the original text's author. Relying entirely on language is possessed of these problems of connectivity. In visual culture and especially in art, however, the connections are made abundantly clear in a single, manifest depiction of war. If one examines Georges Leroux's 1917-18 painting L'Enfer (Figure 14), for instance, the title coupled with the depiction indicate the same sentiment as Savage's narrative. Conceived at Verdun in

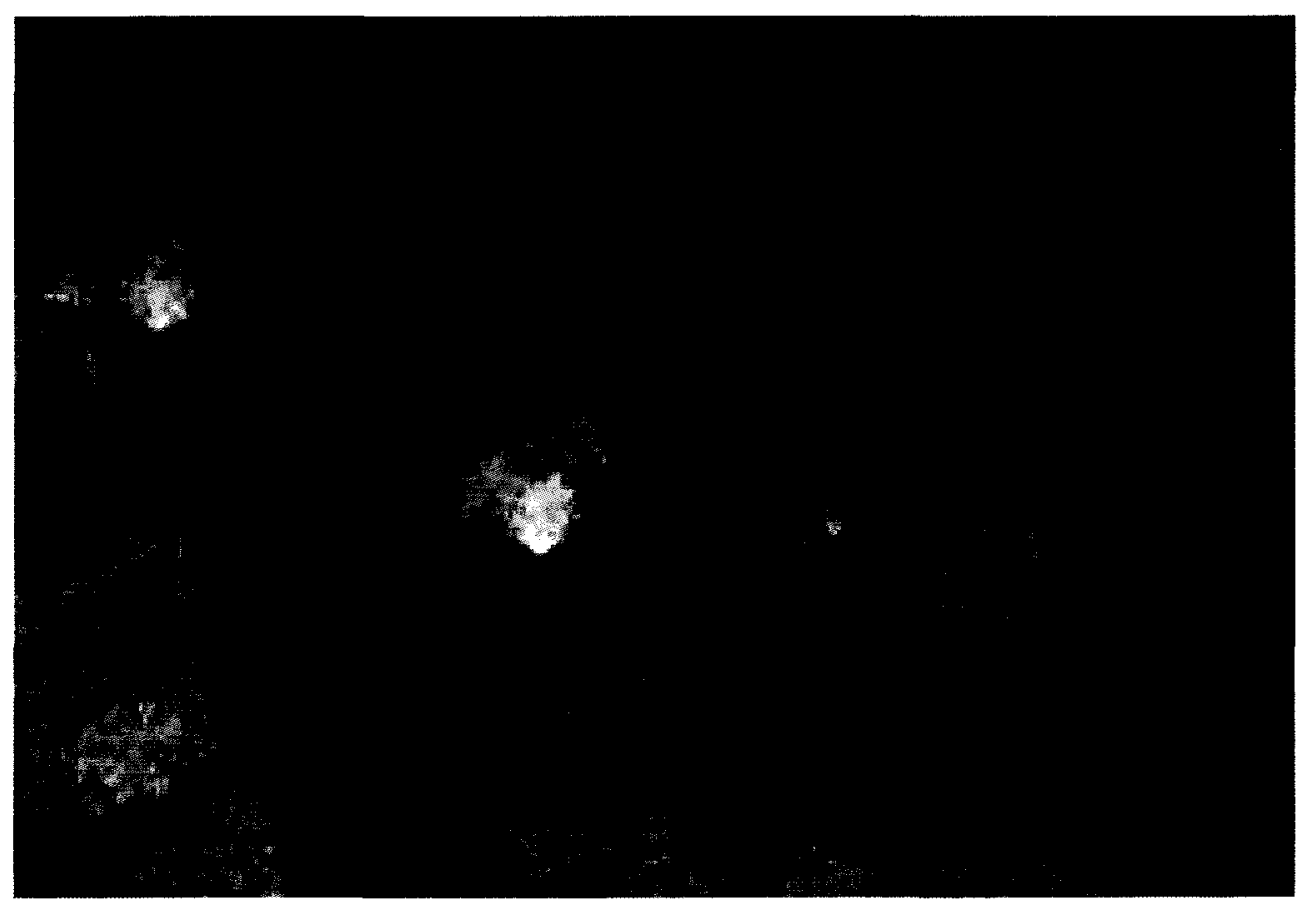

Figure 14: IWM, IWM ART 4415, Georges Leroux, L'Enfer, 1917-18, Oil on canvas, $114.3 \times 161.3 \mathrm{~cm}$.

Nightfall. But it is only 9 o'clock in the morning!" Anonymous, Carnet de route d'un officier d'alpins, Vol. 2 (Paris: Berger-Levrault, 1915): 22-3. 
1916 while the artist was returning from a patrol, Leroux's painting contains the standard iconography of hell, with its emphasis on toxic fumes, open pits of flame, and the wreckage of humanity strewn about. It also posits the living and the dead together, inhabiting the same pits and in essence suffering the same fate. Leroux's depiction is hardly unique in this regard, either, despite taking place at a battle synonymous with brutality. As Canadian Keith Campbell Macgowan states of the conditions of battle in March of 1917, a period of intensive assaults leading up to the capture of Vimy Ridge: "the whole country seemed to be spitting fire ... Men were getting burried [sic] and had to be dug out." ${ }^{175}$ Also included in this imagery is the confluence of fire and burial, where the latter seems to amplify the torment far more than hellfire ever could. In an issue of the French trench newspaper Le bochofage, a soldier-journalist writes: "Hell is not fire, that would not be the ultimate in suffering. Hell is mud!"176 Even if the anonymous French soldier who penned this article employs only the most common of hellish tropes, he nonetheless establishes that it is the inescapability of the muddy hell that makes the trenches so awful.

As with Macgowan's description of inescapable violence and inevitability in a landscape "spitting fire," Leroux's painting connotes a temporal distortion attributed to the space of war, and to which he has assigned a hellish label. There is no sense of escape from the situation he depicts; the soldiers are encapsulated first in their hole, and second by the billowing smoke which wraps around the central image like a shroud. Even the dead are not departed, while the living may suddenly vanish if testimonials such as Macgowan's are considered. Any sense of continuity established in the image is

\footnotetext{
${ }^{175}$ Keith Campbell Macgowan, Diary Entry 8 Mar 1917, 58A 1 154.1, Acc. No. 19990026-[?]. Note: the accession number for this piece is not printed on the document and so is unknown.

${ }^{176}$ Le bochofage, 26 Mar. 1917. In Audoin-Rouzeau, National Sentiment, 38.
} 
paradoxical: the dynamics of temporal existence are seemingly as mired in the locale as the soldiers themselves. Leroux's depiction of Verdun-as-l'enfer offers in visual terms the same as Dante's or Milton's language. In Milton the damned are entreated to cyclical "revolutions" of torment in "confused march forlorn," hemmed in by a "universe of death ... Where all life dies, death lives" and all the while held by gates "impaled with circling fire." ${ }^{177}$ Dante's many depictions of the various punishments of hell can be summarized as being "tossed by conflicting winds," 178 a theme indicating the paradox of dynamically inspired stasis.

Leroux's depiction of hell on the Western Front is but one of many representations evocative of hellishness. Paul Nash's Void, completed in 1918 (Figure $15)$, is another similar portrayal of hellishness, albeit with a more nuanced and ironic title. The void referred to in the painting is anything but void-like, absented of the

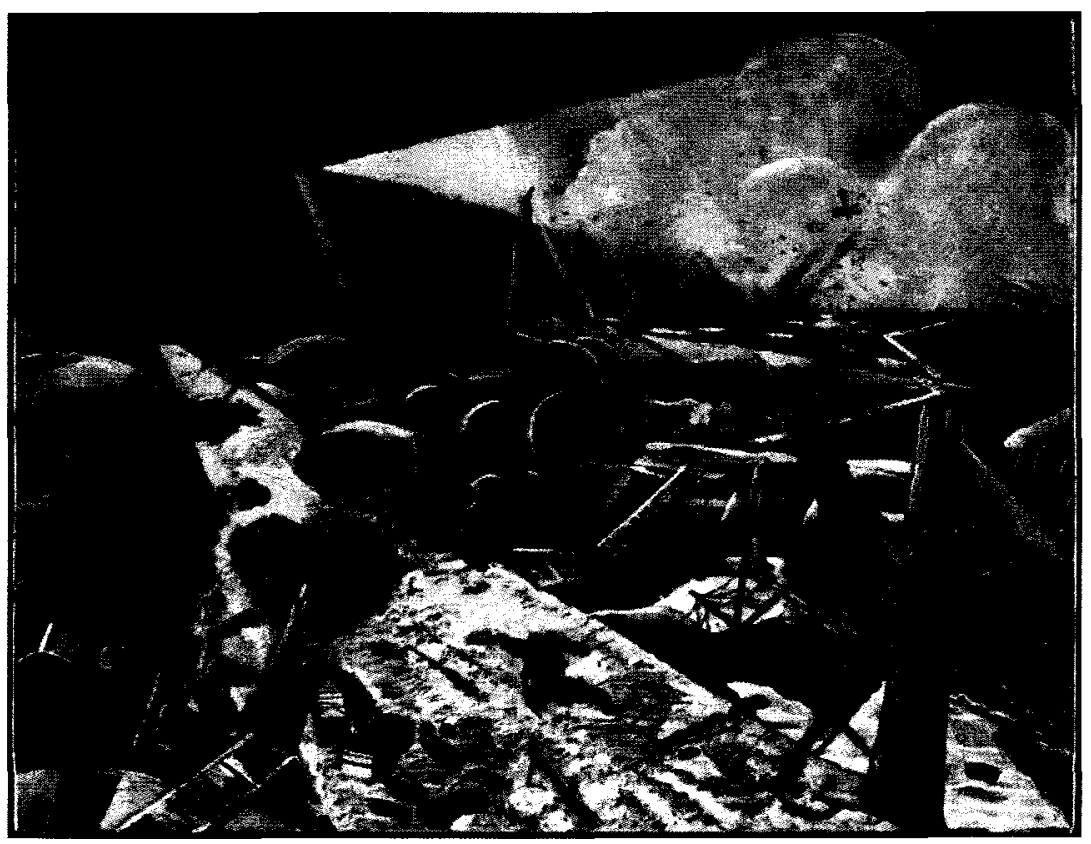

Figure 15: National Gallery of Canada (NGC), No. 8650, Paul Nash, Void, 1918, Painting, Oil on canvas, 71.4 x $91.7 \mathrm{~cm}$, Ottawa.

\footnotetext{
${ }^{177}$ Milton, Op. Cit., II.62-3

${ }^{178}$ Dante, Op. Cit., V.30.
} 
emptiness generally associated therewith. Instead, Nash employs a visual strategy of stylized movement in a circular pattern, achieving much the same effect as Leroux's L'Enfer, but in Nash's trademark visual style. In Void, Nash achieves a shifting focal point that leads the eyes of the viewer around the image through his use of intersecting lines. The slanting road leads to vertical shafts of light, light leads to horizontal clouds, clouds lead to streaking rain and a downward-spiralling aircraft, which in turn leads to a duckboard path that leads back to the road. These lines serve to create a false sense of continuity, furthered by a horizon line interrupted by explosives and the scattered detritus of a ruined landscape. Through the circular depiction of activity, Nash constructs a void of inactivity, where the perception of movement is aimed to return the viewer to the starting point; the journey through the wreckage begins anew and anew again, resulting in a net-zero summation. In the fore as in the depths, the depiction is constant and unflinching. In the centre ground, the cannons are still yet ever-present. Earth, wind, and fire are all implicated in the encapsulated, constant suffering depicted in the painting.

What Nash ends up depicting is a problem of time rather than space: if the whole of the environment within the landscape of warfare is occupied by violent forces, then the inference is one of interminability. When taken in conjunction with Nash's Leaving the Trenches from the previous chapter, one gets the sense that even the quietude of the rear lines is so laden with the capacity for extraordinary violence that Nash cannot envision a space freed from this conditional hell. The tropes of hell, as used by the soldiers, seem to indicate a double quandary of hellishness not only in appearance, but also temporally. Hell, as it is well established in the Western imagination, is endless time-wise, and fixed in a single, seemingly inescapable if traversable place. Yet we know that this latter issue 
cannot hold up under scrutiny in the trenches, and for this reason it becomes impossible to suggest that hell was "actualized" on the Western Front, as one art historian has claimed. ${ }^{179}$ One does not simply walk out of hell; however, we know that soldiers frequently left the front lines, and often for extended periods of leave. As many historians have noted, soldiers would have spent much more time in reserve or in the rear areas than they would have in the front lines, where the hellish imagination might have held most strongly.

Still, just as one does not simply walk out of hell, one does not return to it once freed, and the vast majority of soldiers did just this, and did it continually until injury, death, or armistice dictated otherwise. It seems appropriate in this context, then, that a common song sung by French soldiers from 1915 onward (and achieving some notoriety during the mutinies of 1917) went:

Adieu la vie, adieu l'amour,

Adieu toutes les femmes,

C'est pas fini, c'est pour toujours,

De cette guerre infâme.

C'est à Craonne, sur le plateau,

Qu'on doit laisser not'peau.

Car nous sommes tous condamnés, C'est nous les sacrifiés... ${ }^{180}$

\footnotetext{
${ }^{179}$ Robert Hughes, Heaven and Hell in Western Art (London, UK: Weidenfeld \& Nicolson, 1968): 1. Hughes states, unequivocally, that the First World War put an end to painting hell precisely because of this "actualization." He provides no further proof for his claim, sadly.

${ }^{180}$ Translation: "Goodbye life, goodbye love, / Goodbye to all the ladies, / It's not over, it's forever, / This war of infamy. / It's at Craonne, on the plateau, / We'll have to leave our skin, / Because we are all the condemned, / It's us the sacrificed." Anovi, Anonymous composer, "Chanson de la Craonne." Online: http://www.grande-guerre.org/document.php?num=140. Last accessed: 1 Jun 2010.
} 
The fact of this song being sung while out of the front lines indicates some element of the war's continued presence in the lives of the soldiers, regardless of their location. "C'est pas fini, c'est pour toujours" and the singers' identification as the "condamnés" both contribute greatly to this notion of an interminable, damning venture. It would also appear that part of the torment was in the seemingly endless, forced return to the trenches: there was no real departure, as the inevitable return played heavily upon the soldiers' imaginations.

This matter of seemingly interminable engagement is where the notion of a hellish space becomes most interesting, as the persistence of hellishness in the vocabulary of the soldiers is not simply attributed to the landscape of war. Just as Sherman stated that war "is all Hell" [emphasis added], so we must consider that it was not solely an image, but also a set of actions to which hellishness is attributed. The matter is subtly presented in Nash's Void, as it is in Leroux's painting. The still images aid in such a perception as the matter of time comes to a halt even as the eyes are left to wander about the image. Yet the medium is part of the message, to slightly modify (and moderate) Marshall McLuhan's hypermodern claim. ${ }^{181}$ The stasis of the image reflects the stasis of the content; the constant to-and-fro of foreground to background in Nash, or the encircled torment of Leroux's Poilus illustrate that stasis is occasionally expressed through a lack of fruitful action rather than solely being confined to a discrete geo-physical space. And if the actions of soldiers in the front lines are any indication, they spent more time engaged in

\footnotetext{
${ }^{181}$ This very famous, and often misunderstood claim, is attributed to Canadian philosopher and cultural theorist Marshall McLuhan, and is associated with Understanding Media: The Extensions of Man (New York: McGraw-Hill, 1964): 7. In this book, McLuhan makes a compelling argument that the medium of transmission (of ideas, of performances, of sounds, etc...) itself is an object of study and that the medium often supersedes the content of the medium. I argue instead that the medium and the content are mutually reinforcing, with the content of a medium being constantly tailored toward medium specificity.
} 
hellish periods of labour and waiting than they did in the hellishness of combat. While descriptions of a hellish landscape are abundant in soldiers' writings, their constant descriptions of long periods of back-breaking labour and eternal waiting between and even during attacks is yet another dimension of front-line space, and one which the soldiers carried with them in and out of the line.

\section{$\underline{\text { Sisyphean Labours }}$}

Before proceeding with this analysis, a few words are needed to clarify a matter to which I have only briefly alluded above, concerning a material hell seemingly actualized on the Western Front. It must be stated that even in the direst representations of trench space on the Western Front, it remains unconvincing to suggest that these articulations were not being deployed in relation to a terrible place. In essence, hell is part of an imaginative spatial conceptualization, occasionally similar to, and at times even drawing upon some canonical texts from Western religious literature. Without a "real" hell to compare to the space of war, it would be nigh impossible to suggest any actualization beyond an imaginative one in the form of metaphor. Still, the metaphor is evocative and draws upon centuries of Christian cultural imagination. Yet that metaphorical conceptualization is incomplete if "hell" remains at the level of a description of place. While one might look upon one's surroundings and deem them terrible or ghastly, hellishness is a concept that is far more severe. It is also a space to which the notions of punishment and torment are invariably attached-in short, there is extraordinary violence associated with the space of hell. It is also violence of a type that effaces or renders moot the modest efforts of inhabitants to exert control over that space. Moreover, the torment 
of hellish conceptualization is attributed to a set of activities that take place within the space. Hell is more than an imagined, confining geo-physical configuration; rather, it is the sum of its materiality and the activities taking place within its material environment. As geo-spatial theorist Benno Werlen states, one must conceive of all spatial identities as both "geographies of things" and as "geographies of subjects." 182 Werlen is essentially stating that beyond and also bounded by the "things" of material description are a whole set of human interactions with that geo-physical space. The following analysis, based on the allusive language of experience within a particular setting, must be situated within this broader understanding of space possessed of the aforementioned material properties and coupled with actions undertaken therein.

The first complementary matter for the notion of hellish geo-physical space is the notion of fruitless and seemingly endless toiling which almost invariably contributes to any notion of a hellish space-a matter to be demonstrated in short order, following an analysis of soldiers' activities. One example comes from Keith Macgowan who wrote on May $12^{\text {th }}, 1918$, and at a very late stage in the war: "We are messed about from morn till night but the actual daily work accomplished seems little." ${ }^{183}$ Having been at war for just over two years, Macgowan expresses what was a common sentiment, or at least from the perspective of the soldiers on the ground. While many contemporary historians are advocates of a strategic "learning curve" upon which the Allied armies were steadily moving toward the combined-arms sophistication of the Last Hundred Days offensives, the day-to-day activities of even a captain like Macgowan were difficult to situate within

\footnotetext{
${ }^{182}$ Benno Werlen, "Regions and Everyday Regionalizations: From a Space-centred Towards an Actioncentred Human Geography," B/Ordering Space, H. Van Houtum, O. Kramsch, and W. Zierhofer, eds. (Burlington: Ashgate: 2005): 47.

${ }^{183}$ Macgowan, Op. Cit., 12 May 1918.
} 
that meta-narrative of militaristic progress. To Macgowan, as it was to others who experienced the drudgery and destructiveness of trench existence, ${ }^{184}$ the tasks they were expected to undertake had seemingly become an interminable process of being "messed about." Though he expresses this outlook at a discrete moment during the war, this revelation in no way diminishes the overarching sentiment embedded within the words. Macgowan's comments are neither isolated in his own diary, nor are they uniquely Canadian. As Stéphane Audoin-Rouzeau has observed in a study of French trench newspapers, the daily toils of war were akin to suffering, and that suffering "does not belong ... to the past; in some respects the suffering is still to come." ${ }^{185}$ So, too, are Macgowan's words implicitly anticipatory; he never says he was "messed about," but rather that he is and presumably will continue to be.

Amongst English-speaking soldiers, one of the most popular soldiers' songs of the war was positively chant-like, evoking similar concepts as Macgowan's lament. Sung to the tune of "Auld Lang Syne" and repeated, as long as desired, the lyrics are: "We're here because we're here because / we're here because we're here. / We're here because we're here because / we're here because we're here!" ${ }^{\prime 186}$ The song not only demonstrates the tautologies of military life by answering an implied and unstated query with the restated terms of the query itself, but it also undermines the very nature of the original song. While "Auld Lang Syne" appeals to "old time's sake" as a measure of continuity, including the fact that it is traditionally sung on New Year's Eve, when hope and promise

\footnotetext{
${ }^{184}$ I intentionally avoid calling it "trench life" in this instance because, as previously noted, there was a near-constant conflation of living/dying that occurred on the Western Front, in terms of material objects, experience, and often in the soldiers' fatalistic attitudes. "Existence" works better here owing to the fact that neither the living nor the dead cease to "exist," per se.

${ }^{185}$ Audoin-Rouzeau, National Sentiment: 36.

${ }^{186}$ Walter, ed., The Penguin Book of First World War Poetry, 57.
} 
and the future are on most peoples' minds, "We're Here Because We're Here" does nothing of the sort. It is the antithesis of continuity, both in its syntactic and semantic structures. Firstly, it repeats the same three words indefinitely, mirroring the sentiments of soldiers engaged in many of the same operations day in and day out. It further emphasizes this point through the perpetual "here" referred to in the song. There is no "succession of "nows"" demarcating a continuous narrative, to borrow a concept from philosopher Paul Ricoeur; ${ }^{187}$ it lacks continuity or any linear sense of progress. Instead, the song, much like Macgowan's testimony, devolves into an eternal present.

The aforementioned sentiments are complemented by a range of expressions from other soldiers describing similar subjections. Tom Kettle, an Irish professor-turnedsoldier writing for American readers, wrote the following about his first two years of war: It is wrong, indeed, to call [the Great War] a campaign or even a series of campaigns: one had better style it the Wall-paper War. Everywhere the same type of development and fighting, the same pattern repeated and indefinitely repeated. [...] One is reminded of those endless chains by which some well-buckets are worked, except that nothing or very little ever seems to come up in the bucket to the labour of turning. ${ }^{188}$

Kettle's descriptions match many others, albeit with his typically creative turns of phrase. Charles Savage's memoir describes such conditions as "nightmares of constant duty and

\footnotetext{
${ }^{187}$ Paul Ricoeur, "La Fonction narrative et l'expérience humaine du temps," Archivio de filosofia 80 (1980): 343-67. Translation in Leonard V. Smith, The Embattled Self: French Soldiers' Testimony of the Great War (Ithaca: Cornell University Press): 17.

${ }^{188}$ Kettle, Op. Cit., $175-7$.
} 
work" undertaken under awful conditions, ${ }^{189}$ thereby emphasizing the powerlessness to sever oneself from such soldierly travails.

Though none of these people mention "hell" explicitly, many soldiers employ a range of descriptors that are nonetheless evocative of hellishness if not hell itself, such as the "nightmares" of Savage's memory. In virtually every case, their words (or depictions, as seen in the previous section) exceed mere triviality; these are not idle expressions of dislike, but rather serve as fundamental qualifiers of their experiences. For instance, Private J.P. Baston writes that since his arrival at the front, he has "seen many 'cold, grey dawns,' some of them merely cold, and some of them damned cold."190 Baston's expression aligns with another Canadian soldier's observation, with Francis Harold McLorg transcribing a common expression among the English-speakers around Ypres: "there is fighting, there is damned heavy fighting, and there is the Ypres salient." ${ }^{191}$ In both McLorg's and Baston's letters, the pattern is the same. What McLorg expresses as a damnable attribute of the war-the "heavy fighting," with Ypres somehow exceeding even that in terms of harshness-Baston associates with the misery of simply being there. In both cases, the situation is "damned" because of its sense of inevitability, rather than its mere existence. The conditions of waiting and suffering are inseparable and inescapable, especially in Baston's claim.

While "damned" might be dismissible as a linguistic commonplace, it is clearly used in the examples above as a means of elevating the severity of the sentiment Baston and McLorg are expressing (or rather, debasing and thus exacerbating a trivial difficulty

\footnotetext{
${ }^{189}$ Savage, Op. Cit.

190 J.P. Baston, Letter home, 20 January 1916. In Canadian Bank of Commerce, Letters from the Front, 123.

${ }^{191}$ CLIP, Francis Harold McLorg, Letter to Family, 13 Jun 1916, Online: http://www.canadianletters.ca/ letters.php?letterid=2723\&warid=3\&docid=1\&collectionid=185. Last accessed: 1 Feb 2010.
} 
like fighting or the cold-things which would be known to any schoolboy). We know that the soldiers' routines consisted of near constant work parties, toiling in the darkness, marching to and from the front laden with supplies, and long hours spent in the front lines, simply waiting. In each of Dante's cantos in Inferno, the residents of hell are forced to perform fruitless tasks, such as staring at the ground, pushing great stones about endlessly, and being cursed to hang upon thorny bushes for eternity. ${ }^{192}$ Substitute sandbags, signalling cable spools, and being wounded and ensnared in barbed wire for the aforementioned torments of Hell and one can see how akin to the damned the soldiers were at the front. Though few soldiers cite Dante in their descriptions, such descriptions as Dante's juxtaposed with the soldiers' own words serve to illustrate the ability of humankind from most ages to imagine the significance of such situations. Dante's wasteland or "the empty landscape" full of vague, grey forms on the Western Front as described by one intelligence officer are both the ends of fruitful movement and definable activity. ${ }^{193}$ Each depiction couples activity with material environment, the two elements combining to form a more complete sense of hellish space, and it is only through this coupling that the concept attains its fullest measure.

James Ross, writing home from Ypres, states that it is "the infernal waiting under fire that gets on your nerves." 194 It is as though the landscape of violence is secondary to the "infernal" lingering in Ross's letter; there is no mistaking the reference to a hellish sense of inactivity even as Ross's surroundings are privy to actions of all kinds. Being under fire is one aspect of the awfulness of war, but it is the waiting under fire that debases the experience into an "infernal" realm. Even at times of peace, the lack of

\footnotetext{
${ }^{192}$ Respectively in Dante, Op. Cit., "Canto XIV," "Canto VII," and "Canto XIII."

${ }^{193}$ Eric Fisher Wood, The Note-book of an Intelligence Officer, 183.

${ }^{194}$ Ross, Op. Cit.
} 
meaningful activity could be terrible. Charles Savage remarks that busy soldiers were often deemed lucky by their colleagues, "for to those who had nothing to do but wait [for the next attack], the time was interminable and the suspense nerve-wracking." ${ }^{195}$ When Savage writes only a paragraph later that "everything was grey and dead," he is as much describing the overwhelming sense of stasis felt when he looks upon "the utter and dreadful desolation" of the front as he is describing its physical appearance. ${ }^{196}$ Savage's language is that of absolutes, whether or not that reflected the reality of his experience. There does not appear to be any sense of anticipation or reflection in these instances. He continually invokes the idea of time collapsing into eternity. This sentiment is cemented when Savage describes reserve routines at Zillebeke, where "the eternal working party was very much part of the life," and for all the "soldierly relaxations" they could partake in, "the Orderly Sergeant could be counted on to appear with his bad news for the night."197

Social historians of the First World War have already identified the soldiers' activities in some significant detail. Dan Todman notes that "probably the most frequently endured experience for most soldiers in the combat arms was not terror or disgust but boredom. [...] They did not get to pick and choose their jobs, locations or food." ${ }^{198}$ Freedom of action, then, was at a premium on the Western Front. The idea of being subjected to tasks not of one's choosing is at least a modest departure from the (relatively) liberal ideas in which most soldiers of the Western nations would have been

\footnotetext{
${ }^{195}$ Savage, Op. Cit.

${ }^{196}$ Ibid.

${ }^{197}$ Savage, Op. Cit.

${ }^{198}$ Todman, Op. Cit., 5.
} 
raised. ${ }^{199}$ Based on Todman's descriptions, even as he seeks to undermine the myth of perpetual bloodshed he enacts another trope of extreme limitation, verging on imprisonment. The violence to which the soldiers were subjected in the front lines was awful enough, as witnessed when Keith Macgowan suggests "we would rather go over and drive [the Germans] out than stand and take every thing [sic] he has to throw at us." 200 This sense of powerlessness in the face of the enemy's weapons was compounded by the boredom to which Todman refers, even if boredom and the barrage appear as antitheses.

Todman describes in some detail the ordinary routines of trench life: toiling, cleaning, eating, and even resting. Some soldiers, after a long stint in the front lines, were clearly quite happy to be away from the activities described by Macgowan above.

Canadian Private A.P. Glasgow, for instance, writes: "We have just lately been moved to a quiet part of the firing line... After being at the front for a month or so, one's appetite for bloodshed and excitement becomes somewhat satiated." ${ }^{\text {"201 }}$ Though Glasgow is naturally quite pleased to be in a calm sector, breaks like his were often tempered by the doldrums of trench routine which persisted no matter the setting. Rifles had to be cleaned regularly; kit and body inspections were done; and sentry duties were performed, with men staring out into the void of No Man's Land and watching for signs of life that were rarely seen. ${ }^{202}$ While this routine was undoubtedly more desirable than being blown into

\footnotetext{
${ }^{199}$ It is certainly possible to see the aforementioned problems of choice in the labouring classes of the time, but there is a fundamental question of choice at play in civilian life that is not present in the military. In the former, one may easily refuse to perform a task, for instance, and the most severe punishment would be termination of one's employment. Refusal to perform a task in the military, depending on the task, could result in termination, period.

${ }^{200}$ CWM, MHRC, Macgowan, Diary entry, 4 Feb. 1917, 19990026-006.

${ }^{201}$ A.P. Glasgow, Priv., Letter home, 4 July 1915. In Canadian Bank of Commerce, ed., Letters from the Front, 27.

${ }^{202}$ Cook, At the Sharp End: 239, 240, and 249, respectively.
} 
atoms by the artillery, there was also an extreme distaste for the constant labour, much of which seemed to be without any clear objective, or at least without any sense of having achieved some permanent resolution.

It is easy to reflect in hindsight upon the war and dismiss claims of futilitysurely the actions of the soldiers were not futile, as the collective Allied actions eventually won the war. Yet it is far more difficult to situate oneself in their boots, at the time of the war, and not detect that pervasive sentiment. The lives of the signallers admirably demonstrate this sense of futility, when we read the final lines of Canadian Major Brook Ferrar Gossage's untitled poem: "Hello, Hello, Gee Whizz hello / The line is out again."203 Major Gossage was an artillery battery signaller, and he writes frequently of the experience of having to repair phone cables which are constantly being destroyed by artillery near the front lines. The frustration is almost palpable when he writes of "working all morning" to repair a break, but "[making] nothing of it.",204 In his extensive diary collection, these are among the most common entries. On their surface such entries appear banal and even frivolous, yet in their proper context of having to locate the damaged wire while under fire, having to repair it, and then returning to one's station only to discover a fresh break, one gets a far better sense of how this futility becomes entrenched. It is the combination of the task and the extraordinary nature of the space that renders the labour so terrible.

The agonies of tedium are almost ever-present in soldiers' writings, and these observations contribute much to our spatial understanding of the First World War. As historian Stefan Goebel has observed, "destruction and endurance were two sides of the

\footnotetext{
${ }^{203}$ CWM, MHRC, 58A 1 13.7, Brooke Ferrar Gossage papers, No date for entry, 19930034-021. Emphasis in original.

${ }^{204}$ CWM, MHRC, Gossage, Diary entry, 15 Oct. 1915, 19930034-020.
} 
same coin, the novel experience of modern warfare." ${ }^{205}$ Of course this is also one of the defining characteristics of hell, albeit as a parody of endurance, more properly called hopeless resignation. In other words, endurance of that violence is at the core of the experience of being situated in hell. Regardless of whether or not hellishness was the de facto state of affairs on the Western Front, the soldiers so often mention their endurance of the violence that it becomes a dominant motif in their experiential lexicon. When Canadian Archie MacKinnon writes to his brother that "you never see any Germans of any account but you will see all kinds of shells exploding, killing and wounding fellows, ${ }^{206}$ he implies that the violence transcends enmity of a perceived foe. The two are associated, yes, but also distinctly and significantly separated with the shells clearly hierarchically situated above all else on the horror scale—-both literally and figuratively. As French officer René Nicolas observed: “Le bombardement croissait et l'on ne distinguait plus les coups les uns des autres. [...] Une demi-heure durant ce fut un assourdissement affolant; on avait la sensation que la tête s'enflait, tant ce bruit était infernal. ${ }^{207}$ In similar terms, Sergeant J.A. Caw of the $5^{\text {th }}$ Battalion, CEF, describes fighting around Ypres in June 1916 as "a matter of attack and counter-attack" for two full weeks, during which time "a man could get no sleep or peace for the shelling, and at night every man was required for patrol, working parties, etc." ${ }^{208}$ In addition to the sense that the violence is once again a concern beyond the foe's presence, Caw's letter suggests

\footnotetext{
${ }^{205}$ Goebel, Op. Cit., 157.

${ }^{206}$ CLIP, Archie MacKinnon, Letter to Neil MacKinnon, 8 Nov 1916. Online: http://www.canadian letters.ca/letters.php?letterid=6999\&warid=3\&docid=1\&collectionid=294. Last accessed: 10 Feb 2010.

${ }^{207}$ Translation: "The bombardment was crossing and one could no longer distinguish the explosions from one another. [...] A half-hour into it and the sound was maddeningly deafening; one had the sensation that one's head was inflating, such was the infernal noise." René Nicolas, Carnet de campagne d'un officier Français, Edward Manley, ed. (Boston: Benj. H. Sanborn \& Co., 1919): 32.

${ }^{208}$ J.A. Caw, Letter home, End of August 1916. In Canadian Bank of Commerce, Op. Cit., 143.
} 
an intimate, implicit relationship between toil and violence. Toil is inextricable from destruction in the trenches, with each reinforcing the continuation of the other.

While most of the above references speak of damnable conditions and infernal stasis (among other choice descriptors), they rarely reference hell specifically. Those that do arise, however, are done in the same terms as those soldiers mentioned above.

Canadian Amos William Mayse writes home: "it's a miracle how men stand the continual strain, day \& night \& day after day. [...] I am sure that Dante in the wildest flight of his imagination could not describe such an 'Inferno' as we have here." ${ }^{209}$ Mayse makes this reference precisely in relation to his experiences, and not simply to describe his surroundings. And it is precisely the omnipresence of what Wallace Reid describes as the "hellish forces [of artillery]" that keeps soldiers like Will Bird hard at work repairing trenches. ${ }^{210}$ Eric Fisher Wood, in a fashion that once again links toil and ruination, articulates how the sheer mass of matériel and manpower required to maintain the war efforts, even outside the immediate shelling areas, becomes the architect of its own selfdestruction when he remarks:

Working parties of engineers are scattered along the route in greater and greater numbers. They are continually filling crushed stone in the craters and ruts. The heavy traffic works against them in a race of destruction which soon reduces their repairs to muddy morasses. Their work is never ending. ${ }^{211}$

${ }^{209}$ CLIP, Amos William Mayse, Letter to Betty and Children, 23 Jun 1917. Online: http://www.canadian letters.ca/letters.php?letterid $=9656 \&$ warid $=3 \&$ docid= $1 \&$ collectionid=369. Last accessed: 10 Feb 2010.

${ }^{210}$ Respectively: CLIP, Wallace Aubrey Reid, Letter to Mother, 1 Oct 1916, Online: http://www.canadian letters.ca/letters. php?letterid=7611\&warid=3\&docid=1 \&collectionid=313, Last accessed: 10 Feb 2010; and Will Bird, Op. Cit., 16-9.

${ }^{211}$ Wood, Op. Cit., 168. 
Bridging Bird's and Reid's independently stated commentaries is Mayse again, who on July $22^{\text {nd }}, 1917$, writes that sharing with his wife " "light' stuff" such as purchases made in England on leave seems odd when he is so much "in the midst of horrors - \& hardships."212 The mere mention of "horrors" appears to prompt the inclusion of "hardships," just as he linked the two previously. The commonality between these aforementioned observers is that the notions of toil and terror are linked, more or less explicitly, but also invariably.

While one can certainly find many a banal entry describing the hardships of war-one might in fact be harder-pressed to find a soldier who fails to mention such things, even amongst those more inclined to keep a chronology of events rather than a narrative-there are occasional, erudite reflections upon these matters. The aforementioned Major Gossage, perhaps owing to his education but nonetheless writing in a basic, rhyming sonnet scheme, expresses these ideas in all their intricacies, but also with a degree of ambivalence and ambiguity which is rarely seen in such an orderly fashion. The poem, entitled "The Battery O Pip," is worth analyzing in its entirety:

Cramped in a crumbling dugout

Adjoining No Man's Land

And chilled to the bone I squat on the phone

That sits on a sandbag stand

My ticker points at midnight

I've two more hours to do

And keeping awake would [wrest?] the cake

\footnotetext{
${ }^{212}$ CLIP, Amos William Mayse, Letter to Betty, 22 Jul 1917. Online: http:/www.canadianletters.ca/ letters.php?letterid=9544\& warid=3\&docid=1\&collectionid=369. Last accessed: 10 Feb 2010.
} 
From the torture that Tantalus knew

Tis here the eyes of the Battery

Detail the Hun at work

And targets fair we phone to where

Our eighteen pounders lurk

Then shells of high explosives

Frustrate the plans of Fritz

Who runs to ground as we promptly pound

His parapet to bits $^{213}$

The first stanza very clearly articulates the combined spatial-temporal dismay previously demonstrated. The whole space is attuned to a barely-human occupant, buried underground, body contorted in a state of physical ruin that matches its surroundings. The writer is both intellectually and physically sapped. Despite the fact that the author has a mere two hours of his shift left, his remarks that they are akin to the "torture that Tantalus knew" is significant if one recalls Tantalus as the figure in Greek mythology who was banished to Tartarus, the deepest part of the Grecian Underworld. He was cursed to stand in a pool of water for eternity, a fruit tree dangling its prizes just above his head. If he bent to quench his thirst, the water would recede; if he reached for the fruit, the branches would always just exceed his grasp. Tantalus's torture is his ability to conceive of his end goal, but he lacks the means to achieve it. His objects of desire are tantalizingly close but unattainable — and hence the origins of the word "tantalize."

${ }^{213}$ CWM, MHRC, Gossage, Op. Cit. 
What is most striking in Gossage's poem is not the equating of being on a seemingly endless shift to Tantalus's situation. That parallel, I think, has been made quite clear through the many other soldiers' depictions of their situations. Rather, it is Gossage's explicitly stated reason for being on shift at all that is most remarkable: he is there to facilitate the destruction of the German lines by the lurking guns. The concept calls to mind Paul Nash's Leaving the Trenches, which we saw in Chapter Two, wherein extraordinary violence is hidden from personal view, but always present in the space of modern war. Yet if one takes from his earlier observations that it is the guns themselves that are so frequently to blame for the repeated failings of his own system, we can see a profound ambivalence in Gossage's ostensibly cheery conclusion. He has accomplished so very little in calling down the shells. By his own admission, he has merely locked the German soldiers into the same pattern of dynamic stasis which he spends most of his time bemoaning. At the core of his remarks, when observed in their totality, lurks a seemingly irresolvable paradox.

That paradox is located in a sense that, even in periods of ostensible success as depicted by Gossage's final line, the conditions of warfare remain unresolved. Though Gossage employs the analogy of Tantalus to depict his situation, he has in fact conflated both Tantalus and another Greek tragic figure, Sisyphus, who was cursed for all eternity to push a boulder up a hill only to have it roll down the other side every time he completed the task. In the story of Tantalus, the tragic figure cannot fulfill any fundamental desire; in Sisyphus, the character is locked in a repetitious set of irresolvable actions. One anonymous French soldier rather awkwardly makes the case for Sisyphus in a 1918 trench newspaper: "Then there are the detested digging fatigues for the reserve 
company, a real labour of Sisyphus, to fix to the parapet a runny brew which is determined to have run down off it." ${ }^{214}$ The soldier's lament is the need to repair that which is constantly being unmade, and hence the reference to Sisyphus.

The lament of the French soldier-journalist addresses the labours about which the previous pages have spoken. Even during long periods of attacking, however, this Sisyphean association becomes evident, and especially in those testimonies written during the Last Hundred Days campaign. ${ }^{215}$ Samuel Laycock, on August $8^{\text {th }}, 1918$, and embarking upon what would prove to be the final push of the First World War, states in his diary:

Everything was the usual confusion of a big battle. Staff officers tearing their hair for information, didn't know where the flanks were, etc. Would we attack again? Where were the rations? H.Q. was a beehive of industry. Messages to go to the Bns. [Battalions] and no one knew just where they were. $^{216}$

The overwhelming sense of unresolved confusion is present in Laycock's words. In a less eloquent yet undeniably evocative diary entry also in August, 1918, Canadian lieutenant Garnet Montague Babbitt writes: "8 A.M. Over the top. Advanced about 1000 yds. Run into heavy Barrage of m.g. [machine guns] and art [artillery]." Two months later, in late October, he writes: "Over the top. Capture ST. MARTIN and BERMERAIN, advance about 3000 yds. Very heavy losses only 5 left in my platoon out of 30. [...] Only 50 left in

\footnotetext{
${ }^{214}$ Le bulletin désarmé, 1 Mar. 1918. In Audoin-Rouzeau, National Sentiment, 37.

${ }^{215}$ This makes a particularly compelling exploration, mostly because of the incongruity of the time frame. So often, one is inclined to recall this campaign in retrospect as the last big push. While it was being undertaken, however, it would have been difficult for soldiers to anticipate the end of the war and the threeplus months of combat appear no different than the purported initial successes at the Somme or at Third Ypres, for instance. There are ample testimonies during all three occasions to suggest that soldiers felt a breakthrough would occur imminently.

${ }^{216}$ CWM, MHRC, Samuel R. Laycock, diary entry, 8 Aug 1918, 58A 1 43.4, 19850405.020.
} 
Coy [Company] out of $130 ., 217$ Each advance met the same conditions which the soldiers had set out to break, in a Sisyphean engagement of suffering overcome, suffering initiated anew.

The empty spaces between the capitalized place-names in Babbitt's diary—both literally in the sense of there being great lacunae of description, and figuratively as described below-evoke the sense that what transpires between places seems familiar to the point of mere repetition, and repetitious to the point of irrelevance. The entries in Babbitt's diaries are certainly composed in that way. In Will Bird's continuous mention of the snipers, or of Samuel Laycock's constantly chattering machine guns, or the shelling that never seems to abate in Private Charles Robert Bottomley's diary ${ }^{218}$ _each contribute to this sense of a violence which supersedes their every efforts to quell it. It is no wonder so many called it hellish, in its apparently irresolvable violence. Of course then the impossible happens on November $11^{\text {th }}, 1918$. Babbitt notes the event in his diary, along with so many others in his same situation: "Bosche Give Up." ${ }^{219}$ The war which had led to the deaths of some ten million people had simply stopped. The seeming impossibility of that moment of cessation is marked by a Cockney soldier, probably fabrication owing to his lack of a name and location, at the end of Will Bird's memoir. The soldier is approached by a monocled officer, there to inform the Cockney of the Armistice. The Cockney responds to the news by asking a simple, yet profound question: “Beg pardon, sir, but 'oo's won?"220 Like Sisyphus, Bird's character mocks fate with

\footnotetext{
${ }^{217}$ CWM, MHRC, 58A 1 237.8, Garnet Montague Babbitt, Diaries, 22 Aug. 1918 and 24 Oct. 1918, respectively, 20050165-060 to 061 .

${ }^{218}$ Respectively in Bird, Op. Cit., 123; Laycock, Op. Cit.; and CWM, MHRC, Charles Robert Bottomley, Diary entry, 9 Aug 1918, 58A 1 138.15, 19990037-001.

${ }^{219}$ Babbitt, Op. Cit., 11 Nov. 1918. Underlining in original.

${ }^{220}$ Bird, Op. Cit., 175.
} 
scorn, implicitly admonishing the officer's assumption that war might end so easily. The soldier is not even capable of conceiving of a clear resolution.

\section{What Hope!}

In 1942, the French philosopher, playwright, and novelist Albert Camus wrote $\mathrm{Le}$ mythe de Sisyphe, a long essay on the absurdity of a world that reveals very little to the observer, is a tapestry of shifting values, and contains little in the way of inherent meaning. Though written well after the First World War, Camus finds absurd themes throughout history, his most compelling example of absurdity being the myth of Sisyphus-a myth that quite nicely articulates the experiences of the soldiers in their holes in the ground, as I have shown. Anticipating Paul Virilio's later arguments of activity-as-stasis, Camus sees Sisyphus in the same lamentable condition as that which we find the soldiers in the trenches. They toil, they labour, and their concepts of temporal and spatial dynamics are severely muted: the eternal presents itself as an eternal present. Stephen Kern has observed in his landmark survey, The Culture of Time and Space, 1880-1918, that combatants on the Western Front overwhelmingly describe "a contraction of consciousness that took place as one approached the front, fixing spatially on an ever narrower visual sphere and focusing temporally on the present," rather than the concepts that emphasized continuity from past, through the present, and into the future. ${ }^{221}$ Similarly, albeit with a typically poetic flourish, Camus states of Sisyphus: "A face that toils so close to stone is already a stone itself!",222

\footnotetext{
${ }^{221}$ Stephen Kern, The Culture of Time and Space, 1880-1918 (Cambridge, MA: Harvard University Press, 2003 [1983]): 293-4.

${ }^{222}$ Albert Camus, The Myth of Sisyphus, Justin O'Brien, trans. (Toronto: Penguin, 2005 [1942]): 117.
} 
Truly, the image of hellishness on the Western Front moves far beyond the atrocities of the landscape, the blurring of states of life and death, or the incessant, infernal drumming of the guns. The ostensible intelligibility of the war experience was thoroughly upset by trench life, resulting in the need for a language to describe not only the soldiers' surroundings but also their experiences. "Hell" seems appropriate for the soldiers' use, because it is as much a geo-physical descriptor as it is an experiential trope, hinging upon cyclical torment taking place within a given, violent environment. Though it requires more careful readings of the soldiers' words, the evidence that soldiers saw their experiences as hellish is located in their insistence on degrees of discomfort, levels of severity of combat, and the seeming endlessness of their travails. Inquiring after Sisyphus's fate, Camus may as well have been writing about the soldiers in the trenches when he asks: "Where would his torture be, indeed, if at every step the hope of succeeding upheld him?? ${ }^{223}$ This is perhaps the most critical question of all and one which, while not invalidating the analysis of hellish conceptualization by the soldiers, nonetheless complicates matters enormously as we move into the next chapter. Still, the words of a French alpine officer provide some understanding of how this torture is resolved when he writes:

Je me rappelais cette chanson de marche dont l'air est fastidieux comme la marche elle-même, et que chantaient les sapeurs d'un régiment venant de l'Est, devant prendre garnison à Saint-Nazaire. Ils interrogeaient les passants étonnés afin de savoir où se trouvait ce paradis que jamais ils n'atteignaient. L'écho même ne savait que leur répondre :

Où est donc Saint-Nazaire?

${ }^{223}$ Camus, Op. Cit., 117. 
Répétait l'écho indécis.

C'est peut-être au bout de la terre,

A moins que ce n'soit par ici.

Et moi-même je répétais toute la nuit, en balançant la tête, l'esprit incapable de formuler une autre idée : 'Où est donc Saint-Nazaire?... ${ }^{224}$

In the anonymous officer's words, one finds not only the Sisyphean sensibility mentioned above, but also a means of disrupting it, anticipating Camus's arguments. Implicit in the practice of perpetual inquiry located at the centre of the above passage is a practice of resistance despite the futility of the search for the mythological town.

A new series of questions must be raised. What if futility and hopelessness are not mutually inclusive terms? What if the sense of a spatial and temporal contraction, as Kern posits, is a perceptual fallacy easily broken by a little creativity? What if the distinctly temporal dimension of hope does uphold the soldier, making him "superior to his fate" and "stronger than his rock" as Camus envisions Sisyphus—a heroic figure, rather than tragic? $?^{225}$ There is much evidence to suggest that despite extraordinary violence, despite the boulder-like burdens of trench life on the Western Front, many still managed to smile, just as Camus imagines Sisyphus in the moment before the boulder its inexorable descent back to the base of the hill. This is the parallax view of trench life. While this chapter has attempted to address one particularly powerful expression of violent discontinuity, the following chapter addresses several articulations of resistance to the violence of the front.

\footnotetext{
${ }^{224}$ Translation: "I remember a marching song whose air is as fastidious as the march itself, and was sung by the sappers from a regiment coming from the east before being garrisoned at Saint-Nazaire. The inquired with every stunned passerby in the hopes of finding this paradise they would never attain. Their echo, even, knew only how to answer with: 'Where, then, is Saint-Nazaire? / The indecisive echo repeated. / It's perhaps at the edge of the earth / As long as it's this way.' And myself, I repeated it all night, while bobbing my head, my spirit incapable of formulating another idea: 'Where, then, is Saint-Nazaire?...'." Anonyme, Carnet de route d'un officier d'alpins, Vol. 1 (Paris: Berger-Levrault, 1915): 58-9. ${ }^{225}$ Camus, Op. Cit., 117.
} 


\section{Chapter Four:}

\section{Appropriation and Differentiation, or The Self Separated from Violence}

In a well-known film—albeit one not commonly deemed a "war film" per se-a depiction of the First World War battlefield is represented as one might expect: shell craters, barbed wire, and broken equipment adorn a generally barren landscape. The cinematic depiction allows the spectator to perceive what the soldiers, soon to appear on screen, would only rarely have seen firsthand, as I have argued in Chapter Two. There is nothing particularly revolutionary about the scene's iconography of the trenches; in fact, it could well be the set for one of any number of classic First World War films. But All Quiet on the Western Front this is not. No, instead the comedic troupe, Monty Python, had set out to make a film about life, appropriately titled: The Meaning of Life (Terry Jones and Terry Gilliam, 1983). The scene is notable not for its depictions of the battlefield, or for its semi-serious claims about the centrality of conflict even in ostensibly civil societies, but rather for its representation of people continuing to live despite the terrifically violent setting in which they are immersed.

Perhaps it is a cardinal sin to take seriously anything Monty Python does, yet the spatial inferences made by the comedians are profound even if they are disguised by an absurd surface. It is precisely for the reason of life that this film is significant in this chapter's opening remarks, and especially because it situates a discussion of life within a setting that most people, quite reasonably, tend to associate with death. In the scene, a British officer played by Terry Jones is about to lead his men on what appears to be (yet another) futile raid, evident by a private suggesting to the Jones character that it is likely 
they will all die. Prior to mounting their ultimate action, then, it seems the soldiers have decided to express their appreciation for all of their officer's niceties-part of an oblique jab at his leadership skills - right there in the midst of combat. Part of the humour is derived, quite obviously, from the very idea that such an exchange would take place in No Man's Land, the chatter of soldiers' camaraderie standing out against the chatter of the guns. Perceived silliness aside, it is the presentation of several gaudy clocks that is remarkably clever. Firstly, a man ostensibly facing certain death-repeatedly iterated throughout the scene- - has no need for any new timepiece when his time, so to speak, is up. Also, skimming past the notion of gifts as objects of memory, they also symbolize the very notion of continuity so easily disrupted by high explosives. The absurdity of the rhythmic 'tic-tocking' of time passing by stands in stark opposition to the 'kerrump' of shells, even if this juxtaposition must be audience-supplied. Yet another ridiculous scenario is presented as the Eric Idle-played private now presents a lemon-almond cakeperfectly iced!- just after being shot through the neck, but not before withering away. The soldier played by Michael Palin then upbraids the incredulous officer for not appreciating just how long it took to scrounge for the ingredients and then melt the butter in a frozen trench at "fifteen degrees below zero, sir!" A card is also given, to complete the image of the most bizarre "office" party imaginable.

So not only have the Python troupe presented us with a perfectly hyperbolic image of persistent humanity in even the worst of situations, they have also raised another fundamental matter in our understanding of war space: it is not all about killing and death even if, as the Idle character states when handing over the card, one must occasionally "mind the blood, sir." The Pythonesque portrayal of life in the battlefield is 
complimented by a clear invitation for the spectator to picture the Idle character in his filthy khakis, churning butter amidst the ruins, and thereby transforming the space of violence into a space of domesticity, replete with harmless (and delicious!) creature comforts. The scene ends with most of the soldiers dead or dying, but they have had time to set up a table, complete with pristine table cloth that stands prominently and persistently against the skyline, a symbol of nourishment and intimacy that undermines the brutality of the scene.

There are three principle historical concerns to take from this scene, all related to the represented space of violence in which they occur, and for which there are ample supporting records from the period being depicted. In order, these concerns are viewing war and violence as a spectacle (which is located in the scene's viewer), the development of a context-specific material culture (such as the pursuit and procurement of luxuries in a theatre of war), and the conflicting soundscapes of war (their social formalities contrasting with the disruptive sounds of explosions). The first matter to be considered is the spectacle of war, which I will argue is a process of soldiers distancing themselves from violence and thus imagining themselves as separated from it at various points, even if total physical separation from violence was nearly impossible (as the scene clearly depicts). There is obviously a geo-physical distance involved in any established spectatorial distance, yet it is the psycho-social act which concerns me, one which constructs violence as, in the soldiers" parlance, a "big show" or "fireworks" when the soldiers in the trenches knew firsthand the implications of a targeted barrage. The second matter concerns the appropriation of the materiel of war, and especially when these objects were used for domestic comfort, for decorative purposes, or generally to give an 
object of violence a meaning beyond its specific intent. The final matter to be considered is that of the sounds of war, and specifically looking at singing and laughter as the aural antithesis of the soundscape of the trenches and its constant significations of death and destruction. In singing, like in a large variety of trench art and other forms of material transformation, and also likening to the notion of spectatorial distance from violence, one encounters a recurring theme of differentiation from the violent space of the trenches and an affirmation of spaces of life that stress harmony over disharmony, and creativity over destruction.

My intent in this chapter is to show the subtle connections amongst these myriad practices in the hopes that they prove to be a fertile ground for further expansion. Recall that the previous chapters were concerned with a set of material conditions in the trenches that promoted radical limitations to perceptual spaces. From this setting arose a new science of killing that saw total destruction as a viable solution to the problems of waging war under such conditions, and all the while perpetuating the alienation of the human element from the battlefield. A distinct social response arose as a result of these conditions: that of a hellish space punctuated by seemingly endless violence, futile labouring, and destruction. Within this same environment, however, arose the antithesis of violent, paradoxical continuity (that is, perpetual discontinuity at the hands of modern armaments). That persistent human spirit, which emphasizes connectivity, creativity, collectiveness, and most importantly continuity forms the bulk of this inquiry, and the items listed above are chosen because they all, in their own subtle ways, contribute to these sentiments. The one item that makes such an analysis possible, and the reason it is first in this analysis, is the idea of establishing distance from the violent event. 


\section{$\underline{\text { Spectatorship and its Limits }}$}

This section is concerned with the act of viewing violence from a detached experiential space, rather than from the same space in which the violence is occurring. This act of spectatorship often invoked by the soldiers in the First World War (as it may be for other discrete, non-war situations) is a distancing mechanism, albeit of a psychosocial type. When one speaks of "distance," it is typically in terms of empirical measures: inches, metres, miles, and the like. Indeed, these measures form much of the underpinnings of strategic visions of the battlefield as mentioned in Chapter Two, and these sorts of empirical measurements must invariably play a role in any act of observation. ${ }^{226}$ Yet as I have discussed in Chapter Three, it was very difficult to sever oneself from the experience of violent conflict in terms of geo-physical measurements, primarily owing to the pervasiveness of the rumbling guns, the soldiers' aching bodies recalling their brutal labours, and any number of other tangible reminders of the participants' situation. The soldiers, at a social and psychological level, remark frequently upon the intrusions of the guns into their lives, even when they were not in immediate danger of bombardment. Rather, it is an internalized model of "distance" that will be addressed in this chapter; in this particular section, I will elaborate a theory of mental distancing that I will argue was necessarily part of the soldiers' experiences as much as their "proximity" to violence was articulated in the previous chapter through their nearconstant articulation of the suffering they had to endure. ${ }^{227}$ In the iteration of the dream-

\footnotetext{
${ }^{226}$ By its very nature, "observation" implies a distance between observer and observed object; otherwise, one is dealing more with "reflection" or some similar term.

${ }^{227}$ I consider that "suffering" is implicitly tied to matters of "proximity" for two reasons. The first is that suffering inflicted upon the self is inherently close to the self; without the immediacy of the sufferingcausing agent in relation to the self, there is no suffering of which to speak. Pushing the matter still further, we could also consider that observing the suffering of others can be taken upon the self quite personally. While the self might not "feel" the sensations of violence inflicted upon the victim, the empathic response
} 
like, cinematographic, spectacular, or show-like qualities of war, one is presented with a consistent theme of an observer looking upon a performance of sorts. Taking the position of a spectator to the war, many soldiers actively constructed a psychological distance from the horrific events of war to which they were exposed. This act of psychological detachment accompanied what would have had to have been a geo-physical, observational distance as well. As a result, the soldiers established a sense of separation from the actions of which they were frequently a part (and thus transforming "a part" into “apart”).

When dealing with human perception of an event, observing the "spectacle" of war in our case, there is much debate on the most useful mode of analysis. In Film Studies, for instance, spectatorship has been part of the central discourse since the invention of the cinématographe. As such, the discipline is well-developed in spectatorship studies and marks a logical point of departure for such considerations as the "spectacle" of war. Despite a myriad of perspectives, two principle schools of thoughtpsychoanalysis and cognitivism—emerge as dominant approaches. ${ }^{228}$ The first is from the Lacan-influenced philosopher Jean-Louis Baudry, who is the apparent driving force

can nonetheless promote "feelings" of violence in a different way. Further still, the memory of violence experienced is rarely totally purged from the psyche, and so even time does not necessarily distance the self from violence inflicted upon the self; for psychologically traumatized victims of violence, the reliving of the trauma(s) is akin to experiencing them repeatedly, and thus is a thoroughly intimate affair even when the original experience is long past.

${ }^{228}$ There are other modes of analysis that eschew altogether or at least significantly modify these two dominant strains of spectator theory; philosopher Gilles Deleuze's work on cinema is a notable example, though it too has borrowed extensively from psychoanalytic Marxism. In the interests of simplicity, cognitivism and psychoanalysis provide enough of a framework for my notion of spectatorial distance that they need not be overly complicated by, for instance, Deleuzian concepts of mind-film interactions. For various interpretations of Deleuze's work on cinema, see Gregory Flaxman, ed., The Brain is the Screen: Deleuze and the Philosophy of Cinema (Minneapolis: University of Minnesota Press, 2000). Other significant approaches to cinema are found in the American school of analytic philosophy-especially Stanley Cavell's extensive work on film-and also in the Frankfurt School theorists (Theodor Adorno and Siegfried Kracauer being the most prominent, spectacle-engaged theorists, but see also Max Horkheimer and, to a lesser extent, Walter Benjamin). 
behind Apparatus Theory, ${ }^{229}$ and American film theorist David Bordwell, whose work in cinematic cognitivism in recent years incorporates more neuroscience than it does film theory. While Bordwell's and Baudry's approaches differ, they both express a mutual interest in a viewing apparatus. The "apparatus," for these theorists, consists of the interactions between a viewing subject (here, referring to the "the perceiving and ordering self" of Freudian origins), a limitation imposed upon an ostensibly "objective reality" through the production of a visual work, the projector through which the realityinscribed celluloid is passed, the camera which in a deliberately restricted fashion transcribed the "reality" on to celluloid, and finally the objective reality itself. ${ }^{230}$

For Baudry, there is an ostensibly ideological function to this "work" being performed by the apparatus, and that is to reinforce the dominant cultural ideology of the space in which the apparatus operates. ${ }^{231}$ In other words, Baudry suggests that the apparatus is designed to facilitate the promotion of an ideology, selectively yet invisibly chosen through its operation, and then to implant that selectively produced ideological object directly into the psyche of the viewing subject. In essence, the theory is concerned with a notion of intimacy between the various components of the apparatus as a whole, all of them working together to promote a result (in Baudry's case, ideology, and

\footnotetext{
${ }^{229}$ Apparatus Theory has a myriad of applications stemming from French neo-Marxism of the 1960 s, which is why I cautiously term Baudry the "originator" of the theory-at least in the context of film studies. The concept of an "apparatus" was circulating widely at the time of Baudry's use of the term, and in an extrafilmic context is most notably used by Louis Althusser to describe state-run institutions in his seminal essay, "Ideological State Apparatuses." Regardless, Baudry is the first to acknowledge the presence of a cinematic apparatus, and appears to have been the first to elaborate upon its structure.

${ }^{230}$ Jean-Louis Baudry, "Ideological Effects of the Basic Cinematographic Apparatus," Alan Williams, trans., Film Quarterly 28, no. 8 (Winter, 1974-5): 40.

${ }^{231}$ These notions of dominant ideological structures are primarily the work of French Marxist philosopher and critic, Louis Althusser, whose seminal work in the 1960s and 1970s on the institutional promotion of state ideologies has profoundly affected Western society and permeated virtually every academic discipline dealing with culture or society. Althusserian Marxism essentially posits that social factors primarily affect personal choice, occasionally (and rather tautologically) suggesting that choice is no choice at all. For more details, see Lenin and Philosophy and Other Essays, Ben Brewster, trans. (New York: Monthly Review Press, 1971).
} 
specifically Capitalist ideology in Western society). While Bordwell rejects the "passivity of the spectator" in the structural, psychoanalytic model of spectatorship, ${ }^{232}$ he explicitly posits a synthesis between filmic creation and the viewer's comprehension of that construct. ${ }^{233}$ In other words, Bordwell substitutes passivity for activity, but in so doing he leaves a significant problem unaddressed: the proximity of viewer and viewed event. In both Baudry and Bordwell, there is virtually no space between spectator and event. In one, the spectator is an ideological stooge; in the other, the viewer eagerly seeks to comprehend the narrative and so becomes purposefully immersed in the product.

The major error made by Baudry and Bordwell is that they each assume a theory of spectatorship can be elaborated by looking at the viewed object or event, rather than by looking at the spectator him- or herself. They cannot account for the spectator who rejects, either consciously or unconsciously, what he or she sees. ${ }^{234}$ As we have seen in the last chapter, it is quite possible for an event or set of events not to be comprehended in a manner intended by the authorial figures (in this case, one might speak of recruitment rhetoric, grand strategy, the language of command, and so on). Though Bordwell and Baudry are specifically film theorists, the matters they address are about the broader relationship between viewer and viewed object or event. Bordwell and Baudry's flawed conclusions result from their respectively idealized spectators, rather than in their understanding of an apparatus of sorts. Focusing on the apparatus allows us to move beyond the cinema and into any structured environment, of which the Western Front is

\footnotetext{
${ }^{232}$ David Bordwell, "The Viewer's Activity," Narration in the Fiction Film (Madison: The University of Wisconsin Press, 1985): 29.

${ }^{233}$ Ibid., 32.

${ }^{234}$ As a point of fact Baudry, among the other apparatus-oriented neo-Marxists like Althusser, claim they can account for such forms of rejection: they would argue that rejecting the product of the apparatus is equally part of its trickery and the invisible work of the apparatus. In other words, buying into the ideology of the apparatus or rejecting it amount to the same insidious process. This claim of being right even when they are wrong, so to speak, has been one of the central critiques of neo-Marxist apparatus theories.
} 
one (as was argued in Chapter Two). Additionally, rather than relying on an imagined soldier implicated in the apparatus of trench warfare-simply a system of perceptual limitations, authorial control, and perceiving bodies occupying a single conceptual space - we can turn to the ample testimonials they have left behind to better understand their spectatorial position.

Beyond passive and active engagement with an observed event, however, is a third option in which competing narratives can occupy and even undermine the same discursive spaces as dominant narratives. In other words, there is yet an opportunity for any spectator's active disengagement from the perceived event. While Baudry and Bordwell emphasize the proximity implicit in viewership, one must also consider that there is always a very real, physical distance involved in spectatorship, in addition to an immense capacity for psychic distancing from an event. There certainly is far more of an active perceptual process at work in the act of spectating than Baudry generally gives credit for in his theory, but that activity need not be in the service of comprehension of events being perceived, or even be about constructing some intended narrative. The observer may opt for pure observation and a deliberate separation of self from the event as intended, anticipated, or otherwise deliberately structured. In the words of historianphilosopher Michel de Certeau, a lone soul looking down upon the city of New York from a $110^{\text {th }}$ storey observation deck in the World Trade Centre (WTC, now destroyed) has exercised one's capacity for self-extrication from New York's "gigantic rhetoric of excess" that "carries off and mixes up in itself any identity of authors or spectators.",235

\footnotetext{
${ }^{235}$ Michel de Certeau, The Practice of Everyday Life, Steven Rendall, trans. (Berkeley: University of California Press, 1988): 91-2.
} 
Certeau situates his discussion in both a physical and psychological space, but the allegorical strength of Certeau's remarks is noteworthy for the concept of choice. The soldiers, unlike the WTC visitor who chooses to ascend to the heights of the cityscape, have no choice but to be in the space of war. In the soldiers' cases, too, they are rarely ever in a position akin to Certeau's observer. Rather, they are almost invariably in its inverse position: the gutters, the pits, and the sewers. And yet I would argue the soldiers, like Certeau's observer, manage to enact a similar discourse of self-extrication in their viewings of the violence of war. For example, many soldiers likely could not extricate a discourse of beauty from the terrific ugliness of killing forces-a "rhetoric of excess" if ever there was one-without a major psychological and reconfiguring gesture on the part of the observer. More than self-extrication, the soldiers deliberately enact a form of distancing from the violent space in their assumption of a spectatorial gaze. The difference between Certeau's and my use of this concept is that the WTC observer makes the choice to return to the city-trenches; the soldier does no such thing. The conditions of war absolutely—and likely traumatically—ensure the re-entry of the soldier into the violent space, its near-instantaneity annihilating empirical distance. The soldier's disengagement, through an act of spectatorial distance, is thus enacted as a primarily psychological gesture which establishes a localized space of observation, differentiated from the space of war.

The intended narrative of war, grounded upon violence enacted in a given space for the purpose of killing one's enemy, is subverted in this distancing from the event. The words of a British Lance-Corporal, Harold Sandys Williamson, express exactly this achievable vantage point when he writes: 
I was gazing down on Sanctuary Wood, where we had lain two days ago, and on Zillebeke, now as ever under bombardment. I could see the white road stretching away until it vanished towards Ypres... the plain below still shimmered in the sun. Men moved mere specks on the landscape, and, far away, lorries on the roads were being shelled. I noticed that nothing could move unseen by me, and I realised that I sat where for years the enemy had sat and observed our every move in the fatal Salient. ${ }^{236}$

Williamson's position is exceptional in that it is, like Certeau's observer, a rare convergence of both physical and psychic extraction from the field of war. In this described moment, Williamson is struck by a clarity previously unattainable from being on the receiving side of the German shells. This vantage point, as Certeau might say, "allows one to read [his surroundings], to be a solar Eye, looking down like a god ... the fiction of knowledge is related to this lust to be a viewpoint and nothing more. ${ }^{, 237}$ It is hard to miss the implications of omnipotence, and all its rejection of the bodily related sufferings of that awful place, that "hell" of the trench lines. But the "lust" to be a nothing more than a "viewpoint" is a desire, not an actuality. Yet even as he acknowledges the continued violence in the space of war, Williamson explicitly differentiates himself from those figures below, as well as from his past position among them. In Williamson's testimony one encounters distance, differentiation, and displacement-all located still within a space of war, and all abundantly employed by other soldiers and observers in the trenches.

\footnotetext{
${ }^{236}$ IWM, The Fatal Salient, Harold Sandys Williamson, manuscript, Aug-Dec 1917, online exhibit. Online: http://london.iwm.org.uk/upload/package/45/FatalSalient/fww-art4.htm. Last accessed: $12 \mathrm{Apr}$ 2010.

${ }^{237}$ Certeau, Op. Cit., 92.
} 


\section{Violence By-Passed / Passed By}

The soldiers of the trenches, occupants of that highly organized and perceptually limiting military space of modern warfare, were as institutionally controlled as Certeau conceives of the masses in streets-a notion at the core of this thesis's second chapter. Yet while attaining the heights of a ridge line, as Williamson did at Ypres, might cause a sudden onslaught of self-extricating reflection upon one's situation past and present, the barren wasteland of No Man's Land could provide ample reflexive space for the soldier lusting for observational purity. Is it any wonder, in this environment, that historian Richard Holmes has observed a tendency for soldiers to recall their experiences as having a "dream- or film-like quality, like clips of film assembled haphazardly from the cuttingroom floor?" Holmes cites Marc Bloch's description of war as "a discontinuous series of images ... like a [poorly edited] reel of movie film," as well as British Field-Marshal Alanbrooke describing the attacks on the Somme as feeling "as if one was in a dream, or that one was watching some extraordinary cinematograph film, and that it could not all be true.,"238 The key word is "watching" in Alanbrooke's testimonial, with both he and Bloch implying a moment of the self looking upon a representation of the self. While it may appear contradictory to employ the metaphor of a dream and the cinema interchangeably, there is a similarity between the two insofar as each tends to concern an external framework of observation. In Alanbrooke's case, it is clear that he is engaged in a state of immediate reflection, the intellectual self has been extracted from the setting, observing the physical self within it.

\footnotetext{
${ }^{238}$ Richard Holmes, Firing Line (London, UK: Pimlico, 1994): 156. Holmes gives no specific citations for Alanbrooke or Bloch, though Bloch's quote may be found in Memoirs of War, 1914-15.
} 
What seems clear in each of these soldiers' observations, as in others to follow, is neither the active engagement of Bordwell nor the passive absorption of Baudry. Rather, Bloch and Alanbrooke are involved in a form of active disengagement or divorce from the events to which they are forced to attend. In essence, through the act of adopting a spectatorial vantage point to the events, whether dreamlike or cinematic or simply spectacular (i.e. having a show-like quality), these observers enact a distance and differentiation from immediate participants-themselves included, it seems-in the events they are observing. Rather than total participation, Bloch and Alanbrooke among many others appear instead to have adopted a quasi-participatory stance, akin to being in the auditorium during the show, implicated in the spectacle, but not being an actual player in the immediate and enclosed performance space. This is not to suggest that soldiers did not participate in combat, did not feel the concussion of shells in their vicinity, or otherwise achieve some true, physical separation from the events. Still, one must recall that from a sensorial perspective, empirical distance was often little comfort as the sounds and smells of the battlefield were ubiquitous and far-ranging. Thus, one must consider the metaphysics of distance, and not merely physics. As such, one must bear in mind that, at various critical moments, the soldiers do appear to psychologically separate themselves from the violence to which they are so regularly exposed, thereby adopting a self-preserving fortress amidst the ruins.

The transfiguration of war space into show space occurs in three significant ways: those who praise the spectacle, those who fear it, and those who seem ambivalent toward it. The ideas of distance from the violent event are most objectively articulated in the last of these sentiments, and so they make a good starting point. War correspondent Frederick 
Palmer, as a regular visitor to the front lines, reports that in his experiences being in the French trenches he had seen his fair share of firing. Bombardments created a "landscape bathed in smoke and dust and reverberating with explosions; but all as a spectacle from the orchestra seat, not too close at hand for comfort."239 Palmer's role as a paid spectator rather than a participant in military actions complicates his testimony to a point, of course. Regardless, his remarks are not unique in their insistence upon the space between bursting shells and himself, as though the action is taking place in an auditorium and he is merely a spectator. A French soldier, Joseph Hassler, employing still more evocative language, states in a letter sent home on July $14^{\text {th }}, 1916$ from the Somme: "hier soir, le spectacle de toutes les batteries bombardant l'ennemi était féerique." ${ }^{240}$ Literally translated, the word "féerique" means "fairy-like." Given the previous references by Palmer, Alanbrooke, and Bloch, the more likely it is that Hassler is not merely suggesting an unreal quality to his experiences (as though "unreal," itself, is not a profound expression of spatial separation from "objective reality"), but is rather situating the bombardment outside of the realm of his own existence and positioning it in a land of fantastic occurrences beyond Hassler's immediate reality. Not merely unreal, the spectacle of bombardment is otherworldly; Palmer's allusion to a darkened orchestra seat opposed to the lighted action on stage is similarly evocative of two separate spaces.

This notion of observing bombardments as something outside of the soldier's inhabited realm might sound somewhat akin to the hellishness described in the previous chapter, and undoubtedly hell should be understood as an otherworldly conceptual space.

\footnotetext{
${ }^{239}$ Palmer, Op. Cit., 276.

${ }^{240}$ Translation: "Last night, the spectacle of all the batteries bombarding the enemy had an unreal appearance.'Joseph Hassler, Ma campagne au jour le jour (Paris: Perrin et $\mathrm{C}^{\mathrm{ie}}$, 1917): viii. Online: http://www.archive.org/stream/macampagneaujour00hassuoft\#page/n11/mode/2up. Last accessed 12 Apr 2010.
} 
Still, in many instances soldiers erect a distance between themselves and the perceived awfulness of trench warfare. Theirs is a process of differentiation between the self as observer and the naked intimacy of the self-and more often others-in an awful space. Many soldiers quite explicitly convey the terrible quality of the explosives but, metaphorically speaking, they do so from afar. Describing casualty clearing, Charles Henry Savage writes: "If a big show [a battle] was on with a great number of casualties coming through, many with quite slight wounds would be rushed straight to England to make room for new casualties. ${ }^{241}$ Savage, a member of the Canadian Mounted Rifles and not a member of the medical staff, combines a casual detachment from the injuries suffered by colleagues with a description of battle as a "big show." This combination articulates a real understanding of degrees of hurt, and as a result what it means to be hurt, while he also differentiates himself from those soldier-performers engaged in the "show."

In far more explicit terms, the previously mentioned Harold Sandys Williamson expresses his fear of the horrors of war, even while enacting a distance in a manner somewhat akin to Savage. Williamson writes in an unpublished manuscript, written between August and December of 1917, of the period preceding an attack: "Once more something malevolent hung in the air. In all that great amphitheatre no sign of life showed itself above ground." ${ }^{242}$ It is remarkable that Williamson employs "amphitheatre," a term that is better suited to describing a playhouse or a place of open-

${ }^{241} C L I P$, Charles Henry Savage, Op. Cit. (no dates given).

${ }^{242}$ IWM, The Fatal Salient, Harold Sandys Williamson, manuscript, Aug-Dec 1917, online exhibit. Online: http://london.iwm.org.uk/upload/package/45/FatalSalient/fww-art4.htm. Last accessed: $12 \mathrm{Apr}$ 2010. 
air spectacle - this was not a term in common usage to describe a locale of conflict. ${ }^{243}$

Instead, Williamson speculates upon the space as an external observer might. When he states that "no sign of life showed itself," he is expressing knowledge that cannot be known by those on the ground and by extension, himself. Thus, he imagines himself in an idealized narrator's position, above or external to the battlefield. Thus a separation is created between himself and those other soldiers concealed in the landscape. In another case of similar differentiation, British soldier J.C. Tait simultaneously worries about his comrades facing a bombardment, but still calls the explosions a "pleasing spectacle."244 Williamson and Tait's articulations of this separation are linked through the self in relation to the violent space, rather than through their companions (especially true in Tait's case). The central matter is that neither Williamson nor Tait include themselves in the violence to which those around them are exposed.

A further example of this same type of expression is found in the memoir of British war correspondent Phillip Gibbs, who writes: "I had been scared awhile because death was on the prowl in a noisy way and I had seen it pounce on human bodies. I knew that to-morrow I was going to another little peep-show of war, where I should hear the same noises." 245 The reference to a "peep-show of war" is quite evidently about being an external observer, but this is emphasized by Gibbs's employment of the senses of sight and sound. He has quite remarkably omitted the sense of touch, meaning his contact with

\footnotetext{
${ }^{243}$ According to the Oxford English Dictionary, the term "theatre" to describe a "particular region ... of the world in which a war is being fought" is very much a contemporary term, with Winston Churchill employing it first in a letter dated 15 Oct 1914 to describe the Western Front (he called it the "Western Theatre"). Online: http:// dictionary.oed.com.proxy.library.carleton.ca/cgi/entry/50250420/50250420se11?single=1\&query_type=wo rd\&queryword=theatre + of + war\&first= 1 \&max_to_show $=10 \&$ hilite $=50250420$ se 11 .

${ }^{244}$ IWM, P 315, J.C. Tait, Diary, 23 May 1916. Quoted in Jessica Meyer, Men of War: Masculinity and the First World War in Britain (New York: Palgrave Macmillan, 2009): 55.

${ }^{245}$ Philip Gibbs, Now It Can Be Told (New York: Harper \& Brothers, 1920): 12.
} 
violence is anticipated to be perceived by means of sensorial distance as opposed to the closeness of the body. In another case of these spectacularly terrible depictions, Alan Seeger writes of a town in France he and his companions passed through in 1915:

[No] scene of ruin that we passed through exceeded the spectacle that met our eyes here. There had been no conflagration in C-----, ... [but] there was literally not a house that had not been riddled with shrapnel or disembowelled by the deadly "marmites" that must have fallen on it in a perfect inferno of fire. ${ }^{246}$

Seeger not only speaks in terms of the imagery identified in the previous chapter"conflagration" and "inferno" being obvious hellish metonymies—but he simultaneously distances himself from that awfulness by encountering it as a "spectacle" for the eyes.

In most cases, it would seem that soldiers employing such terms as "spectacle" tend to do so in the way that recently commissioned British infantry officer Seabury Ashmead-Bartlett does when he states: "The hills round Morlancourt have been literally torn to pieces by shell-fire, and the whole country-side presents a spectacle of terrible desolation." ${ }^{247}$ What matters in such expressions is the displacement of the violence, divorced from the self even while the self might yet observe the damage inflicted upon the region. In this case, Ashmead-Bartlett attributes the damage to shell fire to which he is a witness and little else; his description evokes images of a hastily emptied staging area, littered with debris. In combination with the above remarks, one gets the impression of a terrible performance by the big guns, who then act as their own cleanup crew. The "spectacle" to which Ashmead-Bartlett refers is self-effacing, with the aftermath as

\footnotetext{
${ }^{246}$ Seeger, Op. Cit., 57-8.

247 Seabury Ashmead-Bartlett, From the Somme to the Rhine (New York: John Lane, 1921): 12.
} 
awesome as the show itself. When Frederick Palmer speaks of the forty-thousand shells dropped on the Plateau D' Amance in 1915 and he describes "[kicking] up fragments of steel as peanut shells after the circus has gone, ${ }^{, 248}$ perhaps it is to this very indexical symbolism of the "big show" that he speaks.

Yet if many soldiers were awestruck by the spectacular capacity of the guns and their effects upon the ground, others were more interested in the extraordinary beauty of bombardments underway. In a rather startling about-face in tone, Ashmead-Bartlett, only a few short pages after his description of a "spectacle of terrible desolation" in the aftermath of a bombardment, speaks of another batch of explosions as a "magnificent spectacle — the night shattered by a thousand spurts of flame, and countless reports merging into a vast thunder of sound." ${ }^{249}$ The terrible desolation of his earlier remark seems to suggest a lament for the departed magnificence of the sights and sounds of war, rather than grief for the dead or wounded. At least in this situation, as long as the bombardment was not falling on him, Ashmead-Bartlett found it a stirring and stimulating event. The implications of Ashmead-Bartlett's testimony about the spectacular effects of war are profound, mostly owing to the distractedness of his vision. Rather than his eyes being drawn down to the trenches, and thus appreciating the damage done by the shells—-something he does only afterwards, but not during the bombardment- - his vision is instead drawn upwards. ${ }^{250}$

\footnotetext{
${ }^{248}$ Palmer, Op. Cit., 169.

${ }^{249}$ Ashmead-Bartlett, Op. Cit., 16.

${ }^{250}$ An obvious avenue of investigation of the phenomenon of looking skywards would be the soldiers' frequent musings on the airplanes flying overhead, to say nothing of the imaginative aesthetic war artists employed to depict this novel phenomenon (C.R.W. Nevinson's post-1916 oeuvre is one case). In the interests of focus, I have consciously omitted this issue as a discussion point, choosing to remain focused on the war on the ground. Nonetheless, the air war and the frequent duels overhead certainly entertained the troops on the ground, though this discussion has been covered elsewhere, such as in Jonathan Vance's High Flight: Aviation and the Canadian Imagination (Toronto: Penguin Canada, 2002).
} 
The "thousand spurts of flame" and other flashes and flickers above the trenches were quite commonly described by soldiers in the trenches as "fireworks," and thus they became associated with these ancient decorative explosions. Canadian Robert Hale, in a letter dated October $22^{\text {nd }}, 1915$, describes a bombardment taking place at night: "The guns are going some tonight. The star shells make it look very pretty at night. From a distance it looks just like a big firework show. It is quite a sight to watch them. ${ }^{, 251}$ Hale's comment is not isolated at all. Similar descriptive tropes are found in a letter from Walter Sutton writing about "how pretty the trenches are at night. It is just like fireworks," 252 just as they are located in Arthur Brooks's description of a bombardment as "really very fantastic and beautiful." ${ }^{253}$ Canadian war artist A.Y. Jackson, recalling in 1953 a painting he had completed in 1918 (Figure 16), described a gas attack on the German lines "like a wonderful display of fireworks, with our clouds of gas and the German flares and rockets of all colours." 254 Wilbert Gilroy goes so far as to say that these "fireworks" are "better than [the] Toronto Ex." ${ }^{, 255}$ It is extraordinary that Hale and the others employ such descriptions, given that fireworks are essentially the de-militarized application of a military technology, ${ }^{256}$ applied here to describe objects of violence in a distinctly military setting. In Gilroy's description, he even posits them as exceeding the amusement to be

\footnotetext{
${ }^{251}$ CLIP, Robert Hale, Letter to Alice, 22 Oct 1915. Online: http://www.canadianletters.ca/letters.php? letterid $=1443 \&$ warid $=3 \&$ docid $=1 \&$ collectionid $=123$. Last accessed: 20 Apr 2010.

${ }^{252}$ CLIP, Walter G. Sutton, Letter to Ed. Cochrane, 29 Oct 1915. http://www.canadianletters.ca/ letters.php?letterid=2866\& warid=1\&docid=1\&collectionid=205. Last accessed: 22 Apr 2010. ${ }^{253}$ CLIP, Arthur Brooks, "Letters from Men at the Front," Cobourg World, Letter to Margaret Brooks, 21 Apr 1916. http://www.canadianletters.ca/letters.php?letterid=2850\&warid=1\&docid=1\&collectionid=205. Last accessed: 22 Apr 2010.

${ }^{254} \mathrm{CWM}$, Canvas of War: Masterpieces from the Canadian War Museum, A.Y. Jackson, no source provided. Online exhibition: http://www.warmuseum.ca/cwm/exhibitions/canvas/1/cwd222e.shtml. Last accessed: 17 May 2010.

${ }^{255}$ CLIP, Wilbert H. Gilroy, Letter to Em, 1 Oct 1915. http://www.canadianletters.ca/letters.php?letterid $=1303 \&$ warid $=3 \&$ docid $=1 \&$ collectionid=120. Last accessed: 22 Apr 2010 .

${ }^{256}$ It is evident that the Chinese invented fireworks some two millennia in the past, with the technology achieving its real explosiveness some thousand years after that with the development of black powder for
} 


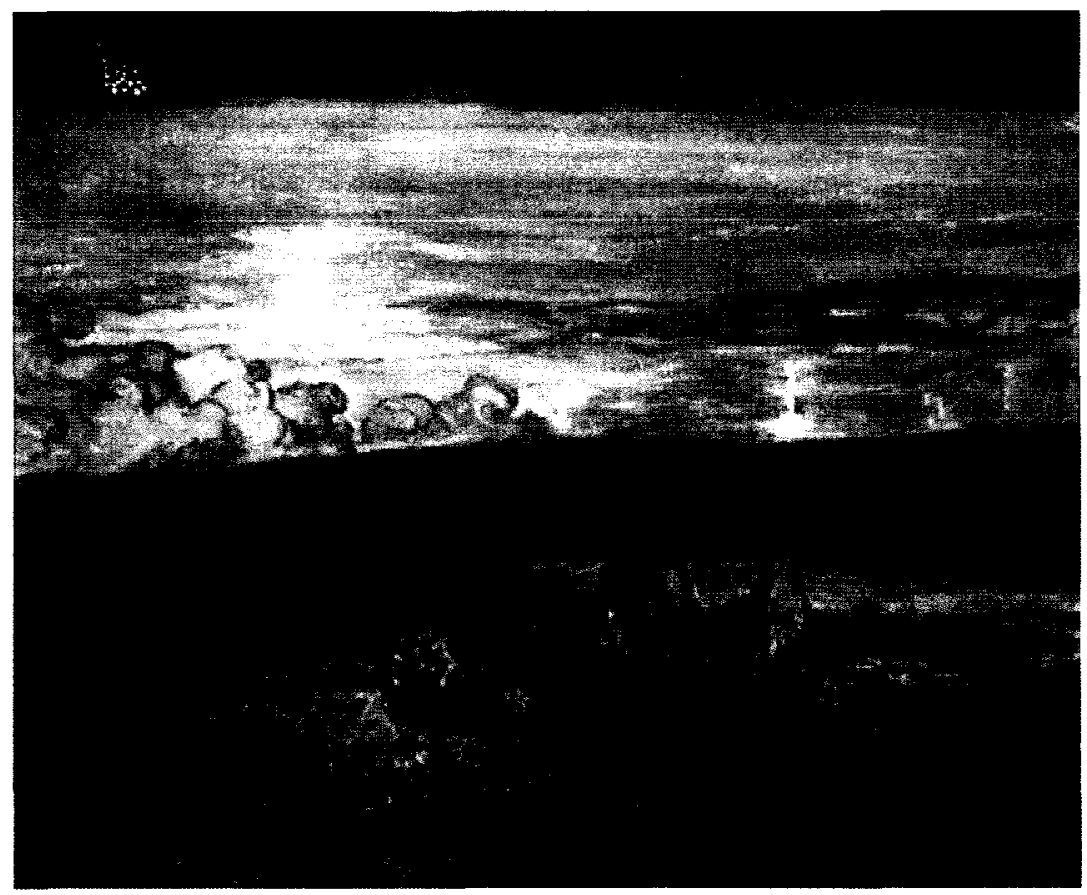

Figure 16: CWM, 197110261-0179, A.Y. Jackson, Gas Attack, Liévin, 1918, Oil on canvas $63.6 \times 77.0 \mathrm{~cm}$.

had at Canada's largest seasonal fair, thus locating them within an ostensibly harmless domestic sphere. Even describing the star shells as "very pretty" detracts from the pragmatics of the device: they were employed to illuminate terrain in order to destroy any enemy soldiers caught in the open. The star shells and the artillery, objects designed to facilitate or effect violence respectively, are stripped of their brutal nature and given feature roles in the "show."

This notion of the violent object as performer is rendered in almost absurd terms by the French describing their affection for the infamous " 75 " (the French army's $75 \mathrm{~mm}$ field gun, whose reliability and rapid firing capacity was a critical component of French defence). Jean de Pierrefeu, in a letter to L'Opinion in 1914, writes: frequently has been for military aims, such as signalling. 
Tout le monde est réconforté, le froid est oublié et l'angoisse de cette immobilité, se dissipe. Oh ! Quelle voix magnifique possède cette bouche d'acier ! J'ai entendu, renforcées par la sonorité des vallons des notes admirables, pleines, denses, vibrantes, une voix de bronze avec des timbres d'argent. Certes ! Je suis sûr qu'un musicien, rien qu'en entendant chanter cette voix prodigieuse, affirmerait que notre canon doit être le meilleur. $^{257}$

While Pierrefeu's expressions are as much to do with relief at having such an ostensibly effective counter to the German advance in the early stages of the war, it is his tone and the terms with which he describes the cannons' firing that are remarkable. As with Hale's comments above, the cannon assumes a central position in this description, and also similarly to the writings above, Pierrefeu stages the 75 as a performative entity. Rather than fireworks, he describes only the "voice" of the gun, as someone might describe an opera singer. Interestingly, it is based only on its "song" that Pierrefeu touts the 75's superiority to all other guns, and not its effectiveness against the enemy. The sound is comforting to Pierrefeu: it disperses the anguish of warfare and dispels the cold. Most importantly, in imagining these objects as spectacular, his sense of feeling trapped is shattered by a reinvigorated sense of dynamism.

The common theme in each of these descriptions—of fireworks, the operatic quality of the guns, or the simple spectacle of war-is that of an individual distancing

\footnotetext{
${ }^{257}$ Translation: "Everyone is comforted, the cold forgotten and the anguish of this immobility dissipates. Oh! What a beautiful voice this mouth of steel possesses! I heard, through the echoing valleys its admirable notes, full, dense, vibrant, a voice of bronze with silver tones! Without a doubt, any musician, hearing only such a prodigious voice, would affirm our cannon must be the best!' In Jean de Pierrefeu, Letter to L'Opinion, 3 Oct 1914. Online : http://www.grande-guerre.org/document.php?num=168. Last accessed: 20 Apr 2010.
} 
himself from the intent of the object itself. In several of the passages above, observers actually think in terms of watching a performance: they are spectators to a set of actions and nothing more. Such descriptions are evidently a restructuring of the event being described, amplifying the describer's detachment while diminishing the violence at the centre of the event; in short, the soldiers employing such descriptive tropes are appropriating and transforming the events by situating them in another, more fantastic space. To establish a space between objects or events is to differentiate, and not merely through the act of syntactical difference as in the act of constructing a narrative, but also through semantic choices. ${ }^{258}$ This is an oppositional stance that undermines the brutal, levelling violence of modern warfare-the barrage which erases indiscriminately, or else the strategic vision of war which reduces the living and breathing to mere enumeration on a page-and reinvigorates the individual, whose nakedness is so keenly felt in the trenches but whose eyes still see and whose mind possesses the immense capacity to reject and reinvent. Instead of simply being present to kill or be killed, which might appear to be the obvious narrative of warfare to the rank-and-file, these soldiers appear to be there to enjoy the sights and sounds, take in the show, and rave about its beauty as a cultural event. The intimacy and inevitability of violence which is implicit in the previous chapter is severely undermined in the process, though establishing oneself as spectator to an event is not the only means of transfiguring violence.

\footnotetext{
${ }^{258}$ This notion of narrative syntax as an inherently differentiating process is in Hayden White's "The Question of Narrative in Contemporary Historical Theory," The Content of the Form: Narrative Discourse and Historical Representation (Baltimore: Johns Hopkins University Press, 1987): 52. Some parallels can certainly be drawn between White's concepts above and Jacques Derrida's notion of differance, in which language attains meaning through its contextualization with preceding terms. In other words, narrative construction is reliant on differentiation in order to propel the narrative forward.
} 


\section{Material Transformation}

If soldiers could transform the violence of an artillery barrage into a fireworks display, an operatic performance or some other vague, spectacular form, it should come as no surprise that this tendency to transform the undesirable into the desirable could be manifested in many ways. Another way was through the alteration of war materials by turning them into practical or decorative objects-the latter practice being not unlike the idea of spectatorial distance, in that both are preoccupied with aesthetically transforming an event or object so it can occupy a new social or psychological space. War, as has been shown, is already bound up in converting all manners of spaces into military spaces. While this superficially simple matter has been discussed in some detail in Chapter Two, it bears repeating here in order to recall the manner in which a military, typically through a tangled set of accidents, imposes itself upon a landscape and its occupants. Dugouts, saps, fire steps, traverses, and so on—all are constructed as military applications.

As philosopher Arthur Danto observes, "battle thematizes certain features of the terrain, transforming them into what soldiers call 'ground." ${ }^{259}$ Thus, warfare effects a certain emphasis on some features over others; it gives them military purpose and assigns them military roles. There are spaces to be defended or captured, shelters from the enemy, and so on. Not often does this process of thematization, which is effectively the limiting and restructuring of one cultural space for another, consider the occupants' responses to inhabiting such a space. The Western Front, at least in the entrenched phase of early 1915 to early 1918 , is effectively located at the intersection point of two

${ }^{259}$ Arthur C. Danto, “Gettysburg," Philosophizing Art: Selected Essays (Berkeley: University of California Press, 2001): 242. 
contradictory cultures: military and civilian. ${ }^{260}$ The former appears to be a realm of killing and maiming one's enemy; the latter is woven through with living and the persistence of life. As such, it seems inevitable that such non-military persons might seek to re-appropriate from the military space a non-military or indeed anti-military space for themselves. Using what they had access to, many soldiers engaged in symbolic acts of spatial appropriation, one manner of which resides in the domestication or ornamentation of violent objects. ${ }^{261}$

Prior to an assessment for domestication or ornamentation, one must also consider some implications of ostensibly simple pragmatic appropriations of military objects. In the absence of any large-scale, consumer based material culture to which soldiers might have become accustomed at home-estaminets and canteens seem to cater to the transience of military life, rather than creating a diversified consumer base-so soldiers often created desired or needed items from what they had on hand. In many cases, the basics of comfort were provided by the remnants of those objects for which comfort appeared antithetical. For instance, Alexander McClintock states:

Hanging on a string, at the elbow of each sentry on the fire-step was a siren whistle or an empty shell case and bit of iron with which to hammer

\footnotetext{
${ }^{260}$ At a certain point, roughly in 1915 , virtually all regular armies of the belligerent nations were in need of fresh recruits. These recruits were invariably drawn from civilian sources, and are especially true of Britain and its colonial armies, which were tiny in comparison to the French and German militaries.

${ }^{261}$ There may well be other modes of exploring this topic, yet again for the sake of focus I have chosen these two. Also, it should be noted that soldiers certainly had access to materials from home, and that these materials formed an important part of trench life. However, this chapter-as with the whole-is primarily interested in violence and space, and so the focus remains upon objects related to violence rather than already domestic items.
} 
on it. This—siren or improvised gong —was for the purpose of spreading the alarm in case of a gas attack. ${ }^{262}$

This is a seemingly practical use of a discarded object, but employing an empty shell casing as a gas alarm is a subversion of the object's initial intent. Where once the object housed materials of violence — explosives, fuses, shrapnel, propellant—its emptied remains now housed the sound of anti-violence in its newfangled reverberations. One imagines a sound akin to a dinner bell (and in fact, this is how some are now used by collectors—see Figure 17), but this one sends soldiers scrambling for the nutritive

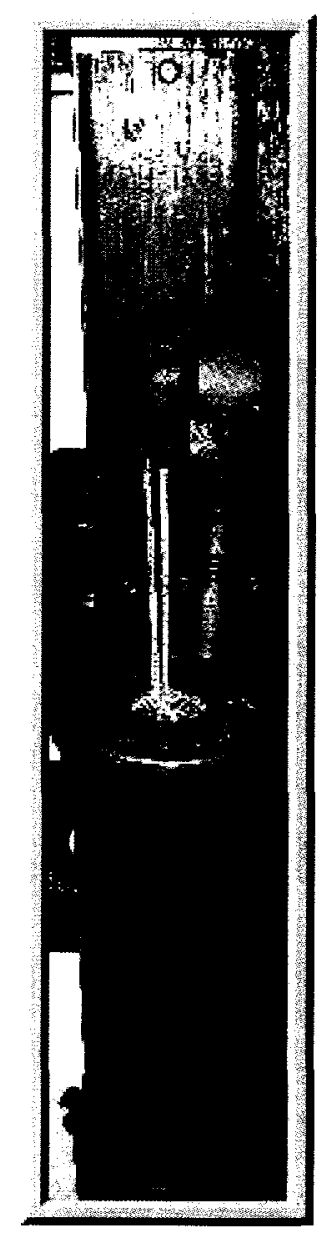

Figure 17: $\quad$ Trench Art of World War I, Gallery 1, Photo 68, "Gong Shell," Unknown maker, Unknown location.

\footnotetext{
${ }^{262}$ Alexander McClintock, Best O'Luck (New York: George H. Doran, 1917): 48-9. Online:
} http://www.archive.org/stream/bestoluckhowfigh00mcclrich. Last accessed: 3 May 2010. 
sustenance of breathable air. The propulsion of its essential message is generated not by industry, but now by the industriousness of human creativity: shrapnel struck on steel, a new tool producing a warning of impending violence, and filling space with the hope of life rather than the creeping, toxic death to which it stands opposed. To a de-limited form of violence-the insidious gas cloud—a similarly spatially preoccupied limiter was firmly applied in the form of a warning bell.

There are many cases of objects such as these being appropriated for practical use. In one case, Frederick Palmer notes:

The woven wicker cases for shells which the German artillery uses and leaves behind ... make excellent fascines, and a number that I saw were of this ready-made kind. After carrying shells for killing Frenchmen they were to protect the lives of Frenchmen. ${ }^{263}$

In these lines, Palmer explicitly acknowledges the transformation of these former violence facilitators, and marks their reappearance as violence inhibitors. The fascines, containers used in the construction of earthen works, found their way into the trenches, and thus they became objects of anti-violence (at least insofar as they would now be part of a defensive system rather than an aggressive one). While it is unclear from where the shell casings in McClintock's observation were procured, there is no mistake in Palmer's narrative. These objects, of German origin, would be used by the Poilus to resist the very objects once nestled within them.

Skirting the boundaries of oppositional pragmatism is the notion of domestication, or perhaps the idea of using objects of past violence to promote domestic comforts is a more appropriately nuanced concept. Paul Duval-Arnould, a French soldier, writes from

${ }^{263}$ Palmer, Op. Cit., 188. 
his dugout in Champagne in 1915: “Comme fatalement l'espace y était resserré, nos poilus avaient fait des prodiges pour accumuler tous les éléments d'un confort assez moderne en fort peu de place. ${ }^{264}$ Such attempts at recreating a home in the dirty, troglodytic conditions of the Western Front would surely have been commonplace, given the dearth of familiar domestic objects like chairs, couches, and beds. British soldier E.E.F. Baker, in a letter from early 1918, states that he and his dugout mates "have constructed two couches of ammunition boxes, 265 thereby appropriating the boxes' initial intent — to house objects intended for killing — and transformed them into a key component of their lived comfort. Canadian John P. Sudbury, on December $18^{\text {th }}, 1916$, writes similarly, albeit without the explicit reference to an item of war being re-purposed. Rather, it is in his actions that the practice resides: "I sit here on an ammunition box and look up the steps (carpeted of course) - (with mud).,"266 Sudbury forges, in comical fashion, a space akin to a home-front sitting room rather than the bomb shelter it is in reality. Even civilians were engaged in such pursuits, as Frederick Palmer notes at a spot near Paris, from where the Germans had shelled the city in 1914: "It was not the way that [the Germans] wanted us to get the shells,' said a French peasant, who was taking one of the shell baskets for a souvenir. It would make an excellent umbrella stand."267 These appropriations are all part of a process of taking an object from one spatialtemporal interval and giving it new meaning in a new space and time, and often in contradistinction to its initial purpose.

\footnotetext{
${ }^{264}$ Translation: "Since space was terribly limited, our poilus took measures to accumulate all the elements of modern comfort in those tiny dimensions." Paul Duval-Arnould, Crapouillots: Feuillets d'un carnet de guerre (Paris : Plon-Nourrit et $\left.C^{\text {ie }}, 1916\right)$ : 167. Online : http://www.archive.org/stream/crapouillotsfeu00duvagoog. Last accessed: 4 May 2010.

${ }^{265}$ IWM, Con Shelf, E.E.F. Baker, Letter to parents, 1-2 Jan 1918. In Jessica Meyer, Op. Cit.

${ }^{266}$ CLIP, John P. Sudbury, Letter to Mother, 18 Dec 1916. Online: http://www.canadianletters.ca/ letters.php?letterid $=2405 \&$ warid $=3 \&$ docid $=1 \&$ collectionid $=160$. Last accessed: 4 May 2010 .

${ }^{267}$ Frederick Palmer, Op. Cit., 49.
} 
If war spaces are the result of institutional thematization as Arthur Danto suggests, then surely these occurrences of rejected thematization are part of a counter process that reaffirms the creative space of the soldier rather than the destructive space of war. ${ }^{268}$ The pragmatics of the objects (re)created are clearly interesting, but must also be considered in a more nuanced fashion. These items, especially in the language in which they are described, are clearly not merely objects of convenience, but are rather part of a further, more elaborate practicality that juxtaposes killing with the persistence of living, and the ugliness of war matériel with objects of beauty. Returning to Duval-Arnould, one can observe the admiration he has for such acts as he describes the contents of one particularly well-adorned dugout:

Des grenades étaient devenues des lampes à essence; des obus non éclatés servaient de lampadaires; des boîtes de singe se transformaient en jalousies; les capotes boches en rideaux d'alcôve, des canons de fusils en chenets et des fourreaux de baïonnettes en soufflets. ${ }^{269}$

Duval-Arnould's description is a blend of the practical and the beautiful, but most certainly of the military made domestic, and the destructive made productive. Such descriptions show a great admiration for these heterogeneous applications of previously violent material specificity.

Even with an object intended to have a more fluid identity such as the sandbag, one encounters praise for its multiple uses. John Sudbury, again with characteristic

\footnotetext{
${ }^{268}$ It should go without saying that the aforementioned instances obviously complicate the cognitive claims of Bordwell. To extrapolate from cinematic space to material space is less of a leap than one might imagine, given that each is the product of cultural intent, and each is clearly equally capable of being exploited by the user/observer.

${ }^{269}$ Translation: "Grenades had become gas lamps; unexploded shells served as standing lamps; des boittes de singe [note: translation unclear-likely a small box of some type] were turned into mobiles; boche overcoats were made into alcove curtains, gun barrels into chimney grates and bayonet scabbards into wind instruments." Paul Duval-Arnould, Op. Cit., 168.
} 
humour, writes "Our Pal - the Sandbag” in a letter home to his mother, and copied in its entirety to preserve its sentiment:

The sandbag is a wondrous thing

To us in France today

He's used for every kind of job

In every kind of way.

A suit of clothes he makes complete

When your uniform is wet

And if he's stuffed with dirt or sand

Makes a dandy parapet.

We use him every night, you know

To bring the rations up

And afterwards as tablecloth

On which to have our "sup".

If torn to shreds and greased a bit

With candle fat, He's fine

On which to boil a cup of tea,

A stove for any time.

He makes the dugout cosy

And soaks up all the damp

I've even seen him used as wick

Inside a handy lamp.

We use him as a dishcloth

To wipe our mess tins clean

And he makes the warmest stockings 
That anyone has seen.

As blanket broom or brush

He's really very fine

Likewise as helmet trimming

To cover up the shine.

There's one I've always near me

Used as a refuse bin

I hope 'twill come in handy

To put the Kaizer in. ${ }^{270}$

The details in Sudbury's poem are extraordinary. His observations on the uses of a seemingly simple object are profound, and the structure of his poetics employs a constant juxtaposition of military use with an alternative use. With each stanza, Sudbury's subversive style is showcased. For every moment of burden, the sandbag provides comfort; with each allusion to dirt and filth, Sudbury incorporates its capacity to provide cleanliness (even if that cleanliness would undoubtedly be of a highly relative sort). Similarly, Frenchman René Nicolas writes of the juxtaposition of appropriated matériel with domestic extravagances in his captain's dugout: images of the "Vie Parisienne," Bach's violin sonatas, and the captain's violin occupying the same shelves and corners as decorations made from bomb fragments. ${ }^{271}$ Within Sudbury's and Nicolas's writings, one encounters two spaces, one military and one domestic, both occupying the same place at the same time.

${ }^{270}$ CLIP, John P. Sudbury, Letter to Mother, 7 May 1916. Online: http://www.canadianletters.ca/ letters.php?letterid $=2360 \&$ warid $=3 \&$ docid $=1 \&$ collectionid $=160$. Last accessed: 4 May 2010.

${ }^{271}$ Nicolas, Op. Cit., 84-5. 
We have seen war materials turned into protective agents, domestic objects for soldiers' comfort, and the multitude of material uses available outside of institutional intentionality. The prevailing theme in each is the notion of something once associated with harmfulness being turned into something harmless. Like explosives imagined as fireworks - the epitome of commuted destructiveness-some soldiers found ways to make a game of the trappings of war. During the daytime hours, during which short naps and long waits often prevailed, soldiers found ways to fill their time. One such way was playing board games, and in the following passage, British journalist Stephen Graham describes the unique components of a sergeant's chess set:

We had an original set of pieces. The white rooks were white buttons from the pull-strings of stick bombs; the knights were part of the detonators of hand-grenades; the perfect bishops came out of the internal structure of German egg bombs; the queens were the unscrewed nosecaps of shells. [...] The kings were anti-tank cartridges; the black pawns were the black cordite tablets used as charges for the heavy guns, and the white pawns were the bright yellow circles of material sometimes discoverable in unexploded star-shells. Sometimes revolver ammunition or parts of German respirators did duty $\left[\ldots . .{ }^{272}\right.$

The unnamed sergeant has taken the catalytic elements of the war object-detonators, pull-strings, propellant-and given them new meaning in a harmless proxy of war. The real violence of war is thus reduced to a point of mere theory, in what amounts to a clever parody of grand strategy by rendering the tools of war absolutely safe. The objects'

\footnotetext{
${ }^{272}$ Stephen Graham, A Private in the Guards (London, UK: MacMillan, 1919): 250-1. Online: http://www.archive.org/stream/privateinguards00grahrich. Last accessed: 4 May 2010.
} 
'violence' is now merely symbolic. Additionally, and quite unlike the war described in chapters two and three, this sergeant may now exercise perfect control over the pieces in that there is no unpredictability in their potential manoeuvres. ${ }^{273}$ His manipulation of the pieces is exercised in a clever, twofold manner of material and strategic appropriation.

As a final instance of these personal appropriations of violent objects, at least for this analysis, one should observe the practice of souvenir creation as a form of material transformation from despised object into desired ornament. This has already been observed by René Nicolas above, however the practice amongst soldiers was nearly ubiquitous. Archaeologist Nicholas Saunders has observed that "souveneering' became a thinly veiled euphemism for looting" during the First World War, noting that objects of all shapes and sizes were acquired, exchanged, or fashioned between 1914 and $1918 .{ }^{274}$ More importantly, Saunders notes that many objects created from the detritus of war-trench art, as it is now called—link "the object and its maker ... in time and/or in space" with the First World War, in this case, and its effects and consequences. ${ }^{275}$ While this is indeed a useful starting point for an analysis, Saunders stays primarily at the level of description of the practice rather than its implications. Above we have seen some of the symbolism inherent in the creative act, and in the pieces of trench art Saunders describes such as rings made from scrap metal by the French (see Figure 18 for a rarer British example), or the popular British trend of making vases fashioned from shell casings (Figure 19), one can go further than the taxonomy offered by Saunders.

\footnotetext{
${ }^{273}$ It should also be noted that this appropriation of a strategic vision of "war," insofar as chess is a war game, is also fundamentally linked to the issue of spectatorship mentioned earlier. Rather than occupying a space of perceptual limitations, the sergeant now occupies an ideal vantage point from which he can oversee the whole field of battle. The only ambiguity he might yet encounter is in failing to bend his opponent to his own strategy.

${ }^{274}$ Nicholas J. Saunders, Op. Cit., 34-5.

${ }^{275}$ Ibid. 41.
} 


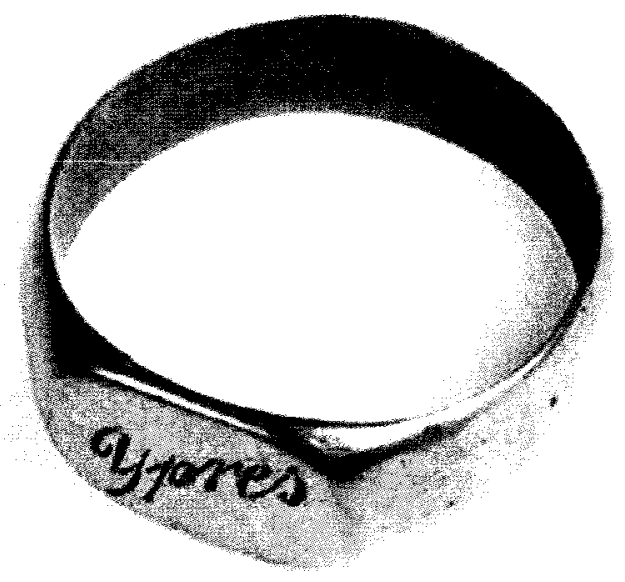

Figure 18: IWM, EPH 5916, Sgt. W. Skinner, no date, "Trench Art Ring, Inscribed 'Ypres'."

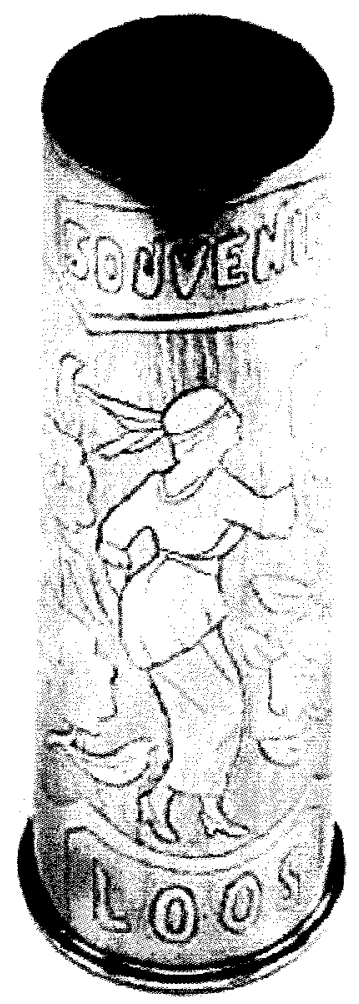

Figure 19: IWM, EPH 3296, anonymous maker, [1915?], "Engraved Shell Case, 18 Pounder," inscribed "SOUVENIR LOOS," metal shellcase, H 29.4 x D $10.3 \mathrm{~cm}$. 
A few examples can illustrate how ornamentation fits within the general scheme of appropriation in its other forms. First, the desirability of something which signifies death is significant, such as the mad dash for shrapnel fragments following explosions which were witnessed on two separate occasions by Frenchmen Joseph Hassler and René Nicolas. Hassler writes, "Les soldats courent à toute allure vers les obus boches à peine explosés, et en prennent les fusées en aluminium dont ils font des bagues. Quelques-uns sont de véritables artistes," while Nicolas writes of the quiet times when his companions, “dès qu'un obus arrive, les voilà en quête de la fusée qu'ils ouvragent de façon assez artistique." 276 In each of these instances, the soldiers are engaged in an act of deliberate shaping and control that stands in opposition to the haphazard shapes of shrapnel and explosives. The space of ostensibly pure chance is offset by an act of pure planning, as seen in the actions of the soldiers scrambling to recover a deadly item from the field of battle in order to turn it into a souvenir of one's experience of having survived the blast. That they were frequently inscribed with the names of major operations or operational locations only furthers this sense, as Harold Simpson writes: "[I] also have a couple of rings made out of the fuses of German shells, one with La Somme ' 16 and the other with Manetz'16. They make a very nice souvenir."277 In this way, the widespread violence of the Western Front is condensed down into an object of localized intimacy, the ugliness of killing reformed into a piece of aesthetic beauty and an object of memory (and thus, continuity).

\footnotetext{
${ }^{276}$ Respective translations: "The soldiers run eagerly toward the recently exploded German shells, and take the aluminum fuses from which they make rings. Some are true artists!" and "No sooner have the shells arrived, then they are off in search of the fuse which they tool in an artistic fashion." Respectively, in Joseph Hassler, Ma campagne au jour le jour (Paris : Perrin et $C^{\text {ie }}, 1917$ ): 255, online : http://www.archive.org/stream/macampagneaujour00hassuoft; and René Nicolas, Op. Cit., 125. Each last accessed: 4 May 2010.

${ }^{277}$ CLIP, Harold Henry Simpson, Letter to Mother, 11 Nov 1916. Online: http://www.canadianletters.ca/ letters.php?letterid=8190\&warid=3\&docid=1\&collectionid=331. Last accessed: 4 May 2010.
} 
In various ways, material objects of the war were appropriated, re-purposed, and simply remade altogether, giving them new meaning, new value, and new form. As with the act of spectatorship, the act of crafting personal objects from the remainder of violence is an act of differentiation. Whether crafting aluminum rings from shell fuses, creating a makeshift chess set from defunct matériel, or simply finding alternative applications for objects beyond their intended use—such acts stress the force of will operating in opposition to the potential for victimhood, life in opposition to death. But these are all local efforts, attached to the personal space of a creator and his or her piece; general practices also compliment such local practices, and implicate not merely personal space but the broadest sense of space occupied by the whole body of soldiers. That general expression of differentiation is located in unified voices.

\section{Singing and (S)laughter}

Thus far, this chapter has considered two separate but seemingly linked structural concepts: spectatorship and material appropriation. In each of these acts, one metaphysical and the other very physical indeed, the practice of differentiation is effected in solitude-a private initial act, ${ }^{278}$ standing in opposition to the very private experience of violence. But even if the soldiers on the Western Front were embroiled in a war of limited perceptual spaces, they were nonetheless possessed of a sense of community, occasionally even including their enemies. ${ }^{279}$ It is easy enough to focus upon the acts

\footnotetext{
${ }^{278}$ I employ the word "initial" here because it is quite possible that soldiers watched the "fireworks" together-I have not found any expression of this, though I do not doubt it happened. Regardless, it is certain that material objects were exchanged, crafted for profit, sold, and often sent home. Thus, the initial act ends up shared across space and time. Most historiography addressing memory speaks to this latter issue (see Jay Winter, Dan Todman, et al.).

${ }^{279}$ For a compelling look at the sense of fraternity between front-line opposing forces, see Tony Ashworth, Trench Warfare, 1914-1918: The Live and Let Live System (London, UK: MacMillan, 1980). While
} 
performed during long periods of inactivity, or rather periods liberated from the militaryoriented activities of labouring or fighting, but the possibility of remaining firmly entrenched in themes of enclosure, internalization, or alienation is a real risk. A sense of connectedness was quite possible, and when soldiers came into and out of the line, they often did so en masse. When they marched along those seemingly interminable distances described by Siegfried Sassoon in chapter two, they often did so with voices raised in song, and this was a practice shared by every army on the Western Front. The general sense of discord and disjuncture so often felt in the trenches could be jettisoned with a rousing chorus or a shared laugh. In the acts of singing and laughing one gets a sense of harmony and shared experience, rather than the disharmonious strategies of the barrage or the private malaise of the soldier in his funk hole. This section will consider these two phenomena together, however it should be clear that they could easily be separated from each other and an entire chapter be dedicated to each subject. The similarities of voices filling space with something other than the sounds of violence are what lead to this conceptual unity, not a desire to leave aside the significant complexity of musicality or humour at any time, much less at times of war.

Any consideration of trench songs must begin with a starting point that extends beyond more romantic understandings of composition. While it is certainly true, of wartime as of any other time in recent history, that many songs were composed by specific songwriters and were widely distributed in the age of mechanical reproduction, it

\footnotetext{
Ashworth's theory has flaws, especially during the later years of the war in which trench raiding attempted to assert a state of persistent Allied aggression in the front lines, Ashworth does at least demonstrate the great reluctance of many junior officers and non-commissioned ranks to engage in hostilities, often for extended periods of time. The soldiers knew that acts of violent aggression would only bring retaliation upon them; they were also more cognizant of the fact that the commanders who ordered aggressive behaviours rarely were on the receiving end of returned hostilities.
} 
is not these songs with which I am primarily concerned. Almost invariably the popular songs of the day were altered by the soldiers in the trenches in order to better reflect the soldiers' situations, in any case. Rather than emphasizing the composer, one must consider the importance of the absence of a singular composer for these songs. As historian John Brophy has noted, "these songs are anonymous, and even the method of their composition is a mystery." 280 Thus, their appearance is what philosopher and First World War veteran Ludwig Wittgenstein might call a rhizome, a term he borrowed from botany. In essence, a rhizomatic entity is something that has no central root structure, or in Wittgenstein's usage it means lacking single-mindedness at the compositional level. Instead, the object may appear spontaneously across a vast space. Rhizomes are networks, emphasizing both connectivity and rootlessness. ${ }^{281}$ The songs of the soldiers, beyond being anonymous and mysterious as Brophy suggests, blossomed and flowered from an enormous community of experientially conjoined individuals, but whose continued productivity is not reliant on any single thread in the network.

The implications for this study of such rhizomatic entities as soldiers' trench songs are related to the notion of highly limited trench spaces and also to the sense of timelessness attached to soldiers' travails. These songs, even when possessing slight variations from place to place, nonetheless occupied a familiar, mutually intelligible space that extended the length of the trenches (barring any linguistic limitations, though even those were minimal as songs often helped bridge language gaps). The potential

\footnotetext{
${ }^{280}$ John Brophy and Eric Partridge, The Long Trail: What the British Soldier Sang and Said in the Great War of 1914-18 (London, UK: Andre Deutsch, 1965): 15.

${ }^{281}$ John Heaton and Judy Groves, Introducing Wittgenstein (Thriplow, UK: Totem Books, 2005): 128. Interestingly, Wittgenstein began his first (and only) completed philosophical text while serving with the Austrian army. The text, unsurprisingly, attempts to locate the limits of language and meaning, themes which prevail in the trenches of the First World War. See Heaton and Groves, 20-33.
} 
temporal limitations of trench culture, primarily located in the fragility of human life facing extraordinary violence-a very real problem for the continuance of material productions, such as trench newspapers, which might otherwise have performed a similar function $^{282}$-were circumvented by this structure. The fleeting sounds of a song were complimented by the persistent voice of the soldier, any soldier, capable of always reproducing those songs. As Tim Cook states, "the soldiers' songs were owned by no one, and they were continually updated, their words blurring and shifting with the changes of the war."283 If an 'author' must be located, it should be thought of conceptually as the masses of men, in response to their situational circumstances. I have interpreted Cook's concept of non-ownership as a critical point of differentiation from Brophy's descriptions: the implications of non-ownership are fundamentally akin to those of the sudden appearance of violence in the trenches. These songs had the semblance of simply occurring, external to the control of the individual in the same way as the deadly guns of war. Each entity lacked singular authorship, though similarities end there. The difference, of course, is that the songs of the masses stress connectivity and attachment; the guns represent disconnectedness and destruction.

While the rhizomatic structure of song-knowledge amongst the soldiers of the Western Front is of significant interest for its similarity to the similarly broadly attributed violence to which soldiers were exposed, one may take a step away from the broader syntax of song occurrence and also explore the specific syntactical elements of some

\footnotetext{
${ }^{282}$ In Stéphane Audoin-Rouzeau's study of trench newspapers during the First World War, he remarks frequently upon the instability of the many hundreds of French publications operating clandestinely along the Western Front. If the editor was killed, that usually spelled the end of the journal. Similarly, if the material means of production was lost for whatever reason (capture, damage, seizure, or simply running out of stationery supplies), then so too was the product lost. See Audoin-Rouzeau, National Sentiment and Trench Journalism for more details, and note that the problems encountered by an industrial press- even a minor one-are never met by the human voice.

${ }^{283}$ Tim Cook, At the Sharp End, 400.
} 
songs to see that they operate along related lines of connectivity and harmony. Take the trench classic "The Old Barbed Wire," for instance, which was a traditionally rhizomatic song in that it has no discernable 'author,' nor even is it the product of parody. ${ }^{284}$ The following is a typical verse, though there were variations in order of appearance for the verses and also in the exact wording:

Has anyone seen the Captain?

I know where he is, I know where he is, I know where he is!

Has anyone see the Captain?

I know where he is, he's boozing on the Privates' rum!

(How do you know?)

I saw him, I saw him boozing on the Privates' rum, I saw him boozing on the Privates' rum!

The structure of the song in general, like many marching tunes sung by the soldiers, involves a different soldier singing each verse. Even in cases where a single voice might be the lead, one can see in the fifth line a reply from the other singers. This call-andanswer structure, when contextually situated, can certainly be read as an antidote to the uncertain structures of trench life discussed in Chapter Two. Rather than the alienating effects of trench life-intended to limit the exposure of soldiers to violence, but in so doing limiting the sense of connectedness to one's own comrades-we see the affirmation of kindred spirits and confirmation of their presence nearby.

Granted, there are valid critiques to this approach, with a compelling one singled out in Tim Cook's work on soldiers' songs in the Canadian Expeditionary Force. Cook

\footnotetext{
${ }^{284}$ Eric Partridge, and later John Brophy were both unable to trace its origins to any popular music of the time, either music hall, theatrical, or recorded. See Brophy and Partridge, Op. Cit., 61.
} 
cites Peter Hawkins, who suggests that historians must be careful not to read too much into the song itself, since we do not have access to any audio remnants. This absence means vocal inflections, performative flourishes, and accompaniments are all lost. The "text to be analyzed," Hawkins states, "is surely the complete recorded performance, not the printed lyric." 285 This is a plausible concern, though Hawkins seems unusually fixated upon a form of Apollonian solidity, located in the recording of a living practice, and seemingly suggesting that there is less to be learned from the more sublime, Dionysian elements of live song. ${ }^{286}$ As Cook notes, all historical texts, being inherently fragmentary must be contextualized by further discursive elements, ${ }^{287}$ but in this instance the very fact of the songs' Dionysian aspects is revealing of their contextual value. After all, a recording of a performance is no longer in its original medium, much less is it situated in its proper context.

The songs of the soldiers should be viewed as temporary constructs that fit very nicely with the general, forward-looking sentiments of "Après la Gare [Guerre]" so often on the lips of the soldiers. ${ }^{288}$ The absence of recordings of these songs, though undoubtedly partly owing to the predominantly smutty lyrics often involving far too much fucking of farmers' daughters, ${ }^{289}$ is part of a temporal space that one day will end.

\footnotetext{
${ }^{285}$ Peter Hawkins, Chanson: The French Singer-Songwriter from Aristide Bruant to the Present Day (Aldershot, UK: Ashgate): 11. Quoted in Tim Cook, "The Singing War: Canadian Soldiers' Songs of the Great War," American Review of Canadian Studies Vol. 39, No. 3 (Sept 2009): 224.

${ }^{286}$ Apollo and Dionysus represented two different trends in art to the ancient Greeks. Apollo was god of the plastic arts (painting, sculpture, and such) while Dionysus was the god of less fixed artistic pursuits (music, choruses, and the like). The former is rational and part of a self-reflexive act of recording and preservation; the latter is about wild and unchecked passions which, in the words of Friedrich Nietzsche, "cause the subjective to vanish into complete self-forgetfulness" (4). For a more detailed assessment, see Friedrich Nietzsche, The Birth of Tragedy, Clifton P. Fadiman, trans. (New York: Dover Publications, 1995 [1927]): 1-4. ${ }^{287}$ Cook, "The Singing War," 225.

${ }^{288}$ Cook, Shock Troops, 184.

289 "Mademoiselle from Armentières" is likely the best example of these hyper-masculine songs of sexual conquest, though there were many variations of both the song and the themes therein ("Skiboo" is another
} 
Apart from their use in post-war soldiers' reunions - an element considered in the Canadian context by Jonathan Vance already $y^{290}$ - this concept of contextual usage was indeed observed. The fleeting element of the songs was not merely a reminder of the soldiers' perceptions of war as a temporary event, but it also marked a counterpoint to the unsustainability of any given occurrence of violence to which soldiers were exposed.

One example of singing offsetting violence can be found in two French passages. The first is from a trench newspaper, La Saucisse, whose April 1917 column describes a barrage:

There is nothing worse in war than being bombarded. One man is there alone in his hole. [...] At first he talks to his neighbour in the next hole: he likes to feel someone near him, a comrade running the same risks. [...] [There] can be no doubt about it, this is a bombardment, a real one ... Soon the noise becomes hellish; several batteries thunder out together.

Impossible to make out anything. Shells fall without interruption. ${ }^{291}$

Connectedness is the first thing to go during the bombardment described above. Singing, however, is contrapuntal to this disconnectedness as it was experienced in the trenches. Singing also emphasizes the cessation of violence. French soldier and journalist Henry Malherbe writes of a concert behind the lines following a terrible front-line experience:

Ce que nous avons de meilleur et de sain remonte en nous, s'éploie et chante avec cette mélodie candide. Les hommes qui écoutent ici ... ont vécu sur un océan de meurtre et de férocité! Et les voici comme un peuple

of these song types). See Brophy and Partridge for many more examples, though it should be conceded that Brophy's self-confessed prudishness related to explicit language must be kept in mind in his selection of songs and failure to include certain key " $F$ " words.

${ }^{290}$ See the chapter entitled "O Death, Where Is Thy Sting?" in Jonathan Vance, Death So Noble, 73-110.

${ }^{291}$ In Audoin-Rouzeau, National Sentiment, 73. 
d'enfants vertueux... [...] Vous effacez sur les visages de nos hommes, cette résignation farouche, cette fatigue têtue, cette rêverie funèbre et sans espoir. $^{292}$

In Malherbe's mind, these songs are the antidote to the violence which is understood as the root of these sentiments of despair, fatigue, and resignation. The hope that is reinstated by the concert is felt collectively, occupying both the internal space of the individual soldier, but also permeating his external space with joy, restfulness, and even peace.

Alan Seeger, observing a battle in 1915 between the French and the Germans, relates these concepts even more explicitly, stating:

The roar of rifle and machine gun fire bursts out [from the French lines directed at the German attackers], and a brief, ferocious struggle ensues [...]. The attack in question was a complete failure, [...] [and while the battalion was regrouping] the band broke out into the 'Marseillaise'. [...] There was something sublime about it there in such a place and under such circumstances. $^{293}$

In explicitly Dionysian terms, Seeger describes the appropriation of the soundscape of war, a matter which is affirmed with every song on any given march. It is enough to imagine the sense of community felt by the soldiers when they sang a familiar tune, but Seeger takes it further than that and applies a practical understanding to the act of singing: it drowns out the violence and discord, coming to occupy the same space in an

\footnotetext{
292 Translation: "Our better and most healthy sentiments return to us, they sing with this candid melody. The men participating here ... have been through an ocean of murder and ferocity! Yet they people this space like virtuous children... [...] Erased from the faces of the men, that terrible resignation, that characteristic exhaustion, those hopeless and funereal reveries." Malherbe, Op. Cit., 127.

${ }^{293}$ Seeger, Op. Cit., 80-1.
} 
act of harmony. When he later states in a letter to his mother in 1916, "all the birds of the forest begin to sing. The cannon may roar, and the rifles crackle, but Nature's program goes on just the same, ${ }^{294}$ he is drawing an explicit parallel between the persistent harmoniousness of nature set against the disruptive "roar" of modern armaments. That the songbirds and the Poilus engage in the same act and that they are united in their opposition to the industrial terror of modern war cannot be viewed as coincidence in Seeger's observations.

In addition to the rhizomatic structure of song propagation, their syntax as community-driven entities, and their spatial-temporal opposition to the soundscape of violence in the front lines, one could also look at some semantic concerns. This analysis will be less than exhaustive, if only because an analysis of the contents of every trench song would occupy a book in itself. A few samples must suffice, and are chosen because they illustrate yet another level of appropriation and transformation of violent space. "The Bells of Hell Go Ting-A-Ling-A-Ling" is a typical case of semantic appropriation, in that the lines stress the soldier's slightly ironic feeling of invulnerability: the bells ring "for you, but not for me. ${ }^{, 295}$ Like other aspects of trench songs, the contents of this one reject the pervasive forces of violence and project it elsewhere. While the expression of "me" might appear as a singular claim, the fact that "Ting-A-Ling-A-Ling" was a marching song suggests otherwise, or at least suggests that the group of singers felt as one, unified in their assertion of untouchability. So too is that sentiment located in another popular marching song of the early part of the war, "The Old French Trench,"

\footnotetext{
${ }^{294}$ Seeger, Op. Cit., 201.

${ }^{295}$ Brophy and Partridge, Op. Cit., 55.
} 
which has the emphatically delivered final line: "We're still alive in the old French trench!"296

Returning to "The Old Barbed Wire," the traditional final verse was quite morbid, following numerous humorous verses about napping sergeants, cowering officers, and the 'bomb-proof' jobs in the rear:

If you want to find the old battalion

I know where they are, I know where they are, I know where they are.

If you want to find the old battalion

I know where they are.

They're hanging on the old barbed wire! (How do you know?)

I saw them, I saw them

Hanging on the old barbed wire,

I saw them hanging on the old barbed wire.

There are a few concepts worth examining in the passage, some of which are contradictory. For instance, the verse could be interpreted in multiple ways: as the wisdom of the new battalion who will not end up like the old, or as the inevitability of them ending up like the old. ${ }^{297}$ Regardless of meaning, which likely was as subjective as any other poetic form to the soldiers singing the verses, there is a definite pattern of differentiation that is occurring in the verse. In this case, the singing soldiers, engaged in an act of participatory self-effacement in the Dionysian sense, have distanced themselves from the dead. The singers are also not caught up in the snags and snares of modern

\footnotetext{
${ }^{296}$ Brophy and Partridge, Op. Cit., "The Old French Trench," 55. In this case, French refers to General David French, commander of the British forces prior to Douglas Haig taking over. The song is obviously partly a jab at military leadership in addition to other meanings that may be derived from its contents. ${ }^{297}$ Additionally, it could be yet another jab at leadership, and given the context of the other verses, targeting all the senior ranks, it is quite plausible that the tone is at least slightly accusatory.
} 
weaponry, generally speaking. Despite the barbed wire's presence, an emblem of the modern battlefield, these singers insist upon their freedom from it, and do so in explicitly spectatorial terms.

British Corporal G. Gilliam, describing the action on the Marne in 1914, corroborates this interpretation, stating: "The artillery fire on the Marne was awful in its destructiveness and earsplitting in its noise-sometimes the very air seemed to be solid matter that was broken into chunks and knocked about you; but we soon got used to it all, and laughed and smoked and joked in the trenches. ${ }^{, 298}$ All of these latter actionssmoking, joking, laughing — juxtaposed as they are with the seemingly totalizing control of trench space by the implements of violence, appear to create a localized sanctuary for the soldier in question, and one which is known to be shared with a broad fraternity of fellow soldiers whose poly-vocality possesses the immense capacity to transfigure a space of discord and cacophony into one of unity and harmony. The addition of a new sentiment, laughter, returns us to the subject of spectacle, of what Reginald Farrer describes as "this whole thing being a gigantic bad-form joke [...] [with] the modern Englishman as something tragically grand and Greek-a titanic figure, laughing out against the dark" through absurd juxtaposition. ${ }^{299}$ Though occasionally derided by Farrer and others for not understanding the British sense of humour, the French, too, expressed similar sentiments. Paul Duval-Arnould, having just been missed by two small shells, writes of his guide: "Et lui, follement amusé, secoué de la tête au pied, riait d'un beau rire clair et si franc que j’en sentis, de coup, mon cœur se remettre en place [...] ‘-Tu vois, je

\footnotetext{
${ }^{298}$ G. Gilliam, "The Victory of the Marne," True Stories of the Great War, Walter Wood, ed. (London, UK: Chapman and Hall, 1915): 248. Online text: http://www.archive.org/stream/soldiersstorieso00woodrich. Last accessed: 6 May 2010.

${ }^{299}$ Reginald Farrer, Op. Cit., 125-6.
} 
te l'avais bien dit, qu'ils tirent mal!",300 In another instance, an anonymous French alpine officer expresses derision toward a bombardment when, as soon as it lifts, the whole line bursts into laughter "comme une véritable fusée éclairante." ${ }^{301}$ In this last instance, the anonymous Frenchman posits laughter as the rocket of the would-be victims: a tool of resistance to the real object of violence and launched into the same space.

\section{$\underline{\text { Conclusion }}$}

Though appearing as seemingly mutually exclusive concepts, certain aspects of imagining war as a spectacle, the proliferation of trench art, and the singing and laughter of the allied soldiers on the Western Front can be thematically linked under a broad notion of appropriation, transformation, and resistance. The linkages between these concerns are subtle, but significant enough to be included within the same discussion. A process of differentiation resides in each act, whether one speaks of spectatorship and the explicit act of distancing oneself from violence, or of rendering harmless and ornamental the matériel of modern war, or even in discussing the structure, syntax, and semantics of soldiers' songs, one finds this concept of difference. At the core of each act or practice is a living expression, some singular and some collective, but always anticipating survival. These are the expressions of life carrying on in spite of terrific violence, and it is important to properly situate them in a space of appalling violence in order to understand how they served soldiers in structuring a space apart, where killing and destruction came a distant second to the soldiers' immense creative and life-affirming capacities.

\footnotetext{
${ }^{300}$ Translation: "And he, thoroughly amused, shaken from head to toe, laughed a good clear laugh that was so honest I felt, in a beat, my heart settling back into place [...] 'You see, I told you already, they shoot badly!"' Paul Duval-Arnould, Op. Cit., 11.

${ }^{301}$ Anonymous, Carnet de route d'un officier d'alpins Vol. 2, 54.
} 


\section{Conclusion:}

\section{At the Intersection of Violence and Spatial Studies}

That violence and war are mutually inclusive concepts is perhaps to state the obvious. And of the forms violence takes, "the obvious signals of violence are acts of crime and terror, civil unrest, [and] international conflict," which all are part of what Slavoj Žižek has recently called the "fascinating lure of ... violence performed by a clearly identifiable agent. ${ }^{\text {302 }}$ It appears undeniable that historians of war and conflict have invariably had to address violence in a variety of ways, and yet typically the violence they address is subordinated to other issues. One often encounters combat effectiveness, the roles of wounded soldiers in post-war society or the shaping of national identities, among many other salient topics of historical analysis. Such topics implicitly address violence, employing violence as framework rather than semantic centrepiece. In writing this thesis, I have admittedly taken Žižek's lure, but instead of passively submitting to the angler's will, I have attempted to pull back according to Stéphane Audoin-Rouzeau's instructions: to resist glossing over the obvious, to take violence as a point of initial inquiry and thereby invert the relationship between violence and any other issues that might arise. This has been a phenomenological pursuit, beginning at the beginning so to speak, with the effecting of violence between warring peoples, and thus considering the implications contained therein rather than working backwards from the effects of violence wrought upon a topical concern.

While I took up Audoin-Rouzeau's challenge, I did not find his focus on the socio-political implications of violence wholly satisfying. Indeed, I felt he in turn, as the

${ }^{302}$ Slavoj Žižek, Violence, (New York: Picador, 2008): 1. 
rare champion of the phenomenology of violence, had missed an opportunity to consider the space in which violence occurs: the discourses of grand strategy and their practical (and failed) applications on the battlefields of the Western Front. As Arthur Danto observes in nineteenth century military historian Sir William Napier's discussion of changing infantry technology, a change in a single component in the conduct of war results in a total alteration of the system. ${ }^{303}$ The development of modern armamentsbreach-loading rifles, artillery, and the like-changed the nature of combat between the belligerents, but also resulted in a distinct strategic and social space: the trenches. At the level of strategy, direct sighting required new constructions of space which found its genesis in the photo-cartographic apparatus of aerial surveillance, transcription on to trench maps, and the subordination of gun sights to mathematical calculations. These technologies dominated the space of war, facilitating industrial violence in the form of artillery bombardments, gas attacks, grenades, and the like-all weapons targeting geophysical regions rather than individuals.

Inevitably, those on the receiving end of such forms of violence, concealed in the landscape, obscured as much from the enemy as they were from their own allies, constructed their own discourses. In describing the violence to which they were subjected, soldiers readily adopted linguistic tropes connoting apocalypse, hell, natural disasters, and other concepts related to their experiences within this space of conflict. In other words, they often enacted a language of total, even divine subordination to the ordinance falling incessantly from the skies which resulted in a space where the lines between the living and the dead were blurred, paradoxes of incessant and fruitless labours were constructed, and the hope of an end to it seemed nearly impossible to conceive at

${ }^{303}$ Danto, Op. Cit., 235. 
times. Such expressions do not appear limited to any particular nationality, as the French, British, and Canadian soldiers seem to articulate these concepts equally, linked in all likelihood by the predominantly Christian faiths of the soldiers. "War is all hell," as General Sherman remarked following the American Civil War, and the "hell" experienced by the soldiers on the Western Front was most certainly attributable to the conditions under which the war was fought.

Hope, however, proved a powerful antidote to the hell of the Western Front. So while the soldiers often articulated the sheer awfulness of their situation, the trench culture springing from the same spaces of war was often one of resistance, appropriation, and most importantly of dislocation from violence. Like the social construction of hellish space, here one encounters its parallax view in the spectacle of war, or to put it more generally, the war's features transformed into objects of aesthetic scrutiny by the external observer. Not only was this a psycho-social phenomenon, but it also found its way into the material culture of the trenches in the form of material appropriation, almost invariably in the interests of pragmatic self-preservation, aesthetic transformation of the trappings of war, and creating legacy items for self or loved ones, forward-looking in intent. These individual phenomena were complimented by at least two dominant collective issues—-singing and laughter-that was itself a practice of resistance to violence and equally spatially appropriative: unified voices raised in response to the destructive and individually isolating soundscape of war.

In this project I have tried to establish subtle linkages between such ostensibly disparate sub-disciplines of military strategy, linguistic analysis, and several forms of cultural practice-all of which I have attempted to locate at the intersection of violence 
and the space in which that violence occurs. I have no illusions that the ambition of the thesis has left large gaps, but it is my hope that these serve as the points from which others may undertake explorations of their own, not the least of which could revolve around the many other nationalities omitted from this thesis-notably Germany, Russia, India, and Turkey — and to which I have been unable to attend owing to my own language limitations. There is also much more analysis to be done at the strategic level, relating to the military reconfiguration of space: the use of barbed wire on the battlefield has not been considered at all in this thesis, while methods of signalling have only been allusively addressed in the previous chapters. There is also ample room to expand upon the myriad of visual apparatuses operating on the Western Front (firing arcs, techniques and technologies of daytime and night time observation, and the like), as well as the interpretation and manipulation of such spatial constructions by those on the ground for whom the apparatus was made. It would also be an intriguing undertaking to examine the social construction of spaces behind the lines, and especially those constructed as a relief from violence (estaminets, sports pitches, and the like); the contrast would certainly contribute to greater understandings of the front line spaces. Finally, the methodology adopted in this thesis is by no means limited to the First World War, but rather could be considered far more broadly and need not be limited even to spaces of war. As one may imagine, any setting in which violence is directly experienced (or even strongly implied) for a fairly remarkable period of time would be open to such a socio-cultural analysis by incorporating the type(s) of violence occurring within such spaces and tracing the syntheses between violence, the space in which it occurs, and the culture arising within 
that space. Each of these matters I hope would present a compelling departure point for future study.

Part of the objective of this thesis was to consider new theories, to experiment with historiographical methodologies, and specifically to challenge more commonly accepted traditions of military history by conjoining it with studies of violence, space and culture. Though Canadian military history seems to have been sidelined owing to recent academic trends, it is my hope that studies such as this signal an academic renaissance in military history to compliment the general public's ongoing (and growing) curiosity in the subject. If there is one thing of which I am certain, and which appears to be a growing trend amongst today's younger generation of military historians, it is that the Western Front and the First World War remain interesting, compelling, and relevant subjects of analysis in a number of fascinating contexts. But sometimes these matters require taking a step back in order to consider rigorously and analytically the implications of the obvious. That war and violence occur in the same space may seem obvious and yet, as I have attempted to show throughout this thesis, one may dwell in their profundities for a long time yet. 


\section{Works Cited}

Unpublished Primary Documents:

Anovi. Online: http://www.grande-guerre.org. Jean de Pierrefeu papers.

Anovi. Online: http://www.grande-guerre.org. "Chanson de la Craonne."

Canadian Letters and Images Projects (CLIP). Online: http://canadianletters.ca. Fred Adams papers.

CLIP. Online: http://canadianletters.ca. Alfred Herbert John Andrews papers.

CLIP. Online: http://canadianletters.ca. Roy Clarence Armstrong papers.

CLIP. Online: http://canadianletters.ca. William Beattie papers.

CLIP. Online: http://canadianletters.ca. Arthur Brooks papers.

CLIP. Online: http://canadianletters.ca. Bertram Howard Cox papers.

CLIP. Online: http://canadianletters.ca. Herbert Durand papers.

CLIP. Online: http://canadianletters.ca. Wilbert H. Gilroy papers.

CLIP. Online: http://canadianletters.ca. Robert Hale papers.

CLIP. Online: http://canadianletters.ca. George P. Hatch papers.

CLIP. Online: http://canadianletters.ca. Alf Johnson papers.

CLIP. Online: http://canadianletters.ca. George Hedley Kempling papers.

CLIP. Online: http://canadianletters.ca. Neil MacKinnon papers.

CLIP. Online: http://canadianletters.ca. Amos William Mayse papers.

CLIP. Online: http://canadianletters.ca. Francis Harold McLorg papers.

CLIP. Online: http://canadianletters.ca. John Newton papers.

CLIP. Online: http://canadianletters.ca. Wallace Aubrey Reid papers.

CLIP. Online: http://canadianletters.ca. Charles Douglas Richardson papers. 
CLIP. Online: http://canadianletters.ca. R.S. Robinson papers.

CLIP. Online: http://canadianletters.ca. James Wells Ross papers.

CLIP. Online: http://canadianletters.ca. Charles Henry Savage papers.

CLIP. Online: http://canadianletters.ca. Harold Henry Simpson papers.

CLIP. Online: http://canadianletters.ca. W.G. Singer papers.

CLIP. Online: http://canadianletters.ca. Henry Crozier Smith papers.

CLIP. Online: http://canadianletters.ca. John P. Sudbury papers.

CLIP. Online: http://canadianletters.ca. Walter G. Sutton papers.

Canadian War Museum (CWM). Military History Research Centre (MHRC). 58A 1 237.8. Garnet Montague Babbitt papers.

CWM. MHRC. 58A 1 138.15. Charles Robert Bottomley papers.

CWM. MHRC. 58A 1 42.14. George Howard Bradbrooke papers.

CWM. MHRC. 58A 1 188.26. John Oswald Doyle papers.

CWM. MHRC. 58A 1 13.7. Brooke Ferrar Gossage papers.

CWM. MHRC. 58A 1 43.4. Samuel R. Laycock papers.

CWM. MHRC. 58A 1 154.1. Keith Campbell Macgowan papers.

CWM. MHRC. 58A 1 43.1. George Johnston Spencer papers.

CWM. MHRC. 58A 1 113.2. John Patrick Teahan papers.

Imperial War Museum (IWM). Harold Sandys Williamson. The Fatal Salient. Online exhibit: http://london.iwm.org.uk/upload/package/45/FatalSalient. 
Photographs and Art Work:

Bairnsfather, Bruce. "That 16-Inch Sensation." Cartoon. Originally published in The Bystander, issue unknown. Online: http://www.first-worldwar.co.uk/images/cp7.jpg.

CWM. 19710261-0179. A. Y. Jackson. Gas Attack, Liévin. Mar 1918. Painting. Oil on canvas, $63.6 \times 77.0 \mathrm{~cm}$. Ottawa.

CWM. 19710261-0770. Frederick H. Varley. For What? Dec 1919. Painting. Oil on canvas, $147.4 \times 180.6 \mathrm{~cm}$. Ottawa.

CWM. MHRC. O.1696. Unknown Photographer. Jul 1917. Official Photograph. “All that Remains of a Village Church."

CWM. MHRC. O.2417. Unknown Photographer. Jan 1918. Official Photograph. "Making the Camouflage Instead of the Trench."

Croenart Research Services. No cat. no. Unknown Maker. Dec 1917. Trench Map. “Trench Map of Passchendaele Area." Online: http://www.pathsofglory.co.uk/Trenchmap\%20 extracts.htm.

IWM. EPH 3296. Anonymous Maker. “Engraved Shell Case, 18 Pounder,” inscribed “SOUVENIR LOOS.” Metal Shellcase, H 29.4 x D 10.3 cm. [1915?]. London, UK.

IWM. E(AUS) 1220. Australian Official Photographer. 29 Oct 1917. Official Photograph. "ANZAC Soldiers Walking on the Duckboards through the Remains of Château Wood." 
IWM. Q 1259. Ernest Brooks. Sept 1916. Official Photograph. "The Remains of Delville Wood Near the Somme."

IWM. IWM ART 4415. Georges Leroux. L'Enfer, 1917-8. Painting, Oil on canvas, 114.3 x $161.3 \mathrm{~cm}$. London, UK.

IWM. IWM ART 1145. Paul Nash. The Ypres Salient at Night, 1918. Painting. Oil on canvas, dimensions unknown. London, UK.

IWM. IWM ART 1146. Paul Nash. We are Making a New World. 1918. Painting. Oil on canvas, $71.2 \times 91.4 \mathrm{~cm}$. London, UK.

IWM. IWM ART 518. Christopher R.W. Nevinson. Paths of Glory. 1918. Painting. Oil on canvas, dimensions unknown. London, UK.

IWM. EPH 5916. Sgt. W. Skinner. “Trench Art Ring, Inscribed ‘Ypres'”’ Trench Art. Undated. London, UK.

Musée de l'Armée (MA). 05-533965. 09656.24. Hallo Charles-Jean. 10 Oct 1916.

Official photograph. "French Attack on the Hart Wood on the Somme."

MA. 08-518959. Inv 28854 fb1170. Jolibois Emile. 1916. Official photograph. "The Falfemont Farm on the Somme, 1916."

Nash, Paul. Leaving the Trenches. 1917. Chalk, pen, and watercolour. Dimensions and location unknown.

National Gallery of Canada (NGC). No. 8650. Paul Nash. Void, 1918. Painting. Oil on canvas. 71.4 x $91.7 \mathrm{~cm}$. Ottawa, Canada.

Trench Art of the First World War. Gallery 1, Photo 68. Unknown creator. "Gong Shell." Trench art. Online: http://www.trenchartofww1.co.uk. 


\section{Published Primary Sources:}

Anonyme. 1915. Carnet de route d'un officier d'alpins, Vol. 1. Paris: Berger-Levrault. Anonyme. 1915. Carnet de route d'un officier d'alpins, Vol. 2. Paris: Berger-Levrault. Ashmead-Bartlett, Seabury. 1921. From the Somme to the Rhine. New York: John Lane.

Bird, Will R. 2002 [1930]. Ghosts Have Warm Hands: A Memoir of the Great War 19161919. Ottawa: CEF Books.

Bloch, Marc. 1988 [1969]. Memoirs of War, 1914-15. Carole Fink, trans. New York: Cambridge University Press.

Blunden, Edmund. 2000 [1928]. Undertones of War. Toronto: Penguin Classics.

Canadian Bank of Commerce. 1920. Letters from the Front; Being a Record of the Part Played by Officers of the Bank in the Great War, 1914-1919. Toronto: Southam.

Duval-Arnould, Paul. 1916. Crapouillots: Feuillets d'un carnet de guerre. Paris: PlonNourrit et $C^{\text {ie }}$.

Farrer, Reginald. 1918. The Void of War: Letters from Three Fronts. New York: Houghton Mifflin.

Gibbs, Philip. 1920. Now It Can Be Told. New York: Harper \& Brothers. Graham, Stephen. 1919. A Private in the Guards. London, UK: MacMillan. Hassler, Joseph. 1917. Ma campagne au jour le jour. Paris: Perrin et $\mathrm{C}^{\mathrm{ie}}$. Kettle, Tom. 1917. The Ways of War. New York: Charles Scribner's Sons. Leach, William James. 1922. Poems and War Letters. Peoria: Manual Arts Press. Malherbe, Henry. 1917. La flamme au poing. Paris: Albin Michel. McClintock, Alexander. 1917. Best O'Luck. New York: George H. Doran. 
Miller, Francis Trevelyan, ed. 1917. True Stories of the Great War, Vol. V. New York: Review of Reviews Company. 1917. True Stories of the Great War, Vol. VI. New York: Review of Reviews Company.

Nicolas, René. 1919. Carnet de campagne d'un officier Français. Edward Manley, ed. Boston: Benj. H. Sanborn \& Co.

O'Connor, V.C. Scott. 1917. The Scene of War. London: William Blackwood and Sons. Palmer, Frederick. 1916. My Year of the Great War. New York: Dodd, Mead \& Company.

Sassoon, Siegfried. 1947 [1930]. Memoirs of an Infantry Officer. London: Faber.

Seeger, Alan. 1917. Letters and Diary of Alan Seeger. New York: Charles Scribner's Sons.

Sheahan, Henry. 1916. A Volunteer Poilu. New York: Houghton Mifflin Company. Wood, Eric Fisher. 1917. The Note-Book of an Intelligence Officer. New York: The Century Co.

\section{Fictional Sources:}

Dante Alighieri. 2000 [1966-7]. Divina Commedia. R. Hollander and J. Hollander, trans., Princeton Dante Project. Online: http://etcweb.princeton.edu/dante/pdp/.

Gilliam, Terry and Terry Jones, dir. 1983. The Meaning of Life. Feature Film. Gross, Paul, dir. 2008. Passchendaele. Feature Film.

Kubrick, Stanley, dir. 1957. Paths of Glory. Feature Film. Milestone, Lewis, dir. 1930. All Quiet on the Western Front. Feature film. 
Milton, John. 2005 [1667]. Paradise Lost. Toronto: Oxford University Press.

\section{Secondary Sources:}

Althusser, Louis. 1971. Lenin and Philosophy and Other Essays. Ben Brewster, trans. New York: Monthly Review Press.

Ashworth, Tony. 1980. Trench Warfare, 1914-1918: The Live and Let Live System. London: Macmillan.

Audoin-Rouzeau, Stéphane. 1992. National Sentiment and Trench Journalism in France during the First World War. Helen McPhail, trans. Washington: Berg. . "Extreme Violence in Combat and Wilful Blindness." International Social Science Journal, vol. 54, iss. 4 (2002): $491-7$.

Audoin-Rouzeau, Stéphane and Annette Becker. 2002. 14-18: Understanding the Great War. Catherine Temerson, trans. New York: Hill and Wang.

Barton, Peter. 2008. The Battlefields of the First World War: The Unseen Panoramas of the Western Front. London, UK: Constable.

Baudry, Jean-Louis. "Ideological Effects of the Basic Cinematographic Apparatus." Alan Williams, trans. Film Quarterly, vol. 28, iss. 8 (Winter 1974-5): 39-47.

Becker, Annette. 1998 [1994]. War and Faith: The Religious Imagination in France, 1914-1930. Helen McPhail, trans. New York: Berg.

Bond, Brian. 2002. The Unquiet Western Front: Britain's Role in Literature and History. New York: Cambridge University Press.

Bordwell, David. 1985. Narration and the Fiction Film. Madison: The University of Wisconsin Press. 
Brearton, Fran. "Mapping the Trenches: Gyres, Switchbacks and Zig-zag Circles in W.B. Yeats and Ciaran Carson." Irish Studies Review, vol. 9, iss. 3 (2001): 373-386.

Brophy, John and Eric Partridge. 1965. The Long Trail: What the British Soldier Sang and Said in the Great War of 1914-18. London, UK: Andre Deutsch.

Brown, Malcolm. “No-Man's-Land.” Military History Quarterly, vol. 8, iss. 4 (1996): 28-37.

Bull, Stephen. 2002. World War I Trench Warfare, 1914-1916, Vol. 1. New York: Osprey Publishing.

Camus, Albert. 2005 [1942]. The Myth of Sisyphus. Justin O’Brian, trans. Toronto : Penguin.

Certeau, Michel de. 1988 [1984]. The Practice of Everyday Life. Steven Rendall, trans. Berkeley: University of California Press.

Chasseaud, Peter. "British Artillery and Trench Maps on the Western Front 1914-1918." Map Collector, vol. 51 (1990): 24-32.

Chickering, Roger and Stig Förster. 2000. Great War, Total War: Combat and Mobilization on the Western Front, 1914-1918. New York: Cambridge University Press with the German Historical Institute.

Clausewitz, Carl von. 1982 [1832]. On War. J.J. Abrams, trans. Anatol Rapoport, ed. Toronto: Penguin Books.

Cook, Tim. 1999. Nowhere to Run: The Canadian Corps and Gas Warfare in the First World War. Vancouver: UBC Press. 2006. Clio's Warriors: Canadian Historians Writing and the Writing of the World Wars. Vancouver: UBC Press. 
2007. At the Sharp End: Canadians Fighting the Great War 1914-1916. Toronto:

Viking Canada.

. 2008. Shock Troops: Canadians Fighting the Great War 1917-1918. Toronto:

Viking Canada.

. "The Singing War: Canadian Soldiers' Songs of the Great War." American Review of Canadian Studies, vol. 39, iss. 3 (Sep 2009): 224-241.

Cork, Richard. 1994. A Bitter Truth: Avant-Garde Art and the Great War. New Haven: Yale University Press.

Danto, Arthur C. 1985. Narration and Knowledge. New York: Columbia University Press.

_.2001. Philosophizing Art: Selected Essays. Berkeley: University of California Press.

Eates, Margot. 1973. Paul Nash: The Master of the Image1889-1946. London: John Murray.

Ellis, John. 1977. Eye-Deep in Hell. London: Fontana/Collins.

Ferro, Marc. 1980 [1969]. The Great War 1914-1918. Nicole Stone, trans. Boston:

Routledge \& Kegan Paul.

Finnegan, Terrence J. 2006. Shooting the Front: Allied Aerial Reconnaissance and Photographic Interpretation on the Western Front-World War I. Washington: National Defense Intelligence College Press.

Flaxman, Gregory, ed. 2000. The Brain is the Screen: Deleuze and the Philosophy of Cinema. Minneapolis: University of Minnesota Press. 
Fussell, Paul. 2000 [1975]. The Great War and Modern Memory. Toronto: Oxford University Press.

Goebel, Stefan. 2007. The Great War and Medieval Memory: War, Remembrance, and Medievalism in Britain and Germany, 1914-1940. New York: Cambridge University Press.

Gough, Paul. “The Empty Battlefield.” Imperial War Museum Review v. 8 (1993): 38-47. Heaton, John and Judy Groves. 2005. Introducing Wittgenstein. Thriplow, UK: Totem Books.

Holmes, Richard. 1994 [1985]. Firing Line. London, UK: Pimlico.

Hughes, Robert. 1968. Heaven and Hell in Western Art. London, UK: Weidenfeld \& Nicolson.

Hynes, Samuel. 1990. A War Imagined: The First World War and English Culture. New York: Collier. 1997. The Soldiers' Tale: Bearing Witness to Modern War. New York: A. Lane.

Keegan, John. 2000 [1998]. The First World War. Toronto: Vintage Canada.

Kern, Stephen. 2003 [1983]. The Culture of Time and Space, 1880-1918. Cambridge, MA: Harvard University Press.

Kramer, Alan. 2007. Dynamic of Destruction: Culture and Mass Killing in the First World War. New York: Oxford University Press.

Kristeva, Julia. 1982. Powers of Horror: An Essay on Abjection. Leon S. Roudiez, trans. New York: Columbia University Press.

Lefebvre, Henri. 1991 [1974]. The Production of Space. Donald Nicholson-Smith, trans. Malden, MA: Blackwell Publishing. 
Meyer, Jessica. 2009. Men of War: Masculinity and the First World War in Britain. New York: Palgrave Macmillan.

McLuhan, Marshall. 1964. Understanding Media: The Extensions of Man. New York: McGraw-Hill.

Munson, James, ed. 1985. Echoes of the Great War: The Diary of the Reverend Andrew Clark 1914-1919. New York: Oxford University Press.

Murray, Jeffrey S. "British-Canadian Military Cartography on the Western Front, 19141918." Archivaria, vol. 26 (Summer 1988): 52-65.

Nicholson, G.W.L. 1962. Canadian Expeditionary Force 1914-1919. Ottawa: Queen's Printer.

Nietzsche, Friedrich. 1995 [1927]. The Birth of Tragedy. Clifton P. Fadiman, trans. New York: Dover Publications.

Ricoeur, Paul. 2006 [2004]. Memory, History, Forgetting. Kathleen Blamey and David Pellauer, trans. Chicago: University of Chicago Press.

Robertshaw, Andrew. 2006. Somme 1 July 1916: Tragedy and Triumph. New York: Osprey Publishing.

Robertson, Peter. "Canadian Photojournalism during the Great War.” History of Photography, vol. 2, iss. 1 (Jan 1978): 37-52.

Romm, James S. 1992. The Edges of the Earth in Ancient Thought: Geography, Exploration, and Fiction. Princeton: Princeton University Press.

Saunders, Nicholas J. 2007. Killing Time: Archaeology and the First World War. Gloucestershire: Sutton Publishing. 
Smith, Leonard V. 1994. Between Mutiny and Obedience: The Case of the French Fifth Infantry Division during World War I. Princeton: Princeton University Press. 2007. The Embattled Self: French Soldiers' Testimony of the Great War. Ithaca: Cornell University Press.

Smith, Leonard V., Stéphane Audoin-Rouzeau and Annette Becker. 2003. France and the Great War 1914-1918. New York: Cambridge University Press.

Steiner, Zara. 2005. The Lights That Failed: European International History 1919-1933. New York: Oxford University Press.

Sun-Tzu. 2005 [c. $6^{\text {th }}$ century BCE]. The Art of War. John Minford, trans. Toronto: Penguin Books.

Schweitzer, Richard. 2003. The Cross and the Trenches: Religious Faith and Doubt among British and American Great War Soldiers. Westport, CT: Praeger.

Theweleit, Klaus. 1987, 1989. Male Fantasies Vol. 1 \& 2. Stephen Conway, trans. Minneapolis: University of Minnesota Press.

Todman, Dan. 2005. The Great War: Myth and Memory. New York: Hambledon Continuum.

Tooley, Hunt. 2003. The Western Front: Battle Ground and Home Front in the First World War. New York: Palgrave Macmillan.

Travers, Timothy. 1987. The Killing Ground: The British Army, the Western Front, and the Emergence of Modern Warfare. London: Allen \& Unwin.

Travers, Timothy and Christon Archer, eds. 1982. Men at War: Politics, Technology and Innovation in the Twentieth Century. Chicago: Precedent.

Turner, Alice K. 1993. The History of Hell. New York: Harcourt Brace. 
Vance, Jonathan F. 1997. Death So Noble: Memory, Meaning, and the First World War. Vancouver: UBC Press. 2002. High Flight: Aviation and the Canadian Imagination. Toronto: Penguin Canada.

Virilio, Paul. 2000 [1988]. War and Cinema: The Logistics of Perception. Patrick Camiller, trans. New York: Verso. 2006 [1977]. Speed and Politics: An Essay on Dromology. Mark Polizzotti, trans. Los Angeles: Semiotext(e). 2007 [2005]. The Original Accident. Julie Rose, trans. Malden, MA: Polity Press. 2008 [1975]. Bunker Archaeology. George Collins, trans. New York: Princeton Architectural Press. 2009 [1980]. The Aesthetics of Disappearance. Philip Beitchman, trans. Los Angeles: Semiotext(e).

Walter, George, ed. 2006. The Penguin Book of First World War Poetry. Toronto: Penguin Classics.

Werlen, Benno. 2005. "Regions and Everyday Regionalizations: From a Space-centred Towards an Action-centred Human Geography." B/Ordering Space. H. Van Houtum, O. Kramsch, and W. Zierhofer, eds. Burlington: Ashgate. Pp. 45-59. White, Hayden. 1985 [1978]. Tropics of Discourse: Essays in Cultural Criticism. Baltimore: Johns Hopkins University Press. 1987. The Content of the Form: Narrative Discourse and Historical Representation. Baltimore: Johns Hopkins University Press. 
Winter, Jay. 2007 [1995]. Sites of Memory, Sites of Mourning: The Great War in European Cultural History. New York: Cambridge University Press. 2006. Remembering War: The Great War Between Memory and History in the

Twentieth Century. New Haven: Yale University Press.

Wittgenstein, Ludwig. 2008 [1953]. Philosophical Investigations. G.E.M. Anscombe, trans. Malden: Blackwell Publishing.

Wood, Walter, ed. 1915. True Stories of the Great War. London, UK: Chapman and Hall. Online text: http://www.archive.org/stream/soldiersstorieso00woodrich.

Žižek, Slavoj. 2009. The Parallax View. Cambridge, MA: The MIT Press. 2008. Violence. New York: Picador. 